\title{
The Odd Couple? \\ Mental Health Social Workers in Ontario and the Diagnostic and Statistical Manual
}

by

Josh Goodbaum

A thesis submitted to the Faculty of Graduate and Postdoctoral Affairs in partial fulfillment of the requirements for the degree of

Master of Social Work

Carleton University

Ottawa, Ontario

(C) 2012

Josh Goodbaum 
Library and Archives

Canada

Published Heritage

Branch

395 Wellington Street

Ottawa ON K1A ON4

Canada
Bibliothèque et

Archives Canada

Direction du

Patrimoine de l'édition

395 , rue Wellington

Ottawa ON K1A ON4

Canada
Your file Votre référence

ISBN: 978-0-494-94342-7

Our file Notre référence

ISBN: $978-0-494-94342-7$
NOTICE:

The author has granted a nonexclusive license allowing Library and Archives Canada to reproduce, publish, archive, preserve, conserve, communicate to the public by telecommunication or on the Internet, loan, distrbute and sell theses worldwide, for commercial or noncommercial purposes, in microform, paper, electronic and/or any other formats.

The author retains copyright ownership and moral rights in this thesis. Neither the thesis nor substantial extracts from it may be printed or otherwise reproduced without the author's permission.
AVIS:

L'auteur a accordé une licence non exclusive permettant à la Bibliothèque et Archives Canada de reproduire, publier, archiver, sauvegarder, conserver, transmettre au public par télécommunication ou par l'Internet, prêter, distribuer et vendre des thèses partout dans le monde, à des fins commerciales ou autres, sur support microforme, papier, électronique et/ou autres formats.

L'auteur conserve la propriété du droit d'auteur et des droits moraux qui protege cette thèse. $\mathrm{Ni}$ la thèse ni des extraits substantiels de celle-ci ne doivent être imprimés ou autrement reproduits sans son autorisation.
In compliance with the Canadian Privacy Act some supporting forms may have been removed from this thesis.

While these forms may be included in the document page count, their removal does not represent any loss of content from the thesis.
Conformément à la loi canadienne sur la protection de la vie privée, quelques formulaires secondaires ont été enlevés de cette thèse.

Bien que ces formulaires aient inclus dans la pagination, il n'y aura aucun contenu manquant. 


\begin{abstract}
The Diagnostic and Statistical Manual (DSM) is the main text used in North America to diagnose individuals with mental disorders. Although various researchers have explored the DSM's relationship to social work practice in the United States, no previous research has explored this relationship within the Canadian context. For this exploratory study, semi-structured interviews were conducted with ten mental health social workers in Ontario. Through a thematic analysis of these interviews, four themes were identified that describe the ways that participants used the DSM and their views towards it. These themes illustrate that the DSM had an inconsistent impact on participants' practice, and that participants held mainly critical perspectives toward the manual. The connection of these findings to previous research and literature and their practical and theoretical applications will be discussed along with the current study's limitations and suggestions for future research.
\end{abstract}




\section{Acknowledgements}

Producing this thesis has been an unbelievably rewarding experience, and one that would not have been possible without the help of many individuals. My supervisor, Dr. Karen Schwartz, has provided invaluable guidance in regard to every aspect of my research and writing over the past year-and-a-half. Her knowledge and passion pertaining to qualitative research and mental health discourses have had a deep impact on my work.

I would also like to express my gratitude to the following individuals: Dr. Cecilia Taiana, for sharing her wisdom and insights on various aspects of my thesis, Anne-Marie $0^{\prime} B r i e n$, for her assistance in navigating the ethics approval process, and Dr. Connie Kristiansen, my other committee member. Special thanks to other staff and faculty in the School of Social Work at Carleton University for providing administrative support throughout this process, and those friends, family and colleagues who have provided me with encouragement and feedback.

I am unbelievably fortunate that my partner, Jenna MacKay, has been a consistent source of emotional support through the development of my thesis and has had an active role in shaping my thinking and writing. Thank you for inspiring me with your own work and your friendship.

Lastly, I am deeply thankful for the participants whose perspectives have formed the basis for the current study's findings. Thank you for taking the time to share your thoughts on this topic. 


\section{Table of Contents}

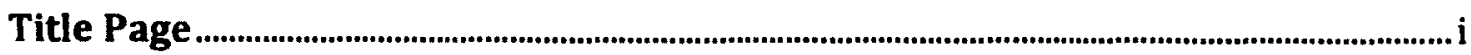

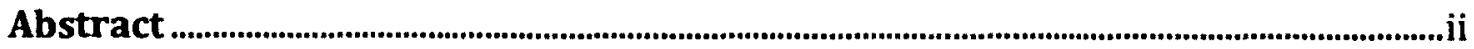

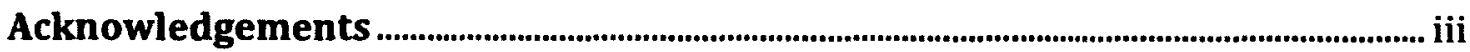

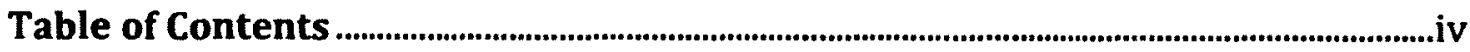

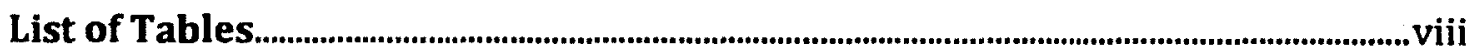

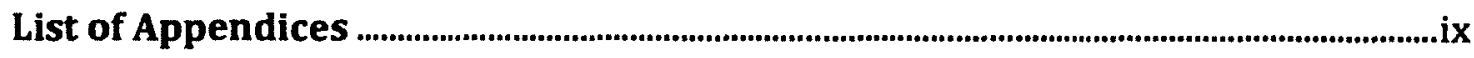

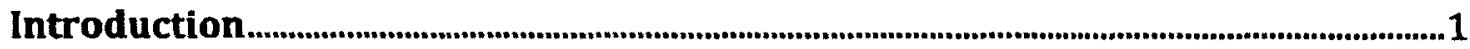

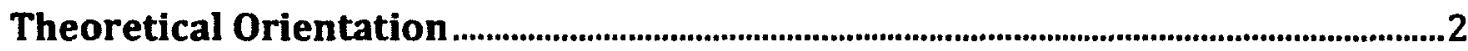

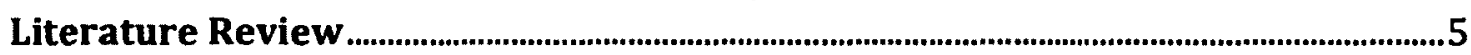

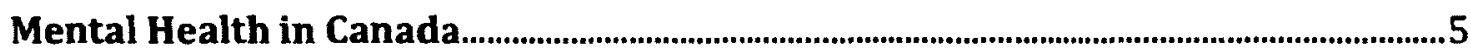

The Mental Health System and Social Work Practice ....................................................6

Assessment and Diagnosis in the Mental Health Field.........................................................8

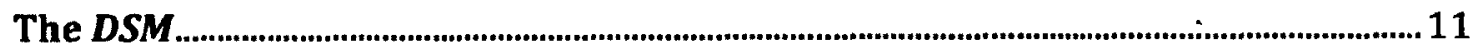

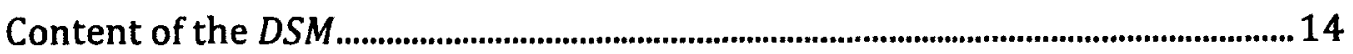

History of the DSM.............................................................................................................. 14

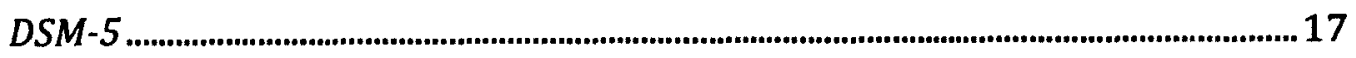

The DSM and Mental Health Social Work Practice ................................................................ 18

The DSM and Social Work Education .................................................................................... 21

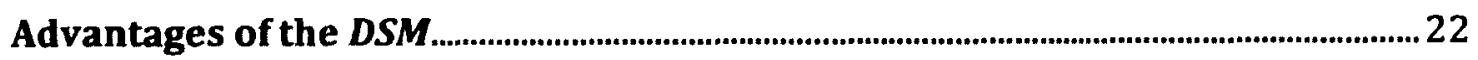

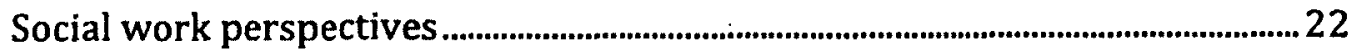

Other professional/disciplinary perspectives ...................................................................26

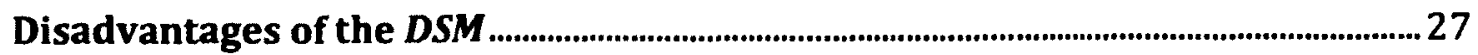




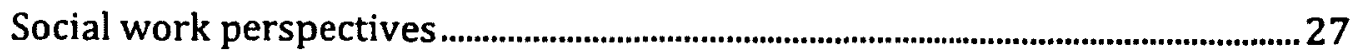

Other professional/disciplinary perspectives ............................................................30

Concerns regarding specific diagnoses …..................................................................32

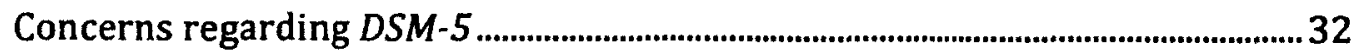

Concerns regarding the economic influences on the DSM .....................................35

Critiques of the Mental Health System ............................................................................. 39

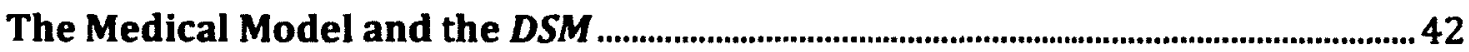

The Impacts of Diagnosis on Service Users .......................................................................44

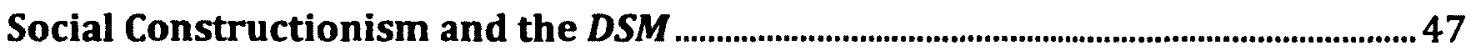

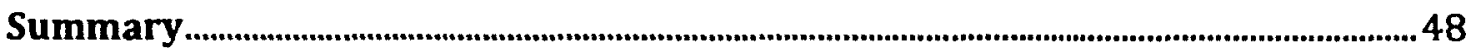

Method

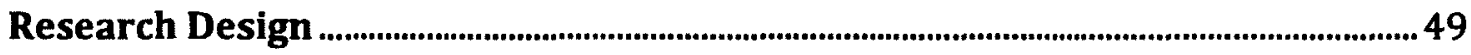

Researcher as Instrument Statement ............................................................................. 49

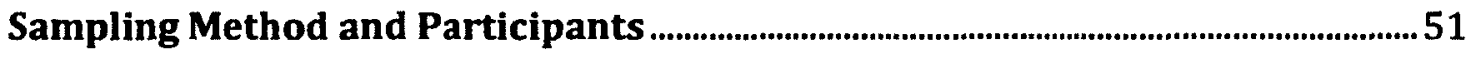

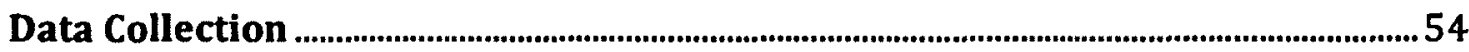

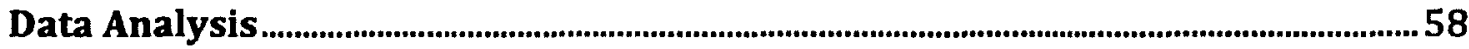

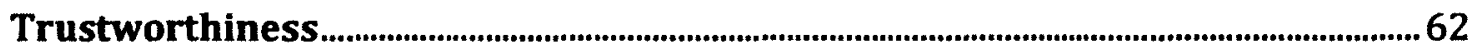

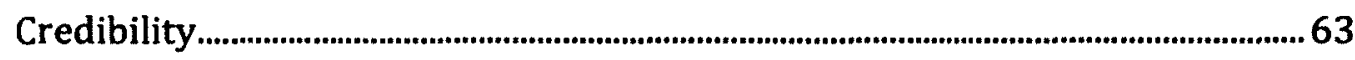

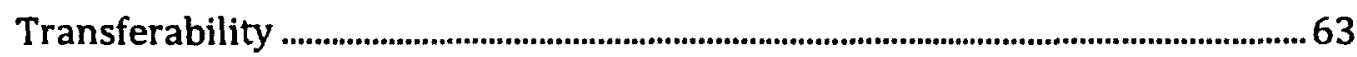

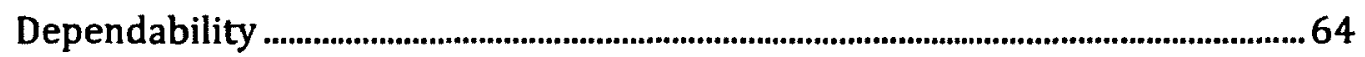

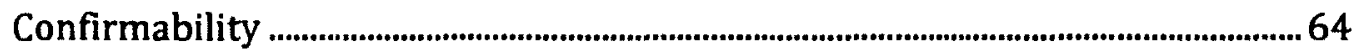

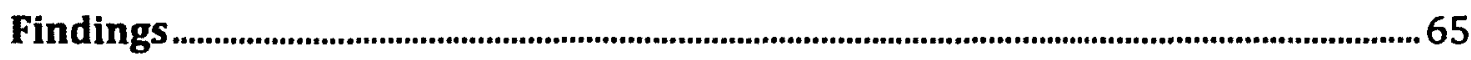

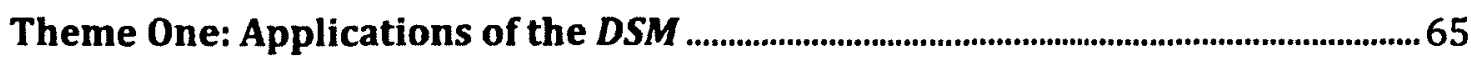


Diagnosis . 68

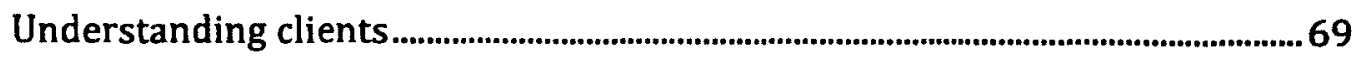

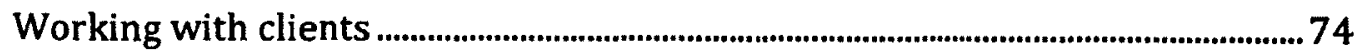

Helping clients make meaning of diagnoses .......................................................77

Professional dialogue

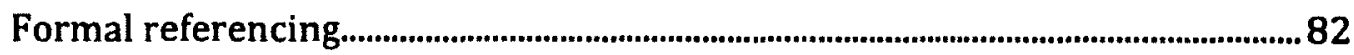

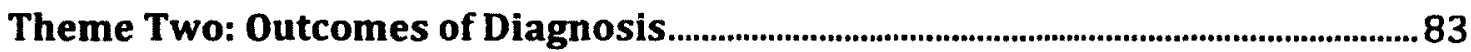

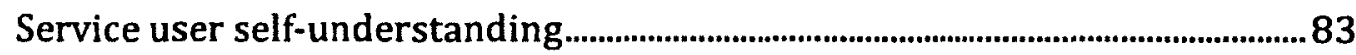

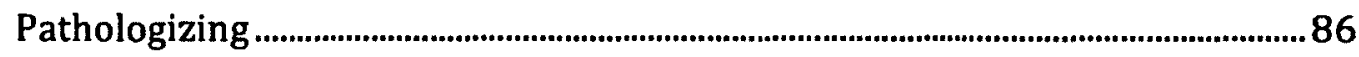

Misdiagnosis .................................................................................................................................... 90

Theme Three: Subjectivity of the DSM............................................................................... 94

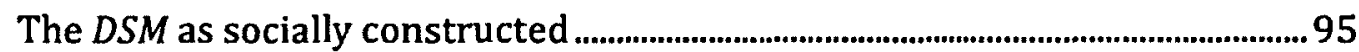

"Major mental illness" versus "everything else" .......................................................98

Concerns regarding specific disorders........................................................................ 100

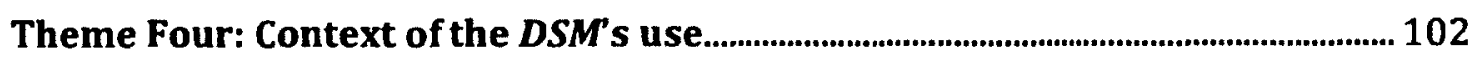

The medical model ......................................................................................................................... 102

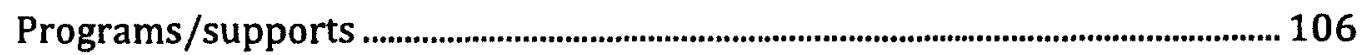

The ubiquity of the DSM..................................................................................................... 109

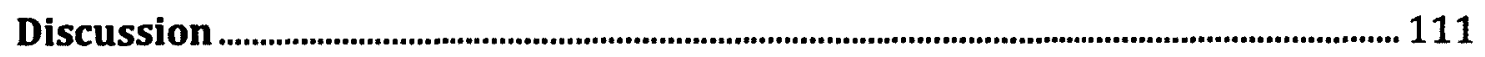

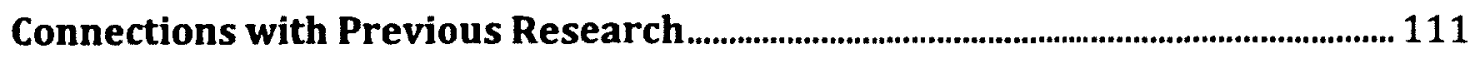

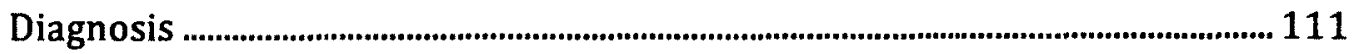

Understanding and working with clients......................................................................... 112

Helping clients make meaning of diagnoses.......................................................... 114 


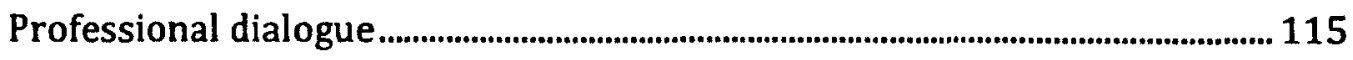

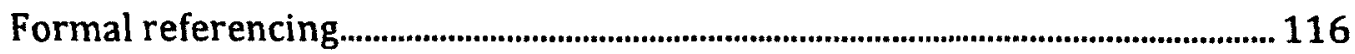

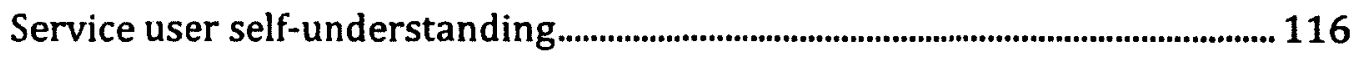

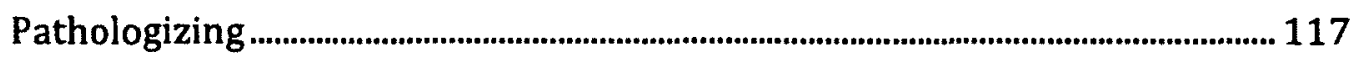

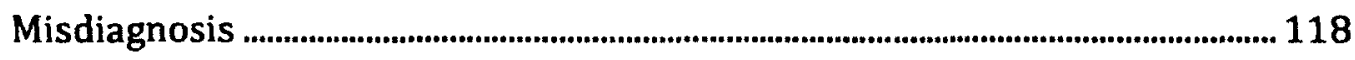

The DSM as socially constructed and "MMI" versus "everything else"........... 119

Concerns regarding specific disorders............................................................... 120

The medical model ............................................................................................................... 121

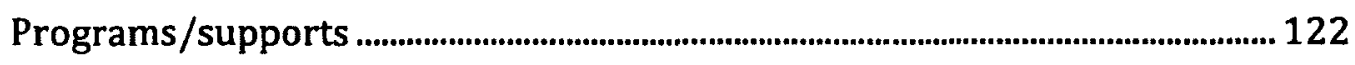

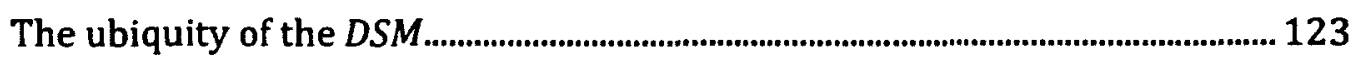

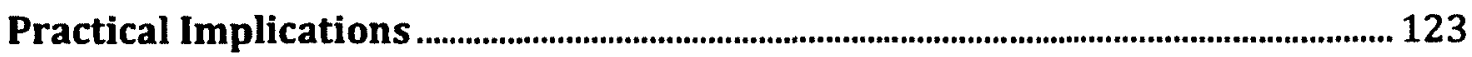

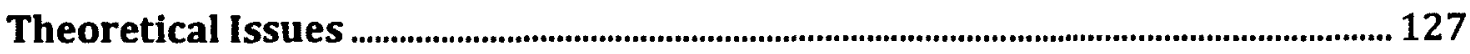

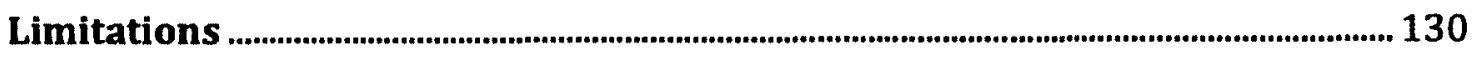

Recommendations for Future Research.............................................................................. 134

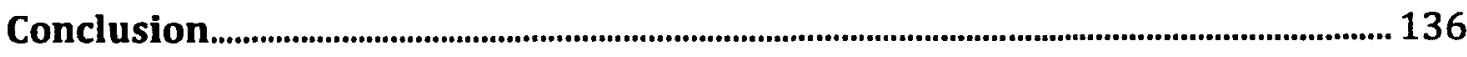

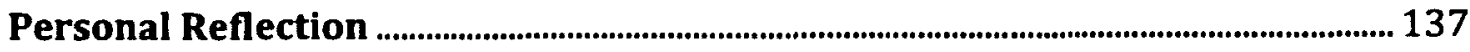

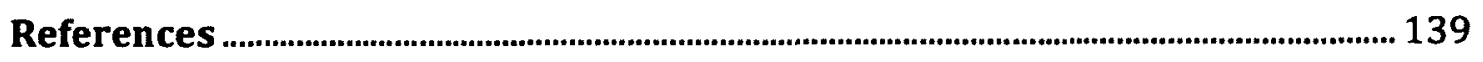




\section{List of Tables}

Table 1: Diagnostic Categories in DSM-IV-TR ............................................................................15

Table 2: Participants' Demographic Characteristics.......................................................................53

Table 3: Overview of Themes in Relation to Participants ......................................................66

Table 4: Service provided by MHSWs in Ontario........................................................... 133 


\section{List of Appendices}

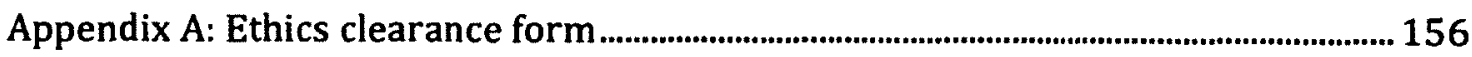

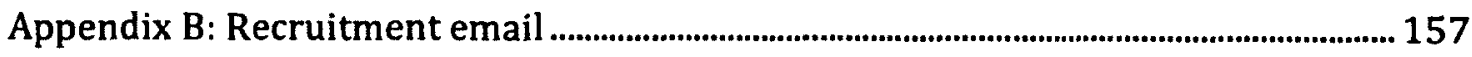

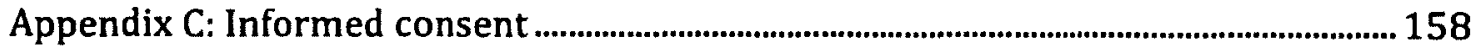

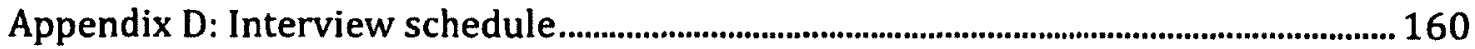

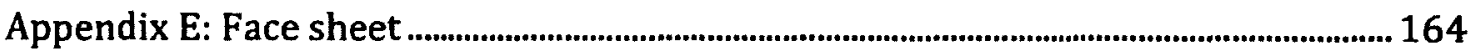

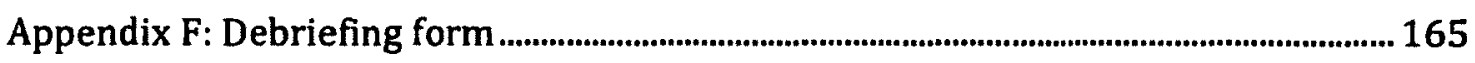

Appendix G: Post interview comment sheet..................................................................... 166 
The Odd Couple? Mental Health Social Workers in Ontario and the Diagnostic and Statistical Manual

For several decades, the Diagnostic and Statistical Manual (DSM) has had a significant role in the how mental disorders are conceptualized and diagnosed in North America (First, Frances and Pincus, 2003). While it is without a doubt that social workers in the mental health sector ${ }^{1}$ would have some exposure to and familiarity with the DSM in the context of their work, a divisive debate exists regarding the manual's relevance as a tool for professional practice and its compatibility with social work values (Lyter and Lyter, 2010). Given this divisive debate, the DSM and MHSWs may be regarded as forming an "odd couple", with the manual having an inescapable, but potentially conflictual, relationship to mental health social work practice. However, there has been no research to date that has examined this relationship from the perspective of Canadian MHSWs, or that has indicated what role (if any) the manual plays in Canadian mental health social work practice. In response to this deficit of research, this exploratory research project investigates how MHSWs in Ontario use the DSM and what perspectives they have toward the manual.

In this thesis I first describe the theoretical orientation - social constructionism - that has informed my work. Following this, my literature review introduces research and scholarship that is relevant to the current topic. This includes an overview of Canada's mental health system, the role of MHSWs in that system, the importance of assessment and diagnosis in mental health practice, the

${ }^{1}$ Social workers who are employed in the mental health sector will be referred to as mental health social workers (MHSWs) in this thesis. 
development (past and future), content and usage of the DSM, how the DSM informs mental health social work practice, and lastly, various perspectives on the advantages and disadvantages of the manual. In my Method section, I discuss the process by which I have conducted my research, from the recruitment of participants through to the thematic analysis of the data that I collected. In my Findings section, I present a thorough overview of participants' comments in regard to my research question. These comments indicate that the DSM had an inconsistent impact on participants' practice, and that participants held mainly critical perspectives toward the manual. Lastly, my Discussion section examines the connection of these findings to previous research and literature, their practical and theoretical implications, the limitations of my research and suggestions for future research.

\section{Theoretical Orientation}

Social constructionism offers a relevant theoretical orientation for analyzing the ways in which social workers in the mental health field think about the DSM and use it in their professional practice. First popularized in the 1960 s, social constructionism has subsequently been utilized by scholars across various disciplines for studying and commenting on a diverse array of social phenomena. Gergen (2003) argues that social constructionist inquiry is generally characterized with "explicating the processes by which people come to describe, explain, or otherwise account for the world (including themselves) in which they live" (p. 15). To accomplish these aims, social constructionist inquiry typically involves one or more of four main assumptions (Gergen, 1985). The first assumption involves 
taking a critical stance toward taken-for-granted knowledge, particularly the categories and concepts we use to understand our world. Social constructionists contend that our beliefs about how the world works (for example, the idea that mental disorders are just like any other type of physical illness, or that mental disorders are caused by chemical imbalances in the brain) are often simplifications that conceal the more ambiguous, and potentially unknowable, nature of reality. This contrasts significantly with positivist epistemology, which informs much scientific research and in which the world is regarded as fundamentally knowable through "objective" human observation (van de Sande and Schwartz, 2011). In fact, Hibbard (2005) describes the central aim of social constructionism as offering an alternative to positivist epistemology, so that the complexity and ambiguity of human experience can be better recognized. Applying an ambiguous lens to the concept of mental disorders, I feel that it is important to recognize that we have an incomplete understanding of the etiology and validity of the disorders that are included in the $D S M$, and that this incomplete understanding has created historical and contemporary issues for mental health service users.

The second assumption of social constructionism is that human knowledge is produced through historically, culturally and socially informed processes and interactions. This implies that knowledge, rather than being "automatically driven by the forces of nature" (Gergen, 1985, p. 267) and therefore fixed and universal, shifts over time and is based on the context in which that knowledge is generated. Thus, in order to understand any social phenomena, it is important to understand the historical, cultural and social context in which it exists (this is particularly 
relevant for analyzing the $D S M$, which has been described as being significantly influenced in its development and usage by various contextual factors.) Moreover, to conduct research, it is important for researchers to reflect on those contextual factors that can inform their understanding and approach to studying the phenomena in question.

The third assumption of social constructionism is that knowledge is developed through social processes. Given this assumption, social constructionists are often interested in studying different kinds of social processes, with language and discourse (written texts, pictures, images and all forms of linguistic and symbolic communication) being particular topics of interest (Burr, 2005). The French philosopher Michel Foucault, through several decades of scholarship, has had a significant impact on social constructionist understandings of the relationship between discourse, knowledge and power (Hook, 2010). Foucault (1972) describes discourses as "practices that systemically form the objects of which they speak" (p. 49). This indicates that the ways that we communicate help to construct the concepts that inform our understanding of the world. While I am not conducting a Foucauldian analysis in this thesis, Foucault has had an influential role in the critical study of discourses and practices and the mental health field (further discussed on page 40 of my literature review.) As such, my social constructionist approach has been strongly influenced by Foucault's writings.

The significant impact of discourse and language relates to the final assumption of social constructionism, which is that how we understand the world informs social patterns and thus can "serve to sustain and support certain patterns 
to the exclusion of others" (Gergen, 1985, p. 268). Thus, the construction of knowledge has important consequences not only in regulating individual behavior, but also in maintaining entire social systems. Given the power associated with being able to define and understand a person's visible behavior and self-reported experiences as reflective of internal dysfunction (Foucault, 2003), texts such as the $D S M$ can be regarded as an important product of and influence on contemporary mental health discourse and thus deserving of critical analysis from a social constructionist orientation. Due to the relevancy of social constructionism to an analysis of the $D S M$, social constructionist perspectives in regard to previous research and scholarship and the findings of the current study will be presented throughout this thesis, and social constructionist perspectives on the DSM will be discussed beginning on page 47 of my literature review.

\section{Literature Review}

\section{Mental Health in Canada}

Social workers and other professionals in Canada (e.g., family physicians, psychiatrists, psychologists, nurses, counsellors, etc.] play a significant role in providing mental health services (Goldner, Jenkins, Palma and Bulsker, 2011). The Canadian Association of Social Workers (CASW) (2001) defines mental health as:

The capacity of the individual, the group and the environment to interact with one another in ways that promote subjective well-being, the optimal development and use of mental abilities (cognitive, affective, and relational), the achievement of individual and collective goals consistent with justice, and the attainment and preservation of conditions of fundamental equality. (p. 1) 
Promoting overall mental health and supporting clients with mental health concerns are important objectives for Canada's mental health service providers. However, the limited funding for mental health services within provinces/ territories means that more intensive professional involvement is reserved for those individuals who are regarded as "priority populations" with the greatest level of "need" (Davis, 2006). This emphasis, along with the socially constructed notion that it is more effective to fund mental health facilities that are treatment-focused than community-based organizations that are prevention-focused, means that a specific focus is often given to the treatment of individuals diagnosed with a mental disorder. Mental disorders or illnesses are a specific type of mental health concern, characterized by alterations in "thinking, mood or behavior (or some combination thereof) associated with significant distress and impaired functioning" (Health Canada, 2002, p. 7). Approximately $20 \%$ of Canadians are believed to experience symptoms indicative of a mental disorder at some point in their life, which can cause serious impacts not only on their own lived experience but those of their family and community members (Health Canada, 2002).

\section{The Mental Health System and Social Work Practice}

Over the past six decades, the mental health system in Canada and other Western countries has shifted its emphasis away from long-term care centered in psychiatric institutions toward a more short-term system that emphasizes outpatient care. This shift has helped to redefine the role of MHSWs by changing the system of service delivery. Leiba (1994) characterizes the modern mental health system as involving a "web of professional and lay networks in the hospital, the 
community and in the voluntary and self-help sectors" (p. 136). MHSWs help provide services in each of these contexts, taking on a number of different roles. Within mental health settings, including hospitals, community-based agencies and private practice, social workers play significant roles, which can include a focus on promoting social supports to enhance the empowerment of clients, taking social histories of clients, discharge planning and coordinating access to community resources (Spearman, 2005). Examining the Ontario-specific context, O'Brien and Calderwood (2010) found that assessment and referrals, supportive counseling, crisis intervention, psychotherapy and advocacy are the primary responsibilities of MHSWs in the province.

Another important part of a MHSWs role involves taking part in collaborative practice with colleagues from different professional backgrounds. This is often referred to as interprofessional work. Within the current mental health system, interprofessional work is often cited as a way to improve service delivery (Health Canada, 2002). Leiba (1994) argues that combining the specialist skill and knowledge of different professionals in assessment, decision-making and treatment planning can lead to a richer understanding of and approaches to working with service users.

Despite these purported benefits, effective interprofessional work can be hindered by a number of factors. These include poor communication, confusion over responsibilities, ideological differences and conflicting power relationships (Rawson, 1994). Power relationship issues are extremely relevant to social work practice in mental health settings, due to professional hierarchies in which social 
workers may be regarded as not possessing the same level of "expertise" as doctors, psychiatrists and psychologists (Walton, 1999). While social constructionists have problematized the concept of "expertise" and the disciplines that claim to possess it in regard to the understanding and treatment of mental disorders (see Horwitz (1999) for an overview of such arguments), doctors, psychiatrists and psychologists are often accorded significant authority within interprofessional settings and have the final say over the diagnosis and treatment of clients. Thus, while social workers can offer their own unique knowledge base and methods to interprofessional mental health teams, this can often be overshadowed by the "individualistic analysis and directive methods of mainstream psychiatry" (Walton, 1999, p. 380).

\section{Assessment and Diagnosis in the Mental Health Field}

The relationship of the DSM to the practice of mental health social workers (and other mental health professionals) is connected to its applications for assessment and diagnosis. While assessment and diagnosis are related terms, there are some distinctions. Assessment is more typically associated with determining an individual's general life circumstances, including both strengths and challenges, whereas diagnosis is more focused on identifying an illness or other problem that impacts that individual. Regehr and Glancy (2010) argue that assessment is key to social work practice in all contexts, while Mezzich (1999) defines diagnosis as the central activity of medicine and psychiatry. Despite these distinctions, the influence of a medical model (discussed on the following page) can mean that identifying a client's perceived functional deficits (the goal of diagnosis) is regarded as more 
important for understanding and supporting that client then identifying their strengths.

The importance of both assessment and diagnosis in the mental health field can be traced to general medical practice. Within medicine, it is believed that if a disease or other physical problem can be identified in an individual, then "effective treatment or even prevention is more likely to be developed" (Spearman, 2005, p. 46). Assessment accomplishes a similar goal within the social work context, as it allows practitioners to understand the factors that impact on a client's lived experiences and to develop appropriate goals, objectives and outcomes (Kerson, McCoyrd and Chimchirian, 2005; Regehr and Glancy, 2010). While there are exceptions, some social workers take a strengths-based and developmental approach to assessment. Spearman (2005) lists several key principles of that approach, including the belief that all people have strengths, can benefit from social supports and empowerment and that difficult situations can be opportunities for growth. Walton (1999) argues that these principles lead to an assessment process that prioritizes the client's perspective on their circumstances and leads to a work plan that reflects the client's priorities.

Diagnosis is seen as particularly relevant in North America's mental health system, since many beliefs that are associated with a "narrow" medical model inform mental health policy, practice and research in North America (Nesse and Stein, 2012). Such a medical model has been developed (and embraced) in North America due to a variety of socio-historical factors. While it is by no means a stable or unified approach to understanding and addressing mental distress, numerous 
scholars have described a medical model perspective as exhibiting certain core principles. A narrow medical model, in a basic sense, characterizes certain forms of mental distress as "disorders" that are comparable to physical illnesses or diseases, such that they can be understood and treated using strategies from general medical research and practice (Rosenberg, 2006; Skene, 1999). A narrow medical model is further defined by five core values/characteristics:

1. Mental disorders are more an expression of individual pathology than a reflection of any issues in one's family, community or wider social context.

2. Reductionist thinking, in which the successful understanding and treatment of mental disorders is thought to rely on using simplified terms that can encompass and describe a variety of people and states of being.

3. Mechanistic thinking, where it is assumed the experiences of individuals with mental disorders can be best understood as the product of their symptoms.

4. Static thinking, in which symptoms are not seen as capable of abating without professional interventions that often involve medication.

5. A reliance "on an objectivist science that pursues linear causality - that is, that a few factors that precede problems in history can be assumed to lead directly to the problem - as an explanation of experience" (Eriksen and Kress, 2005, p. 30).

Given these elements of a narrow medical model, it is unsurprising that in North America the diagnosis of mental disorders in individuals is treated as not only important but entirely valid. In Ontario, the diagnosis of a mental disorder is only 
permissible by doctors, psychiatrists and clinical psychologists, and their diagnostic practices are often guided by the DSM-IV-TR (American Psychiatric Association [APA], 2000). Because of this connection between a narrow medical model and the $D S M$, Arnd-Caddigan and Pozzuto (2010) argue that the specific focus among North American mental health service providers and funders on the treatment of the symptoms of a DSM diagnosis is a key element of a medical model perspective. However, as I will discuss beginning on page 42 , while a narrow medical model may be regarded as having promoted (and having been promoted by) the DSM's acceptance in North America, a "broader" medical model has informed research efforts that challenge the influence of the $D S M$ and the assumptions of a narrow medical model.

\section{The DSM}

In North America, the DSM-IV-TR is the most widely accepted taxonomy of mental disorders and the primary manual used to diagnose individuals with a mental disorder² (Dziegielewski, 2010). The purpose of the manual is to "enable clinicians and investigators to diagnose, communicate about, study, and treat people with various mental disorders" (APA, 2000, p. xi). This purpose applies not only to doctors, psychiatrists and clinical psychologists, but also (with the exception - in all

${ }^{2}$ Some service providers in Canada and the U.S. utilize other diagnostic manuals, particularly the International Statistical Classification of Diseases (ICD). The ICD is published by the World Health Organization and includes diagnostic criteria for mental disorders along with other diseases. Since the DSM is regarded as having a far greater influence in Canada than the ICD (Davis, 2006), my research will be solely focusing on the DSM. For an overview of the similarities and differences between the DSM and the ICD, please see Schulte-Markwort, Marutt and Riedesser (2003). 
Canadian provinces excluding British Columbia $[\mathrm{BC}]^{3}$ - of diagnosis) social workers and other mental health professionals (APA, 2000). In addition to serving as a direct diagnostic tool, the manual also informs the criteria that are used in many other diagnostic tools (e.g. the Structural Clinical Interview for DSM-IV Axis I Disorders: Clinical Version, which is used to assess for various mental disorders among adults, or the Swanson, Nolan and Pelham-IV Rating Scale, which is used to assess whether children are exhibiting the symptoms of Attention Deficit Hyperactivity Disorder [ADHD].)

Over its past several iterations, the DSM has included a categorical, ${ }^{4}$ multiaxial system for classifying mental disorders. This includes five different axes: Axis I (Clinical or mental disorders, or other conditions that may be a focus of clinical attention); Axis II (Personality disorders, or mental retardation or other developmental disorders); Axis III (General medical conditions); Axis IV (Psychosocial and environmental problems); and Axis V (Global assessment of functioning). Different mental disorders are listed on Axis I or II, while Axis III is used to record any medical conditions that may impact (or be impacted by) an Axis I or II diagnosis. When it is believed that a general medical condition or substance use is causing an individual's symptoms, an Axis I or II diagnosis is preempted. Axis IV highlights different environmental factors that may influence individual

${ }^{3}$ Social workers in $\mathrm{BC}$ with a minimum of $\mathbf{3 0 0 0}$ hours of supervised clinical social work experience along with specific training and licensing have been allowed to use the DSM for diagnostic purposes since 2005 (British Columbia College of Social Workers, 2009). In fact, the Board of Registration for Social Workers in British Columbia (2005) partly defines clinical social work as involving the application of "standardized and validated criteria, including the [DSM]" (p. 4).

${ }^{4}$ As a categorical classification system, the DSM "divides mental disorders into types based on criterion sets with defining features" (APA, 2000, p. xxxi). 
functioning, including stressors due to issues relating to an individual's social supports, economic situation and other aspects of their life. Axis V includes a scale by which a clinician can rank a client's recent overall functioning on a scale from zero (at risk) to one hundred (superior functioning).

While Axis IV in particular can help situate a client's mental health within a broader social context, Corcoran and Walsh (2006) point out that it is frequently deemphasized during diagnosis and treatment. In a study by Rubinson (1999), only $50 \%(n=56)$ of surveyed psychiatrists indicated that they regularly used Axis IV when making a DSM diagnosis, with only $50 \%(n=56)$ regularly using Axis V. In line with these findings, Eriksen and Kress (2006) argue that the DSM is often used in a uni-dimensional fashion, with practitioners largely focusing on personal psychopathology while diminishing the importance of various external factors that may impact on mental health. Since the person-in-environment perspective has been described as an important contribution of social work to the mental health field (O'Brien and Calderwood, 2010), the de-emphasis of Axis IV could be regarded as an important concern from a social work perspective. Such uni-dimensional use of the manual could be due the influence of a narrow medical model or the limited time that professionals may be allotted in which to meet with clients and arrive at a diagnosis (Carlat, 2010), compounded by the fact that the use of Axes IV and V is recommended by the authors of the DSM, but not mandatory (Dziegielewski, 2010). Since the fifth edition of the DSM, scheduled for publication in 2013 , is expected to maintain the same multi-axial system, it seems likely that concerns regarding the uni-dimensional usage of the DSM will persist. 
Content of the DSM. A key aspect of deciding whether a set of symptoms should be recognized as a disorder and included in the DSM is defining what a mental disorder is. In the DSM-IV-TR (APA, 2000) a mental disorder is defined as a:

Clinically significant behavioral or psychological syndrome or pattern that occurs in an individual and that is associated with present distress (e.g., a painful symptom) or disability (i.e., impairment in one or more areas of functioning) or with a significantly increased risk of suffering, death, pain, disability, or an important loss of freedom. (p. xxxi)

The definition further establishes that to qualify as a mental disorder, such syndromes or patterns "must not be merely an expectable and culturally sanctioned response to a particular event" (p. xxxi), nor expressions of deviant behavior or conflict between the individual and societal norms (unless either are judged to be related to some form of internal dysfunction.) With these criteria in mind, the DSM includes sixteen diagnostic categories (e.g. Mood Disorders, Anxiety Disorders, Eating Disorders, etc.) across its first three axes (a full list of the diagnostic categories included in DSM-IV-TR is included in Table 1.) Specific diagnoses are grouped within these different categories.

History of the DSM. The modern origins of the DSM are often traced back to Emil Kraeplin, a German psychiatrist. Beginning in the 1890 s, Kraeplin began to note the symptoms of individuals admitted to the psychiatric hospital in which he practiced, and then attempted to gauge any patterns that unified these symptoms and thus allow them to be distinguished as distinct disorders (Carlat, 2010). Although his was not the first attempt to develop a taxonomy of mental disorders, it 
Table 1

Diagnostic Categories in DSM-IV-TR

\begin{tabular}{|c|c|}
\hline Diagnostic Category & Example of a Specific Disorder \\
\hline $\begin{array}{l}\text { Disorders usually first diagnosed in } \\
\text { infancy, childhood or adolescence }\end{array}$ & Autistic disorder \\
\hline $\begin{array}{l}\text { Delirium, dementia, and amnestic } \\
\text { and other cognitive disorders }\end{array}$ & $\begin{array}{c}\text { Dementia of the Alzheimer's Type, with early } \\
\text { onset, with behavioral disturbance }\end{array}$ \\
\hline $\begin{array}{l}\text { Mental disorders due to a general } \\
\text { medical condition }\end{array}$ & $\begin{array}{c}\text { Catatonic disorder due to ... [Indicate the } \\
\text { general medical condition] }\end{array}$ \\
\hline Substance-related disorders & Alcohol Abuse \\
\hline $\begin{array}{l}\text { Schizophrenia and other psychotic } \\
\text { disorders }\end{array}$ & Schizophrenia, Paranoid type \\
\hline Mood disorders & $\begin{array}{c}\text { Major depressive disorder, recurrent, } \\
\text { moderate }\end{array}$ \\
\hline Anxiety disorders & Generalized anxiety disorder \\
\hline Somatoform disorders & Somatization disorder \\
\hline Factitious disorders & $\begin{array}{c}\text { Factitious disorder, with predominantly } \\
\text { physical signs and symptoms }\end{array}$ \\
\hline Dissociative disorders & Dissociative identity disorder \\
\hline $\begin{array}{l}\text { Sexual and gender identity } \\
\text { disorders }\end{array}$ & Sexual aversion disorder \\
\hline Eating disorders & Anorexia nervosa \\
\hline Sleep disorders & Primary insomnia \\
\hline $\begin{array}{l}\text { Impulse-Control disorders not } \\
\text { elsewhere classified }\end{array}$ & Kleptomania \\
\hline Adjustment disorders & Adjustment disorder, with anxiety \\
\hline Personality disorders & Borderline personality disorder \\
\hline
\end{tabular}


was regarded as the most systematic such effort to date. Moreover, his work established the precedent that the successful treatment of mental disorders relied on a comprehensive diagnostic system.

Since its original publication by the APA in 1952, the DSM has undergone a substantial expansion, increasing its scope from 106 diagnoses in DSM-1 (APA, 1952) to well over 350 diagnoses in the current edition. Although every edition of the DSM has added new disorders, differentiated existing disorders into various subtypes and included other important revisions, the DSM-III (APA, 1980) stands out for some significant developments. DSM-III introduced both the above-described multi-axial system for classifying mental disorders and a definition for mental disorders. Additionally, for the first time ever, decisions regarding the inclusion of new disorders and corresponding diagnostic standards were, according to the developers of DSM-III, supported by a rigorous development process and observable, scientific research (Blashfield, Flanagan and Raley, 2010). The argument for the scientific rigor of the DSM-III's development was explicitly made by Robert Spitzer, the head of the task force responsible for the development of the manual, when he stated that it represented "an advance toward the fulfillment of the scientific aspirations of the profession [psychiatry]" (Bayer and Spitzer, 1985, as cited in Kirk and Kutchins, 1992, p.6). Claims such as these fueled the perception of the manual, and, by extension, the diagnoses made by psychiatrists and other mental health professionals, as being empirically valid and reliable (critical perspectives on the "scientific" nature of the DSM will be discussed beginning on page 31 of this literature review.) 
DSM-5. Development efforts for DSM-5 began in 1999, and are expected to reach their fruition when it is published in 2013. This lengthy process has involved fourteen conferences over the past decade, along with more focused efforts since 2007 by thirteen work groups (each focused on a specific diagnostic category found in the manual) comprising 160 leading mental health clinicians and researchers ${ }^{5}$ (Oldham, 2011). Since 2010 the manual has been subjected to a field trial process in various mental health settings (APA, 2010) and a Scientific Review Committee is tasked with making final decisions on whether there is enough evidence to justify those revisions which have been proposed. These proposed revisions are too numerous to adequately summarize in this literature review, but include the renaming, re-categorization, merging, removal or changing of criteria for already included diagnoses along with the addition of new diagnoses (APA, 2012b). Additionally, proposals have been made for changing the manual's definition of a mental disorder so that it provides a better set of criteria with which to distinguish behavioural or psychological syndromes or patterns that are reflective of internal dysfunction (and thus appropriate for inclusion in the manual) from those that are expressions of deviant behaviour or conflict between individuals and societal norms (and thus inappropriate for inclusion in the manual) (Stein et al., 2010). As there has been substantial criticism of the manual's development process, proposed revisions and potential impacts on service users, these concerns will be explored beginning on page 33 of this Literature review.

${ }^{5}$ The vast majority of DSM-5 work group members were psychiatrists or psychologists - only one social worker was involved in a work group (APA, 2012a). 


\section{The DSM and Mental Health Social Work Practice}

Although my thorough review of the literature did not reveal any research that has been has been conducted to date examining the ways in which MHSWs in Ontario or any other Canadian province/territory use the DSM within their professional practice, several studies have explored this very question within the context of the United States (U.S.). In a survey handed out to attendees of a state state conference of the National Association of Social Workers (NASW), Holmes and Raffoul (1984) explored the perceived advantages and disadvantages of DSM-III. In regard to usage rates of the manual, of the total respondents ( $N=53), 26 \%$ stated that they "always" used it, $28 \%$ stated they "sometimes" used it, and $45 \%$ stated they "never" used it. In determining why that use occurs, of the subset of respondents who indicated that they "always" or "sometimes" used the manual $(n=$ 29 ), the survey found that $72 \%$ were required to use of the manual by their agencies, with $28 \%$ using it out of personal preference.

In another U.S. study of DSM-III usage, Kutchins and Kirk (1988) utilized a national sample of clinical social workers $(N=362) .{ }^{6}$ Their findings indicated the $80 \%$ of respondents used the manual several times a month or more, with $84 \%$ also indicating that there was no other diagnostic manual that they used more frequently. The largest reason given for the use of the manual was for insurance

6 The term clinical social worker(s) is a professional designation for social workers whose practice involves the application of social work theory and methods to the assessment, treatment and prevention of mental health concerns (Barker, 2003). The term is more commonly used within the U.S., with specific states often requiring social workers to meet certain educational and professional criteria before they can receive the designation (NASW, 2005). Where this term is used in my thesis, it is in regard to U.S. research in which the participants were registered as clinical social workers. 
purposes, with $81 \%$ of respondents indicating this was a "very important" reason.

Other "very important" reasons included agency requirements ( $46 \%$ of

respondents) and to complete paperwork for Medicaid or Supplemental Security

Income $(\mathrm{SSI})^{7}(45 \%$ of respondents.)

In their survey of Tennessee-based social workers who were receiving training on the use of the DSM in social work diagnosis and assessment $(N=132)$, Dziegielewski, Johnson and Webb (2003) found that $57 \%$ of participants were asked to formally diagnose clients "sometimes" to "always". Additionally, $90 \%$ of participants felt comfortable diagnosing their clients "sometimes" to "always" and $87 \%$ indicated they were comfortable using formal diagnostic criteria "sometimes" to "always". However, as the participants in the study were social workers who had personally chosen to attend a continuing education course on the $D S M$, it is unclear whether they are representative of other social workers in the state or country.

In the most recent published study exploring the use DSM-IV by clinical social workers in the U.S. $(N=558)$, Frazer, Westhuis, Daley and Phillips (2009) found that $78.9 \%$ of respondents to their national study indicated that they use the DSM "often" to "always", with $85.9 \%$ assigning clients diagnoses from the manual "often" to "always". When respondents were asked to indicate the reasons they felt it was important to use the DSM using a six-point scale (with one indicating the manual was "always useful" for a specified purpose and six indicating the manual was

${ }^{7}$ Medicaid and SSI are U.S. programs that are available for individuals and/or families with low incomes. Medicaid provides individuals/families with health coverage, whereas SSI provides income stipends to individuals that are 65 years of age or older or differently abled. 
"never useful" for a specified purpose), insurance billing averaged a mean score of 1.46, assessing clients averaged a mean score of 2.39 and assisting with treatment planning averaged a mean score of 2.99. Other reasons to use the DSM included clarifying clinical impressions (a mean score of 3.02), understanding difficult cases (a mean score of 3.04), determining the need for medication referral (a mean score of 3.19), selecting treatment procedures (a mean score of 3.43), meeting employer requirements (a mean score of 3.64), educating clients on their disorder(s) (a mean score of 3.69), determining client prognosis (a mean score of 3.70) and assessing treatment outcome effectiveness (a mean score of 3.98).

Kutchins and Kirk's (1988) research was partially replicated by Hitchens (2011), in a dissertation drawing on data collected from clinical social workers in six U.S. states $(N=294)$. In the study, $93 \%$ of respondents indicated that the DSM was the diagnostic manual that they most typically utilized in their work. The most common reason given for using the DSM was for insurance purposes, with $75 \%$ of respondents indicating that this was a "very important" reason. Other than the manual's relevance for treatment planning (regarded as "very important" by $46 \%$ participants), analyzing client behavior (regarded as "very important" by $38 \%$ of participants) and reviewing cases with other professionals (regarded as "very important" by $37 \%$ of participants), all remaining rationales for using the manual (including requirements by one's agency, completing paperwork for Medicaid or Supplemental Security Income, legal requirements, determining prognosis of cases and research purposes) were regarded as more "unimportant" than "very important" by participants. 
These studies indicate that the DSM does play some role in the practice of U.S. social workers, to varying levels and for varying reasons. However, there are distinct legal standards in the U.S. that play a role in the rates and rationales for DSM usage by MHSWs in the aforementioned studies. One crucial legal standard that impacts on DSM usage is that in many U.S. states social workers are allowed to diagnose, whereas this is not allowed in Ontario and most other provinces/ territories in Canada. In states where social workers are allowed to diagnose, it is likely that they may be therefore expected or required to diagnose or have knowledge of the DSM in order to satisfy their job requirements, gain professional licensing or obtain insurance reimbursement for their services (Brubeck, 1999; Probst, 2011). Thus, while the aforementioned studies indicate the extent and ways in which the DSM can impact on social work practice, it is unclear whether these findings help to shed light on what role, if any, the DSM plays in mental health social work practice in Ontario.

\section{The DSM and Social Work Education}

The values and practices of social workers, like other professionals, may be influenced by the way they are educated. Although no research to date has explored the impact of the DSM on social work education in Ontario or any other province/ territory in Canada, some studies have explored this question within the context of U.S. social work graduate programs. Based on feedback from a nationwide sample of accredited graduate programs $(N=104)$, Newman, Clemmons and Dannenfelser (2007) found that $74 \%$ offered specific courses in which the DSM diagnostic categories structured an average of $75 \%$ of total course content, with $76 \%$ of 
schools including some DSM content in other courses. In their study looking at the syllabi for mental health practice courses $(N=71)$ offered at 58 different graduate social work programs, Lacasse and Gomory (2003) found that $88.7 \%$ of courses organized their syllabi using DSM disorder categories. Of these courses, the authors found that only $8.5 \%$ required students to read a single publication that empirically critiqued the reliability of the DSM. Thus, the DSM appears to inform the way in which social work students in the U.S. are educated and prepared for professional practice in the mental health sector. The important role that the manual plays in educating future practitioners in the U.S. may be regarded as further evidence of the important role that it plays in social work practice in the country. Whether it plays a similar role in Canadian social work education, and whether or not it is taught in a critical fashion, is unclear due to the absence of research on this topic.

\section{Advantages of the $D S M$}

Social work perspectives. Several U.S. studies have explored the perceived advantages of the DSM from the perspective of practicing social workers. In their nationwide survey of U.S. social workers, Holmes and Raffoul (1984) asked participants to identify the perceived advantages they saw to the DSM-III. Of those individuals who identified themselves as using the manual in their professional practice either "sometimes" or "always" $(n=29), 76 \%$ stated that it enhanced diagnosis, $62 \%$ said it helped them communicate with colleagues, $62 \%$ said it improved treatment planning, $59 \%$ said it led to a better understanding of patients, $45 \%$ said that it met agency requirements, and $41 \%$ said it was necessary for insurance reimbursement purposes. Kutchins and Kirk (1988) found less support 
for the positive benefits of the DSM-III in their survey of U.S. clinical social workers $(N=362)$. In their study, $54 \%$ of respondents believed that manual was frequently helpful in analyzing difficult cases, $33 \%$ felt it was very helpful in treatment planning, and $30 \%$ felt that it served the purposes of clinical social work. More recently, in a study by Rubinson (1999) $(N=145), 52 \%$ of surveyed U.S. clinical social workers indicated that they found DSM diagnoses useful in determining treatment for their clients, with only $31.7 \%$ stating that they would stop using the $D S M$ in their professional practice if they could.

In their partial replication of Kutchins and Kirk's (1988) research, Hitchens (2011) identified similarly low support for the benefits of the DSM-IV-TR among clinical social workers $(N=294)$. In fact, in regard to only one question highlighting the advantages of the DSM (whether it served the purposes of clinical social work) did more respondents agree (42\%) than disagree. However, through follow-up interviews with 20 survey respondents, the author identified four positive themes regarding the use of the DSM: namely, that it assisted practice (especially the assessment of clients), supported professional identity by improving communication with colleagues, comforted clients by providing them with a diagnosis that helped them to make sense of their experiences and that it provided social workers with useful information about their clients.

In a thesis based on interviews with social workers and clinical social workers in the state of New York $(N=30)$, Probst (2011) identified five positive themes regarding the use of $D S M$ diagnoses in professional practice. These themes included the way that diagnoses offer a "jumping-off point" for understanding the 
experiences of clients, provide guidance for how to work with clients, give clients meaning for their experiences and serve as a common language and help them relate to clients. The author described this final theme as "controversial". While some participants in the study felt that it was useful to understand the experiences and behaviors of certain clients as reflective of their diagnosis (thus allowing the participants to not become overwhelmed with guilt or despair regarding their clients' experiences and/or behaviors), others felt that to understand clients in this way was problematic.

Other social work scholarship that discusses the benefits of the DSM includes criteria similar to those in the above-mentioned studies. Following the release of $D S M-I I I$, Janet B. W. Williams, a social worker and the manual's text editor, stated that learning the manual would improve diagnostic decision-making, treatment planning, and personal knowledge of mental disorders among other social workers (Williams, 1981). Over a decade later, Williams described the DSM as the most advanced system for diagnosing mental disorders, and argued that an evaluation of psychopathology should be part of a comprehensive social work assessment (Williams and Spitzer, 1995). Proponents of the DSM have argued that it enhances interprofessional communication (Regehr and Glancy, 2010) and cooperation and understanding (Turner, 1999), as it provides a common language that is vital for working with colleagues from other disciplines (McQuaide, 1999). MHSWs are expected to understand diagnostic terminology, which can come up in team meetings, client case files and other contexts. Kutchins and Kirk (1995) respond to this claim by stating that, while the DSM does provide mental health professionals 
with a uniform language for discussing mental disorders, it does not provide social workers with a language for discussing many other aspects of lived experience, including "social deprivation, individual abilities and strengths, oppression, accumulated disadvantage, racism, sexism, accessing community resources, client advocacy, family and group dynamics, interpersonal struggles and conflict, networking or clarifying what the client really wants" (p. 162).

In regard to an improved understanding of clients, Turner (2002) states that the manual has helped to "greatly expand our range of understanding of the manifest ways in which a person's mental functioning can get off track" (p. 46). While some believe that this type of perspective may lead to the labeling of individuals, Taylor (2006) argues that recognizing psychiatric symptoms in individuals is necessary in order to implement interventions that help individuals work through any mental health concerns. Moreover, Turner (2002) argues that the negative outcomes of labeling are not due to the labels themselves, but the misuse and misunderstanding of these labels by professionals, service users and society in general.

In terms of advantages that have less direct benefit for clients, Brubeck (1999) states that knowledge of the DSM allows MHSWs, particularly those employed in interprofessional hospital settings, to claim expert status similar to other professions, and maintain their standing among colleagues. This can impact not only on the standing of individual social workers, but also on the prestige of the field as a whole, as it helps to align the knowledge base and linguistic practices of 
social work with "what are perceived as scientifically grounded professional disciplines" (Ishabashi, 2005, p. 77).

One final advantage of the DSM is its ubiquity as the most regularly utilized classification system in the mental health field (Jordan and Franklin, 1995). Establishing the presence and severity of any symptoms of a mental disorder in a client's life is a normal component of a social work assessment in Canadian mental health practice (Regehr and Glancy, 2010), and given this, it is unsurprising that the Ontario Association of Social Workers (2006) lists "specialized knowledge of mental disorders, including the psychiatric classification system" (p. 2) as a knowledge standard for social workers in the mental health field.

Many of the advantages of the DSM in regard to mental health social work practice that have been described in this section, such as meeting agency and insurance requirements and assisting with diagnosis, likely differ between the U.S. and Canada. However, other benefits that have been highlighted in the literature may be relevant in the context of Ontario. Treatment planning, communication, understanding clients, comforting clients and meeting the purposes of the profession are all relevant concerns for mental health social work practice regardless of the setting , and thus it is relevant to explore what role the DSM plays in relation to these in the context of Ontario.

Other professional/disciplinary perspectives. While this thesis is exploring perspectives on the DSM from the perspective of MHSWs, it is important to acknowledge that the discourses of other professions and disciplines can have an impact on social work practice. A variety of arguments from non-social work 
perspectives have been in favor of the DSM and psychiatric diagnosis. Many of these arguments echo those that have been already cited in social work scholarship, such the ability of the DSM to greatly benefit the diagnosis and understanding of mental disorders (First et al., 2004), and also provide service users with a diagnosis that professionals feel can serve as a source of comfort (Carlat, 2010). In terms of arguments that are distinct from those already discussed, proponents of the DSM describe it as possessing two important elements: validity and reliability. In regard to validity, proponents argue that the diagnostic criteria in the manual allow for the proper identification of "real" disorders (Dziegielewski, 2010). In regard to reliability, proponents argue that the manual allows for clear and consistent diagnosis, such that different practitioners could see the same individual and arrive at the same diagnosis (Dziegielewski, 2010). While critics of the DSM have challenged both of these claims, others argue that any issues regarding the reliability and validity of the manual are comparable to those of more general medical taxonomic and diagnostic systems (Skene, 1999; Stein et al., 2010)

\section{Disadvantages of the DSM}

Social work perspectives. From a social work perspective, an important concern regarding the DSM is that it is incompatible with the profession's values and principles (Lyter and Lyter, 2010). One value that appears potentially contradictory with the DSM is the pursuit of social justice. The Canadian Association of Social Workers (CASW) (2005) lists this as one of the profession's six key values, asserting that social workers "act to reduce barriers and expand choice for all persons, with special regard for those who are marginalized" (p. 5). One critique of the DSM is 
that it views the struggles of clients in isolation from oppressive social structures, thereby shifting an emphasis away from reducing barriers (Corcoran and Walsh, 2006). In addition, the DSM has been described as promoting a narrow medical model perspective that assigns stigmatizing labels (Saleebey, 2001). Embracing a manual that overlooks the impact of oppressive social structures and relies on stigmatizing labels appears at odds with the value of social justice, as it contradicts the profession's goal of challenging "views and actions that stereotype particular persons or groups" (CASW, 2005, p. 5). This also appears at odds with a strengthsbased approach to professional practice (McQuaide, 1999), in that more emphasis can be placed on an individual's "illness" and deficits than any characteristics of resiliency (Grae and Zide, 2008). Austrian (2005) and Ishabashi (2005) also argue that the DSM is incompatible with person-in-environment perspective, as diagnoses can obscure both problematic and supportive aspects of a client's environment, leading to interventions that fail to promote sustainable recovery. As Saleebey (2001) states, ignoring an individual's strengths or supports disregards "the most important resources in helping a person recover" (p. 184).

While the strengths-based and person-in-environment approaches are not explicitly included among the CASW's key professional values, they have been described as informing the professional practice of many social workers (Spearman, 2005). In their survey of MHSWs in Ontario, O'Brien and Calderwood (2010) indicate that for respondents "an important and often unique contribution of social work to the mental health field was its client-focused, client-driven, recovery, strengths, human rights, empowerment, and person-in-environment perspective" 
(p. 328). Thus, to contradict the above-mentioned perspectives is to contradict the values that many MHSWs consider central to the profession.

Are concerns such as those described above shared by practicing social workers? Several U.S. studies have explored the perspectives of practicing social workers on the disadvantages of the DSM. In their aforementioned survey, Holmes and Raffoul (1984) explored the use of the DSM-III among U.S. social workers. They found that of those social workers who reported using the manual, $55 \%(n=16)$ perceived no disadvantages. Only a minority of individuals who used the manual reported any concerns, with $31 \%(n=9)$ stating that it labeled clients, $14 \%(n=4)$ saying it conflicted with their values and $7 \%(n=2)$ stating that they had too little training to use the manual effectively. However, since the authors do not include perceived disadvantages as listed by individuals who reported never using the manual, it is unclear whether this group held stronger views on this topic. Kutchins and Kirk (1988) similarly explored the use of the DSM-III among U.S. clinical social workers, but found results that were much more critical: $83 \%(n=300)$ of respondents felt that clinicians over-use certain diagnoses because of their practice orientations, $58 \%(n=210)$ felt the manual assigned medical labels to psychosocial problems, $51 \%(n=185)$ felt it promoted a mechanistic "cookbook" approach to assessing individuals and $45 \%(n=163)$ felt that it obscured individual differences. More recently, Rubinson (1999) found that $38 \%(n=55)$ of clinical social workers felt that DSM diagnoses pathologized normal human behavior, with $34.5 \%$ $(n=50)$ stating that diagnoses could sometimes lead to inappropriate treatment. Hitchens (2011) identified similar negative perspectives to those already discussed, 
with $70 \%(n=205)$ of respondents identifying the DSM as insensitive to racial and cultural differences in behavior, $63 \%(n=186)$ identifying it as obscuring individual differences, $61 \%(n=179)$ identifying it as detracting from an in-depth understanding client's problems, $60 \%(n=176)$ feeling that it sometimes leads to inappropriate treatment, $55 \%(n=160)$ stating that DSM diagnoses do not accurately reflect client's problems and $52 \%(n=152)$ stating that it places too much emphasis on pathology. Additionally, through follow-up interviews Hitchens (2011) identified further negative themes regarding the DSM, with participants sharing concerns about the manual's validity and reliability, its relationship with the medical model and its incongruence with the mission of social work. Similar concerns were raised by clinical social workers in by Probst (2011). However, while many of the participants in Probst's (2011) study considered the DSM and diagnoses to be potentially dehumanizing, inaccurate and of little use for professional practice, their concerns depended on the how they perceived the severity of the disorder in question. That is, in regard to working with clients with diagnoses such as schizophrenia and major depression, participants in the study felt that the DSM had a greater role to play in informing their practice.

Other professional/disciplinary perspectives. The DSM has also received significant criticism from other professional and disciplinary perspectives. Many of these critiques take specific aim at the manual's validity and reliability. A number of studies have shown that the same client, if seen by different practitioners, can receive completely different diagnoses (Linder, 2004; Pottick, Wakefield, Kirk and Tian, 2003). One possible explanation for these findings is that there is overlap 
among the diagnostic categories found in the manual, which allows for the subjectivity of individual practitioners to inform their diagnoses (Dougherty, 2005). This not only contradicts claims that the DSM can be used in a reliable fashion, but also raises concerns about whether the diagnostic criteria for different mental disorders found in the DSM are properly defined and differentiated from one another, and thereby possess validity. Paula Caplan, a psychologist who participated as a consultant during the development process of two separate editions of the DSM, has raised similar concerns about the manual's validity and reliability. Caplan (1995) relates these concerns to the DSM's development process, which is overseen by a small group of "mostly male, mostly white, mostly wealthy, mostly American psychiatrists" (p. 31). Since such a small, privileged group of individuals inform the manual's development, Caplan (1995) argues that their decision making process has been informed by different political and personal factors, as opposed to "scientific evidence". A quote from Robert Spitzer, the chair of the DSM-III (APA, 1980) task force, highlights the casual basis with which decisions were once made under his watch. When asked how the task force agreed that there should be five symptoms required for a diagnosis of depression, Spitzer stated, "Because four just seemed like not enough. And six seemed like too much" (as cited in Carlat, 2010, p. 54).

As a consequence of issues with the DSM-IV-TR's reliability and validity, Dougherty (2005) describes DSM diagnoses as "vulnerable to gender and racial bias" (p. 133). In addition to bias that is informed by individual practitioners, the manual itself has been described as culturally insensitive in that it overlooks the 
ways culture impacts on the subjective experience and expression of mental health, and also the fact that the culture of clinicians can impact on how they diagnose (Castillo, 1997; Kress, Eriksen, Rayle and Ford, 2005). Given these issues with bias, individuals from non-dominant cultural groups, including queer individuals, African Americans, ethnic minorities and women, have been shown to be at risk of misdiagnosis with certain disorders (Eriksen and Kress, 2005). However, McLaughlin (2002) argues that this is not entirely the fault of the DSM's diagnostic criteria; rather, that the fallible nature of the DSM can be compounded by the fallible nature of how professionals diagnose their clients.

Concerns regarding specific diagnoses. The DSM has received additional criticism in regard to specific diagnoses that are included in the manual. Some diagnoses have been criticized as totally non-representative of real internal dysfunction, while other diagnoses have been criticized in that they do not provide proper criteria with which to distinguish those individuals who are exhibiting symptoms due to internal dysfunction from those individuals whose symptoms are the product of "normal reactions to adverse environments" (Wakefield, 2005). Either form of argument has been made in regard to a large number of diagnoses in the manual, including: ADHD (Moncrieff and Timimi, 2010), Borderline Personality Disorder (Shaw and Proctor, 2005), Conduct Disorder and Oppositional Defiant Disorder (Wakefield and First, 2003), Gender Identity Disorder in Childhood (Bartlett, Vasey and Bukowski, 2000) and Social Anxiety Disorder (Lane, 2007). Concerns regarding $D S M-5$. With the fifth edition of the DSM scheduled for publication in 2013 , there have already been criticisms aimed at both the proposed 
content of the new manual and its development process. It has been suggested that DSM-5 will lead to a dramatic increase in the number of individuals that are diagnosed with mental disorders, due to the introduction of new diagnoses that would be common in the general population and broadening diagnostic criteria for many existing disorders (Frances, 2010; Wykes and Callard, 2010). In addition, the opposite concern (that changes in diagnostic criteria will lead to lower diagnostic rates, and thus greater challenges in accessing support services for those individuals and families who would benefit from them) has been made in regard to autism spectrum disorders (McPartland, Reichow and Volkmar, 2012).

Criticism of the manual has gone beyond individual scholars and extended to professional organizations. The Society for Humanistic Psychology (SHP), Division 32 of the American Psychological Association (2011), in a letter to the editors of the DSM-5 that was co-signed by over fifty mental health organizations, states:

We are concerned about the lowering of diagnostic thresholds for multiple disorder categories, about the introduction of disorders that may lead to inappropriate medical treatment of vulnerable populations, and about specific proposals that appear to lack empirical grounding. In addition, we question proposed changes to the definition(s) of mental disorder that deemphasize sociocultural variation while placing more emphasis on biological theory.

Other professional organizations have expressed similar concerns regarding the DSM-5. The British Psychological Society (BPS) (2011) lists numerous concerns regarding all but six of the diagnoses/diagnostic categories that were, at the time of 
their letter's publication, being considered for inclusion in DSM-5. The BPS letter argues that mental health professionals need to be embrace alternatives to the DSM in research and practice, while the SHP call for the publication of DSM-5 to be delayed until it receives an independent scientific review.

Should the development efforts of DSM-5 be a concern for social workers? The decision by the NASW (the major social work regulatory body in the U.S.) to refrain from endorsing the SHP's letter comes under specific criticism by various social workers quoted in an article by Allen Frances, the former chair of the DSM-IV Task Force. As Frances (2012) states, social workers should have a say in the DSM development process because of their profession's "responsibility to protect their clients from over-diagnosis and the consequent excessive exposure to medication". While neither the current edition of the DSM nor DSM-5 are designed to serve as treatment manuals, Whitaker (2011) argues that the DSM, by establishing a boundary between "normalcy" and "pathology", has played a major role in the growing number of adults and children who receive psychiatric medication. Although debates regarding the advantages and disadvantages of psychiatric medication are beyond the scope of this Literature review, ${ }^{9}$ arguments such as Frances' (2012) highlight that changes to the DSM can have substantive impacts on service users. Given that O'Brien and Calderwood (2010) identified advocacy as a major role for MHSWs in Ontario, even if individual professionals do not see the development process of $D S M-5$ as a major concern, any negative impacts on clients

${ }^{9}$ For a perspective on the advantages of psychiatric medication, see Schatzberg and Nemeroff, 2009, and for a perspective on the disadvantages of psychiatric medication, see Whitaker, 2011. 
that are due to these changes would likely require advocacy efforts down the road. While the ongoing review process will likely result in many changes to the final manual, it remains to be seen to what extent DSM-5 receives similar criticisms as its predecessors regarding its impact on service users and professional practice once it becomes available for use by mental health professionals.

Concerns regarding the economic influences on the DSM. Many critics of the DSM have expressed concerns about the role that the insurance and pharmaceutical industries have played in the manual's development and/or usage. That these industries would have an impact on the DSM is unsurprising since diagnoses are required for insurance coverage and reimbursement for many mental health services in Canada and the U.S. (Lundy, 2011) and new pharmaceutical drugs are often developed and marketed to target specific diagnoses (Carlat, 2010). Although my review of the literature did not revealed any scholars who have accused insurance or pharmaceutical companies of having an absolute say in the development and/or usage of previous, current or upcoming editions of the DSM, these industries have been described as helping to establish a context in which the need for and acceptance of "clear-cut categories and cures" (Pilecki, Clegg and McKay, 2011, p. 196) is commonplace among mental health researchers, service providers, service users and service funders in North America. From a social constructionist orientation, since pharmaceutical and insurance companies inform the context in which the DSM is regarded as valid and important, their relationship to the DSM is clearly an important topic to explore. 
Some research has explored the role that funding from the pharmaceutical industry has played in the development of the DSM. Examining the financial ties between DSM-IV and DSM-IV-TR panel members and pharmaceutical companies, Cosgrove, Krimsky, Vijayaraghavan, and Schneider (2006) found that $56 \%(n=95)$ had received some kind of financial support from the industry during their careers. The authors also found that specific DSM work groups ${ }^{10}$ were likeliest to have a higher percentage of members who had received financial support if the work group was in a diagnostic category for which medical treatment was regarded as a best practice (e.g. mood disorders.) Such findings and subsequent criticism prompted the APA to institute a mandatory financial disclosure policy for DSM-5 panel members. Examining these disclosures, Cosgrove and Krimsky (2012) found that $69 \%(n=117)$ of panel members had received some kind of financial support from the industry. Moreover, the authors again found that the "most conflicted" work groups were those for which medical treatment was regarded as a best practice. Given the significant level of pharmaceutical company funding for mental health research and professional development in North America (Moncrieff, Hopker and Thomas, 2005), it is unsurprising that a significant percentage of DSM panel members have received financial support from the industry. Nevertheless, this still raises concerns. New diagnoses have led to increased profits for the pharmaceutical industry, and efforts by the industry to market their drugs have enhanced the perceived validity of the DSM, prompting Carlat (2010) to describe the relationship

10 Similar to the previously discussed DSM-5 development process, the development of the DSM-IV and DSM-IV-TR was spearheaded by "work groups", teams of mental health clinicians and researchers that focused on a specific diagnostic category included in the manual. 
between the two as a "symbiotic dance" (p. 67). While Frances (2010) argues that such financial relationships do not bias DSM task force members to make deliberate changes that lead to higher rates of psychiatric diagnosis in the general population and thus greater profits for pharmaceutical companies (e.g., by introducing new diagnoses or changing the criteria for existing diagnoses), he does worry that any problematic changes to the manual that lead to such higher rates will be used to the advantage of the pharmaceutical industry.

The insurance industry has not played the same role as the pharmaceutical industry in financially supporting DSM panel members and other mental health research efforts. However, mental health services in Canada and the U.S. have expanded over the past fifty years, and the cost of paying for many of these services has shifted from individuals to the government and insurance industry (Davis, 2006). This (along with the desire to keep expenses low) has enhanced the importance of the DSM, since it provides a set of standards with which to determine who is "disordered" and thus can access mental health services (Parker, 2006). Turner (2002) argues that the insurance industry has had a significant role in shaping how diagnostic practices in the mental health system involve a narrow emphasis on identifying the symptoms of a disorder that is categorized in the DSM:

This trend to make the DSM the heart and soul of diagnosis by equating diagnosis with a DSM description has been aided and abetted by many health insurance programs that provide coverage only for highly specified diagnostic classifications formulated in DSM terminology. (p. 45) 
This emphasis on only providing insurance coverage for service users with DSM diagnoses has implications for the professional practice of mental health services providers. Several studies have illustrated that U.S. psychologists, when given client vignettes that only differ in regard to whether the client will be paying for services out-of-pocket or through insurance, are more likely to diagnose the client using the DSM when that individual will be paying via insurance (Kielbasa, Pomerantz, Krohn, and Sullivan, 2004; Lowe, Pomerantz and Pettibone, 2007; Pomerantz and Segrist, 2006). In the case of the latter two studies, the vignettes included descriptions of clients with sub-clinical symptoms that should not have warranted a diagnosis, and yet participants were still likely to assign diagnoses if the clients were receiving insurance coverage. None of these studies included any follow-up with participants to explore the rationale behind their diagnoses (e.g., did they consciously choose to diagnose clients in order to "help them" gain access to affordable services?), and decisions made in regard to case vignettes may differ from those that are made in actual practice. Nevertheless, these studies do raise concerns that the role that diagnoses play in allowing service users to access financial support may inform service providers' diagnostic practices. Although the $D S M$ itself should not necessarily be blamed for this, it does highlight one further reason that the validity and reliability of diagnoses may be questioned. Moreover, these are concerns for U.S. MHSWs, with $84 \%(n=243)$ of participants in a study by Hitchens (2011) agreeing that diagnoses are often influenced by insurance and other third-party reimbursement requirements, and $55 \%(n=161)$ stating that 
reimbursement requirements are the primary reason why mental health service providers use the DSM.

\section{Critiques of the Mental Health System}

Criticism of the DSM from social work and other professional perspectives can be related to more general critiques of the mental health system. These critiques have come from various perspectives, including: feminists, gay rights advocates, radical psychiatrists, social constructionist thinkers and consumers/survivors. The feminist critique of psychiatry was motivated by concerns about how mental health professionals disproportionately diagnose women with depression and borderline personality disorder, ignoring the ways in which the symptoms of these two diagnoses are often a normal reaction to widespread sexism and experiences of physical and sexual violence (Chesler, 2005). Gay rights advocates shared similar concerns, as individuals who identified as homosexual were labeled as having a mental illness in the DSM until significant activism prompted changes in 1973 (Everett, 2000).

The radical psychiatry and social constructionist movements, led by such figures as R.D. Laing, Thomas Szasz and Michel Foucault, were driven by more general concerns about how professions, such as psychiatry, promoted oppression by forcibly confining service users, and worked to challenge the understanding of mental disorders as objective, measurable medical conditions (Everett, 2000). Foucault has had a particularly significant influence on subsequent criticism of historical and contemporary discourses within the mental health system, and the idea of mental disorders as objective medical conditions. Through a historical 
analysis of the development of psychiatric practices and the asylum system in Europe, Foucault (1965) argued that understandings of "madness" were constructed on the basis of economic and social conditions, and a history of confinement that can be traced back to the 1600 s. During this Great Confinement, individuals who exhibited behaviour that was perceived as undesirable or abnormal were separated from general society into institutional spaces along with criminals and the unemployed. Through this process, madness became associated with an inability to work or safely and morally integrate into society. Those labeled as mad became defined as a problem for society, and since psychiatry developed out of this context, its roots have as much to do with the social control of deviant behavior as they do with helping individuals. From a social constructionist orientation, the DSM's attempts to delineate a boundary between mental normalcy and mental disorder could be regarded as a contemporary example of mental health professionals embracing discourses that define certain members of society as productive and rational and others as socially undesirable (Crowe, 2000).

As psychiatry, subsequent to the Great Confinement, developed into a medical sub-discipline that specialized in the treatment of individuals who were confined and regarded as mad, members of the discipline (along with psychologists) embraced and utilized classificatory discourses in which madness came to be described as "a series of mental illnesses, each with its own symptomatology, development, diagnostic and prognostic elements" (Foucault, 2003, p. 133). By defining madness in these terms, psychiatrists and psychologists further legitimized their role, work and profession, given that they could be regarded as treating, 
studying and possessing scientific knowledge of diseases in the same fashion as other medical doctors (see Foucault [1973] for a related discussion of similar processes within the medical profession.) Through these arguments, Foucault has inspired further scholarship on the problematic aspects of medicalized understandings of mental disorders, and how embracing such understandings enhance the power and prestige of mental health professionals.

These various critiques occurred alongside a consumer/survivor movement that raised similar concerns from the perspective of individuals who had received diagnoses. Reaume (2002) describes the different groups that were at the forefront of the movement as:

Primarily antipsychiatry in outlook, opposed to forced treatment including forced drugging, shock treatment and involuntary committal. Members also chose to be public about their personal medical history of having been medical patients to an extent that had not been seen before in organized groups. (p. 416)

In striving for independence from the mental health system, consumer/ survivor groups focused on peer support - bringing service users together to share their experiences and help each other recover from abusive institutional experiences - and political action - working to change the people and systems that negatively impact on their lived experience ( $O^{\prime}$ Hagan, McKee and Priest, 2009). One of the main accomplishments of the movement has been to challenge mainstream. medical discourse around mental health. While the consumer/survivor movement and other aforementioned critiques of psychiatry have not always focused their 
criticism on the DSM, they have played a significant role in questioning more general discourses and practices within the mental health system.

\section{The Medical Model and the DSM}

As previously discussed, a theme identified by Hitchens (2011) in interviews with clinical social workers is that there is a problematic relationship between the DSM and a medical model perspective in North America. This problematic relationship is a common concern in the literature. Scholars have described a reliance on the DSM as a key aspect of a medical model perspective in North America (Arnd-Caddigan and Pozzuto, 2010) and described a medical model perspective as contributing to the pathologizing of service users (Saleebey, 2001). However, a medical model perspective is not a simple, uniformly defined approach that implicitly affirms the influence of the DSM or promotes a fixed, narrow and pathologizing understanding of mental disorders. For example, Nesse and Stein (2012) distinguished a "narrow" medical model (which they believe has been encouraged by the DSM and accepted by many mental health professionals in North America) from a "broader" medical model (which they believe is more commonplace among other medical professionals.] A narrow medical model was conceptualized as presuming that the symptoms of mental disorders are best understood as reflections of internal dysfunction, whereas a broader medical model recognizes that many of the symptoms of mental disorders are protective (and thus normal) responses to adverse environmental conditions. Moreover, a narrow medical model perspective is strongly associated with psycho-pharmacological influenced understandings of mental distress. Nesse and Stein (2012) argued that, 
while a narrow medical model has helped legitimize (and been legitimized by) the $D S M$, a broader medical model could also inspire challenges to the DSM. Specifically, Nesse and Stein (2012) described how mental health service providers who embraced a broader medical model perspective would realize that "diagnosing an expression of emotion as abnormal without considering the life context is like diagnosing chronic pain without looking for possible causes of tissue damage" (p. 4).

Further evidence of the DSM's complicated relationship with a narrow medical model in North America is apparent when examining recent international genetic and neuroscience research. Such research, which has looked at the biological etiology and symptomatology of mental disorders (and which has likely been conducted by researchers who subscribe to a medical model perspective in some capacity), has helped to challenge the notion that all of the mental disorders that are categorized in the DSM are clearly delineated forms of intra-psychic biological dysfunction. Although a comprehensive overview of such research is well beyond the scope of this thesis, a short discussion can clarify how research efforts that are indebted to the medical model can challenge the assumptions of a narrow medical model and complicate the status of the DSM. In an overview of recent genetic and epi-genetic studies, Hyman (2010) summarizes a growing body of data that indicates that "no single gene variant or genomic locus appears to be necessary or sufficient to produce any of the major, common mental disorders" (p. 169). Hyman (2010) argues that these findings undercut the DSM's categorical classification system. Moreover, such findings can also challenge the idea that mental disorders are an expression of individual pathology, which is a defining 
assumption of a narrow medical model perspective (Eriksen and Kress, 2005).

Similarly, Phillips et al. (2012) argued that current neuroscience research has yet to validate whether many mental disorders classified in the DSM are reflective of neurochemical dysfunction. As Phillips et al. (2012) discussed, recent findings from psychiatric science indicate that there needs to be either minimal or maximal change to the DSM. Thus, while it is important to reflect on the problematic aspects of a narrow medical model and how these are connected to the $D S M$, one needs to recognize that a medical model perspective is a complicated phenomenon that is capable of both affirming and challenging the DSM's status in North America. The Impacts of Diagnosis on Service Users

Taking into account all of these criticisms, what should remain particularly important from a social work perspective is the extent to which the DSM impacts on service users. One specific concern from this perspective is how the DSM either promotes or inhibits stigma. Goffman (1963, as cited in Scheyett, 2005) describes stigma as a "phenomenon whereby an individual with an attribute which is deeply discredited by his/her society is rejected as a result of the attribute" (p. 80). While this definition implies that stigma is always directed at an individual from outside forces, it can also be internalized such that the individual themselves experience discomfort with aspects of their identity. Individuals diagnosed with mental disorders encounter stigma in both mainstream society and the mental health system. Stigma in the mental health system can take many forms, such that individuals may have their opinions ignored in treatment planning, receive coercive or dehumanizing treatment, and have their behavior interpreted solely as a 
reflection of their diagnosis (Scheyett, 2005). Such forms of stigma are described by consumers/survivors as being relatively common in Ontario, and being associated with receiving a psychiatric diagnosis (Everett, 2000). Furthermore, stigma can also be directed toward service users through discourses that are endorsed in mainstream society and the mental health system, including those depict individuals with mental disorders as "weak" or as "suffering" due to internal flaws that only mental health "experts" are capable of understanding and treating (Walker, 2006).

Many individuals who could potentially benefit from mental health services avoid pursuing them as a way to avoid stigma that comes from receiving a diagnostic label (Corrigan, Watson, Byrne and Davis, 2005; Corrigan, 2007). While there have been public education efforts in recent decades that aim to reduce stigma by framing mental disorders as akin to physical illnesses, research has shown that negative attitudes can still persist towards individuals who receive a diagnosis when such a narrow medical model understanding is embraced (Mehta and Farina, 1997). Gormley and Quinn (2009) argue that the overuse of diagnostic labels, a consequence of the DSM, has meant that more individuals face stigmatization, and that this stigma may cause more coping challenges for consumers/survivors than any difficulties associated with their mental health status. Given these issues, McQuaide (1999) contends that a major goal for social workers is to help empower clients so that they see themselves as distinct from the diagnostic label that they have been assigned.

Another concern regarding the impact of the DSM and diagnosis on the lives of service users is the extent to which it fosters dependency on formal mental health 
supports. As Canadian activist and self-identified psychiatric survivor Irit Shimrat (1997) states:

Once you're diagnosed, you're generally told you have to stay on drugs forever. You are expected to (and therefore expect to, and therefore often do) fall apart whenever anything in your life goes wrong; require continuous professional help; and go back into the hospital now and again when things get really bad. You are likely to see a therapist, counsellor, psychologist or psychiatrist on a regular basis, which reinforces the idea that you are sick and need help. (p. 2)

Although this statement does not imply that diagnosis is the cause of the various frustrations experienced by service users, it does highlight that individuals who have received a diagnosis may view the diagnostic process with scepticism or hostility.

These criticisms regarding stigma and dependency are actually acknowledged within the DSM-IV-TR Guidebook (First et al., 2004), which was designed to add further context to the most recent edition of the manual. Under a discussion of "reasonable concerns" regarding the need to classify disorders, the authors state that a psychiatric diagnosis can lead to "potential stigma", and/or shift the behavior (or interpretations of the behavior) of individuals so that they act "in accord" with the diagnosis. Nevertheless, the guidebook's authors argue that these and other concerns should not outweigh the "enormous benefits" of the manual when it is "used and understood thoughtfully" (p. 21). Whether or not these and 
other previously discussed concerns should outweigh the manual's benefits, they do demonstrate that the DSM is a highly contentious diagnostic tool.

\section{Social Constructionism and the DSM}

From a social constructionist perspective, it is important to take a critical lens not only to the DSM but also to the very concepts of mental health and mental disorder. In fact, the DSM can be seen as playing a major role in constructing contemporary understandings of mental health and reifying mental disorders (Kutchins and Kirk, 1997). Cooper (2005) argues this point, stating that once a disorder is included in the $D S M$, it is "sure to come to be recognized as a problem in popular culture" (p. 1). Ishabashi (2005) provides a further description of how the $D S M$ has helped reify mental disorders, stating, "diagnoses contain an implicit and fundamental assumption that they correspond to real, discrete diseases" (p. 69).

Cotton and Ridings (2011) explicitly define the DSM as being a social construction, citing changes to the manual such as the removal of homosexuality as a mental disorder in 1973 and the addition of posttraumatic stress disorder (PTSD) in 1980 . Both these changes were the result of political action by different interest groups, and their removal from or addition to the DSM played a significant role in shifting public perceptions of homosexuality and PTSD in North America. This indicates that the manual is informed by and also informs public perceptions of what are regarded as "normal" patterns of thought, emotion and behavior. Given that perceptions of normality are distinct from society to society, it is unsurprising that only four disorders (schizophrenia, mania, depression and anxiety disorders) have been found to exist on an international basis (Kleinman, 1996). 
Many of the disadvantages of the DSM that I have discussed in this Literature review appear informed by similar fundamental assumptions as the social constructionist approach. However, acknowledging that the DSM is subjective and socially and historically located does not invalidate the fact that certain symptoms associated with a mental disorder can cause tangible distress for those experiencing them. Additionally, given the wide variety of mental disorders that are included in the $D S M$, it would be presumptuous to assume that each disorder and their corresponding diagnostic criteria can be dismissed as pure social constructions that in no way reflect underlying psychological and/or biological phenomena. As one example, there is a significant distinction in terms of our understanding of the biopsycho-social etiology of schizophrenia versus oppositional defiant disorder. Thus, when exploring the specific diagnoses within the manual, it is important to acknowledge that they reflect not only the "blind spots" but also the "achievements...of the society that created them" (McQuaide, 1999, p. 413).

\section{Summary}

Although no shortage of literature exists to debate the merits of the DSM as a taxonomic system and diagnostic tool, to the best of my knowledge there has been little exploration of how the manual is used in Canadian social work practice. While various studies have indicated that social workers in the U.S. use the manual to some capacity (Dziegielewski et al., 2003; Frazer et al., 2009; Hitchens, 2011; Holmes and Raffoul, 1984; Kutchins and Kirk, 1988; Rubinson, 1999), these studies have come from very different times and places than contemporary Canadian society. Nevertheless, given the importance of inter-professional practice in the 
current mental health system and the significant role that the DSM-IV-TR plays in informing the diagnosis of mental disorders, it seems likely that the manual has at least some impact in the practice of MHSWs in Ontario. Since positions regarding the advantages and disadvantages are so divisive, it is important to both explore how the manual is used by MHSWs in their professional practice and what perspectives MHSWs have toward the manual.

\section{Method}

\section{Research Design}

The aim of the present exploratory study was to examine how MHSWs in Ontario use the DSM and what views they have toward the manual. To accomplish this I undertook a qualitative study. Qualitative research is a bottom-up exploratory method that allows participants' voices to be heard (Fine, 2002). Furthermore, qualitative research is regarded as a useful approach for situating one's research in historical, societal and cultural contexts (Marecek, 2003). The goal of qualitative work is not to do away with bias, but rather to ensure that that a researcher's biases are made transparent and taken into consideration as a factor informing their work. Since my research question focused on the subjective perspectives of social workers, qualitative research is a useful approach, as it creates a space for participants to share their thoughts and feelings in their own words.

\section{Researcher-as-Instrument Statement}

My personal interest in the topic of mental disorders stems from several different contexts. I have been a mental health service user and received a diagnosis at an early age. I have studied issues relating to mental health through my 
undergraduate and graduate degrees, and I have had experience working and volunteering in a variety of different mental health settings. These experiences have affirmed my belief in the subjective nature through which mental health can be conceptualized and experienced. I believe that it is important to question and unpack established knowledge and to view seemingly objective categories such as "mental disorder" as constructions. While acknowledging that constructions such as mental disorder may have tangible benefits, such as allowing individuals with diagnoses access to support, and that many individuals labeled with mental disorders may experience serious concerns regarding their thoughts, feelings and behaviors, I think it is important to look beyond these labels in order to understand and relate to individuals.

Given the above sentiments, it is clear that I bring subjective perspectives to this research topic. In fact, I doubt I would have chosen the topic if I did not have a strong interest in the issue of how we define and understand mental health. Since there are so many possible ways that my subjectivity can inform my work on this thesis, I have tracked my own assumptions, expectations and biases with a reflexive journal. I have reflected not only on my thoughts regarding the issue of mental disorders, but also on issues regarding the nature of knowledge production and the challenges of qualitative work. This journal has allowed me to maintain transparency regarding the thoughts and feelings behind the choices I have made during the research process, thus adding trustworthiness to this study. 


\section{Sampling Method and Participants}

Using purposive and snowball sampling, ten social workers employed (or recently employed] in mental health settings in the Ottawa area were recruited for this study. Following ethics approval from the Carleton University Research Ethics Board (see Appendix A), my thesis supervisor and I began purposive sampling, and reached out to professional contacts in the mental health field via e-mail (see Appendix B for a version of the email script that was sent to potential recruits.) A small number of these contacts were specifically asked to participate in the study because they were MHSWs who were also former service users. This yielded one participant. The majority of contacts were asked to forward information on the study to social work colleagues in the mental health field; such snowball methods yielded an additional four participants. Subsequently, I received ethics approval from the Research Ethics Board at an Ottawa-area hospital (the name of this hospital is not provided in order to preserve participant anonymity). My on-site supervisor at that hospital then submitted information about this study to social work staff employed at the same institution, which yielded four more participants. The final recruitment efforts in the study were made using an online directory of social workers engaged in private practice; I sent an email to every individual registered on this directory, which yielded the final participant in the study.

Braun and Clarke (2006) refer to thematic analysis as grounded theory "light", and in grounded theory theoretical saturation is possible when "diminishing returns from each new analysis mean that no new themes, categories or relationships are emerging and new data confirms findings from previous data" 
(Gasson, 2003, p. 84). There is no fixed number of participants that can guarantee theoretical saturation; rather, any determination of theoretical saturation will vary based on the aim and approach of the research in question. After the completion of ten interviews, I reflected on the content of the interviews in order to get a sense of whether my sample provided a sufficient range of perspectives on my research question. I felt that this was indeed the case. Though further attempts were made at recruitment by forwarding information on the study to additional contacts in the mental health field, the lack of response to these efforts can be regarded as evidence that after a four month recruitment process I had reached a closed network, in which there were no further referrals that could be reached via snowball methods (Neuman, 2006).

The demographic characteristics of the ten participants are found in Table 2. The names assigned to participants in this table are all pseudonyms, and only basic details have been provided in order to ensure participant confidentiality. The average age of participants was 41.7 years, with a range of 31 years of age to 60 years. Six participants were female, while four were male. Nine of the participants had received their Master of Social Work degree from Carleton University, with only one participant having received the same degree from a different institution (McGill University). Participants had an average of 11.9 years of experience working in mental health settings (including paid employment and unpaid placement experience), with a range of 1 year to 24 years. The participants were working (or, in the case of one participant, were recently working) within a variety of settings, including hospitals (both in an inpatient and outpatient capacity), community-based 
MHSWS IN ONTARIO AND THE DSM

Table 2

Participants' Demographic Characteristics

\begin{tabular}{cccc}
\hline Pseudonym & Age & Gender & Interview length \\
\hline Paula & 31 & Female & 58 minutes \\
Molly & 31 & Female & 75 minutes \\
Seth & 50 & Male & 53 minutes \\
Leon & 49 & Male & 87 minutes \\
Robin & 40 & Female & 64 minutes \\
Kim & 31 & Female & 70 minutes \\
Geri & 53 & Female & 45 minutes \\
Sidney & 60 & Male & 54 minutes \\
Ashleigh & 27 & Female & 63 minutes \\
Sean & 45 & Male & 41 minutes \\
\hline
\end{tabular}

agencies and private practice (those individuals who worked in private practice also worked in other settings.) The participants also had experience working with a variety of populations in regard to age (including children, adolescents, adults and the elderly) and specific mental health concerns (e.g., substance use, anxiety, etc.) Only two participants in the study worked with the same population in the same setting, indicating that the participants in the study were able to speak about mental health social work practice in regard to various contexts.

At the beginning of my recruitment process, I was specifically looking to 
interview a small number of participants who identified as mental health service users. The reason behind this choice was the possibility that previous experience with receiving mental health services might inform unique perspectives in regard to mental health discourses and approaches to professional practice (Rooke-Matthews and Lindow, 1998). However, during the recruitment process, only one participant identified as a former service user. Given the potential stigma associated with selfdisclosure of service user status, which can be intense for individuals who work in mental health settings (Stanley, Ridley, Harris and Manthorpe, 2011), it is possible that other participants in my study may have had similar experiences, but were unwilling to volunteer this information. Nevertheless, as only one participant selfdisclosed in this regard, the question of whether service user experiences can inform unique perspectives on the DSM will not be considered in the present study.

\section{Data Collection}

Once participants had expressed an interest in participating in the study, I followed up via e-mail to arrange a convenient location and time for an in-person interview. Seven of the interviews took place at a participant's place of work in a private office, two took place in a private room on the campus of Carleton University and one took place at a participant's home. The interviews were audio-recorded, lasting an average of 61 minutes and ranging from 41 to 87 minutes. I also took notes during each interview so that I could record the comments of participants for later follow-up, thus aiding the interview process. Further data was collected over e-mail via follow-up questions that were sent to participants following the transcribing process. The reason for these follow-up e-mails was to clarify 
comments that were made by participants, and to get their feedback on questions that evolved through later interviews. Eight participants were contacted for followup via e-mail with questions that arose through this iterative process, and three provided feedback that was then utilized as data for the study.

The interviews I conducted were semi-structured. Semi-structured interviews are more open in nature, which allowed me to follow up on the insights raised by participants as they came up in conversation, rather than sticking to a setin-stone script (Esterberg, 2002). This complemented the goals of thematic analysis, as it allowed the interview to be a more bottom-up process informed by the perspectives of participants themselves. The interviews were iterative, in that the questions evolved from interview to interview in order to gain a greater depth of data (Charmaz, 2002). By self-reflecting on the content of each interview after its completion, I was able to keep track of specific questions that I felt would be relevant (or less relevant then originally anticipated) for future interviews. One reason to include this self-reflection and allow this flexibility in my questions was to better respond to issues or topics relevant to my research that participants raised that I had not previously considered. For example, during one interview, a participant discussed the ways in which the structure of mental health services in hospital settings can reflect the categorization system of the DSM. As a result of this interesting point, in subsequent interviews I made sure to discuss this very issue with participants.

Prior to beginning each interview, participants were provided with an Informed Consent form (see Appendix C). This form outlined the purpose of the 
study, the requirements for participating in the study, the benefits of the study, potential risks/discomfort that could result from participating in the study and information on participant anonymity and confidentiality. Participants were given time to read through this form, and then were asked if they had any questions or concerns. Once any questions were answered, participants were then asked if they were willing to consent to participate in the study and to have the interview be audio-recorded. All recruits who agreed to meet for an interview consented in both regards.

Although the interviews were open-ended in nature, I did utilize an interview schedule (see Appendix D), which helped to give structure to the interview and ensured that I asked certain questions that I regarded particularly relevant to the research topic. Furthermore, many of these questions were informed by my social constructionist orientation, in that they encouraged participants to describe their contextualized understanding of various concepts that were relevant to my thesis question. The interview schedule included seven topic areas:

1. Characteristics of professional practice (e.g., "What services do you provide for clients?"]

2. Perspectives on social work (e.g., "What would you describe the values of social work to be?")

3. Perspectives on mental health (e.g., "How do you define the term mental health?") 
4. Education, training, professional and personal experiences (e.g., “Can you tell me about any experiences that have informed your use and understanding of the DSM?")

5. Work with clients who have received a diagnosis (e.g., "Have you ever disagreed with a diagnosis that a client of yours has received?")

6. Use of the DSM (e.g., "Have you ever referred to the DSM at any point in your professional practice?"]

7. Advantages and disadvantages of the DSM (e.g., "Can you discuss any advantages and/or disadvantages that you think the DSM has for mental health service users?")

These questions helped provide me with information on the values and attitudes that participants held toward the DSM and psychiatric diagnosis, and the role the manual played in their practice.

In order to ensure participant confidentiality, upon the completion of each interview, participants were assigned a random pseudonym that was used during the transcribing and analysis of the interview and the reporting of the data in this thesis. Participants were also asked if they would like to review a transcript of their interview for accuracy prior to data analysis, if they would be willing to be contacted for follow-up if any questions arose during transcribing and/or analysis, if they would like to receive a copy of the final results of my research and if they would like a $\$ 15.00$ charitable donation made anonymously to a charity or social service 
agency of their choice. ${ }^{11}$ This information was recorded on a Face Sheet (see Appendix E). All participants were then debriefed orally, provided with a written Debriefing Form (see Appendix F) and thanked for their participation. During the debrief, participants were reminded that they had one week from the date of the interview to ask that the data collected during their interview be withdrawn from the project.

After each interview was complete, I filled out a Post Interview Comment Sheet (see Appendix G).12 This allowed me to reccrd any observations that would not be captured in the audio recording of the interview. The various forms that were completed during the interview process, along with the audio recording of the interview, were securely stored.

\section{Data Analysis}

The specific method of qualitative analysis guiding this research is thematic analysis. Thematic analysis has been used across a variety of social disciplines in a multitude of ways. The first attempt to define and standardize thematic analysis was spearheaded by Boyatzis (1998). While stating that there was no clear agreement on what thematic analysis was or how to properly conduct it, Boyatzis did provide a foundational text that contributed to growing acceptance of the approach. Braun and Clarke (2006) state that thematic analysis is the most

11 The charitable donation option was provided as a way of "thanking" participants for taking the time to sit down for an interview. However, due to concerns expressed by the Research Ethics Board at the Ottawa-area hospital through which I recruited four participants, the charitable donation option was not provided to these participants.

12 This Post Interview Comment Sheet was originally developed by Dr. Connie Kristiansen, and was provided to me by one of her students. 
accessible approach to qualitative analysis, which is relevant for me as this is the first piece of qualitative research I have undertaken. Thematic analysis is a qualitative method that searches for themes or patterns across an entire data set, both reflecting and unraveling "reality" (Braun and Clarke, 2006). McLeod (2001) argues that thematic analysis allows us to best understand the day-to-day experiences of everyday people. In the context of the current study, this method allowed me to gain a deep level of insight into how social workers in mental health settings use and understand the DSM. Thematic analysis can be seen as a highly flexible approach, integrating well with different theoretical orientations, including social constructionism (Braun and Clarke, 2006).

For my analysis I followed the six-phase thematic analysis model outlined by Braun and Clarke (2006). In phase one, I familiarized myself with the data. This was accomplished by listening to each audio-recorded interview, transcribing each interview (using the application ExpressScribe), checking each transcript against the audio-recording for accuracy, and reading through the transcripts multiple times, followed by memoing (writing down my initial thoughts and impressions) in a methodological journal to ensure that my analysis was consistent and rigorous (Morrow, 2005). As an example of the thoughts that I captured through memoing, after transcribing one interview I wrote down the following impressions:

The participant had a bit to say in terms of the positives and negatives of the manual. Positives such as you need to know it, and that having a sense of one's diagnosis can bring a client some relief. However, even this last positive was critiqued, as she described it as being part of a medical model 
perspective that a diagnosis can lead straight to a specific cure. She contrasted this with the goal/mission of social work.

In phase two, I began to generate initial codes based on interesting features of the data. This coding was conducted using Microsoft Word's reviewing feature, which allowed me to highlight specific segments of text and then insert a comment along the side that aimed to capture the meaning of the text. As one example, from my interview with Leon, the comment "Getting LTD, getting insurance, one of the things that's really moving the use of diagnoses, is the access to financial resources..." was initially coded as "Diagnoses open up resources." I kept a separate document including all of the codes that I was applying, and I consistently reviewed this document to identify whether there was any redundancy between codes or codes that were too vaguely worded. As the interviews progressed, I began to notice certain codes that were regularly recurring between interviews, and others that seemed to be connected to each other.

After all the interviews were coded in this fashion, they were printed and I initiated phase three of my analysis by re-analyzing and re-coding the printed interviews. All of the codes were reviewed, with certain segments of text re-coded based on impressions from my initial wave of coding, while other codes were renamed (e.g., the previously described code was renamed "Services are informed by diagnostic categorization.")

During this phase of analysis, I began to search for themes, collating my codes into potential themes, and gathering all the data that was seen as applicable to each theme. To aid with this process, I successively generated different thematic 
maps that aimed to capture patterns among my data set. These maps, and my thoughts regarding each map, were documented in an analytic journal. In an early example of a thematic map that I produced in this journal, I highlighted three themes that I felt reflected the data I had collected: the DSM as a product (i.e., a document that has formal applications for mental health practice), the DSM as productive (i.e., informing praxis in the mental health field) and the DSM as produced (i.e., part of a wider system of discourse.) Although this early model aided with the analysis process and forced me to think further of how I was making meaning of the data, upon further review of my data I realized that these themes did not fully incorporate all of the meaningful codes that I had identified. Through further interpretation of my data, I noticed that several participants had referred to the DSM as a "tool." In reflecting on these statements, I began to think about the defining aspects of tools; namely, that they serve a function, that this function leads to certain consequences, that they are developed and manufactured by people and that all of these aspects are informed by the context of their use. Based on my intimacy with the data I had collected and my familiarity with issues raised in the literature, I felt that these four aspects seemed to fit with the data I had collected, and I then developed a four-theme thematic model (further discussed in my Results section.) Using Microsoft Excel, I generated separate sheets for each sub-theme, grouped these together on the basis of the overarching theme, and transferred coded segments of text to the appropriate sheet in the document.

In phase four, I re-examined the data to ensure that the themes I had identified were relevant to the entire data set. I re-read every transcript, with close 
attention paid to whether any comments or perspectives did not fit within my model and thus were examples of negative cases. As I did not find any evidence of negative cases, this indicated that my model was a relevant way of representing the data I had collected. To ensure that this was not strictly my own personal assumption, I conducted member checks by e-mailing a copy and explanation of my thematic map to eight participants which included a request for participants to provide any feedback they had in regard to the accuracy and validity of my thematic model. Two participants responded to these emails, with Paula commenting that the themes I had identified were "clear and comprehensive."

Based on my own reflections, the feedback from participants and conversations with my thesis supervisor, in phase five I decided upon the final names of my four themes. One of these themes, "Applications to Social Work Practice", was renamed from the original "Applications to Social Work Praxis", as the first phrasing was judged to better fit with the meaning of that theme. I further reflected on the relationship of my thematic model to the research question and literature, and felt that it was both relevant to the former and supported by the latter. Once this phase was complete, I set about selecting appropriate quotes that richly illustrated the story of each sub-theme, and produced the Findings and Discussion sections of my report.

\section{Trustworthiness}

My aim with this thesis has been to produce a trustworthy qualitative analysis. Drawing on the work of Egon Guba, Shenton (2004) argues that qualitative researchers must satisfy four criteria to ensure that their work be regarded as 
trustworthy. These criteria are: credibility, transferability, dependability and confirmability. I believe I have satisfied these four criteria with my research, and thus I will briefly discuss the meaning of each, and describe the ways that I have conducted my research and analysis in order to satisfy their respective requirements.

Credibility. Shenton (2004) describes credibility as relating to whether one's findings are congruent with reality. The author offers an extensive list of provisions with which researchers can ensure the credibility of their work. I believe that I have satisfied the following provisions in my research, analysis and writing: ensuring site triangulation by drawing on participants from different professional settings; utilizing iterative questioning, the well-regarded thematic analysis approach of Braun and Clarke (2006) and negative case analysis; frequently debriefing with my thesis supervisor; encouraging feedback on my thematic model from peers and employing member checks; providing a description of my own experiences and biases relevant to the topic in question; reflecting on similarities and differences between my findings and those of previous research; and lastly, providing a "thick description"13 of my findings in the following results section of my thesis.

Transferability. Shenton (2004) cautions that the results of qualitative research "must be understood within the context of the particular characteristics of the organisation or organisations and, perhaps, geographical area in which the

13 Morrow (2005) defines a "thick description" as involving "detailed, rich descriptions not only of participants' experiences of the phenomena but also of the contexts in which those experiences occur" (p. 252). 
fieldwork was carried out" (p. 70). The author further questions whether it is a realistic aim to produce "truly transferable" results from one study. As I have stated, my aim with this thesis is to conduct an exploratory study. My findings will be presented and discussed within this context, and my overall aim has not been to provide a final answer on how MHSWs in Ontario use the DSM and what perspectives they have toward the manual, but to offer some possibilities in regard to a research question that has thus far been completely unexplored within the context of Ontario or any other Canadian province/territory. Any issues that may affect the transferability of my research will be further discussed in my Limitations section.

Dependability. To ensure the dependability of one's work, Shenton (2004) states that it is important for a researcher to report their analysis process in detail within their report. I feel that in this section I have offered a comprehensive overview of the design and implementation of my research, along with details on exactly how I went about collecting data from participants. In particular, I feel that I have demonstrated that my understanding of the data evolved throughout the analysis process, which is a key element to a high-quality thematic analysis (Braun and Clarke, 2006).

Confirmability. This final criteria of trustworthiness refers to whether one's findings are "the result of the experiences and ideas of the informants", as opposed to "the characteristics and preferences of the researcher" (Shenton, 2004). To demonstrate the confirmability of my work, I have described the beliefs that informed my analysis process, including presenting an early thematic map that did 
not adequately represent the data and describing how I rejected this map in favor of a more representative one. Having maintained a methodological journal throughout the analysis process along with separate documents for each stage of the coding process, I feel that I have provided a comprehensive "audit trail" that would allow observers to follow the step-by-step process of my research.

\section{Findings}

Through a thematic analysis of data collected via in-person interviews, I identified four themes that describe how MHSWs in Ontario use and understand the DSM. The first theme, Applications of the DSM, relates to the different functional uses participants perceived the manual as having on mental health social work practice. The second theme, Outcomes of Diagnosis, describes the ways that participants felt that being diagnosed with a mental disorder can impact on service users. The third theme, Subjectivity of the DSM, encompasses participants' views on whether the DSM provides an accurate and valid taxonomy of and diagnostic criteria for mental disorders. The final theme, Context of the DSM's use, relates to various contextual factors that are associated with the role of the DSM. As I hope to illustrate, the DSM had an inconsistent impact on participants' practice, and participants held mainly critical perspectives toward the manual. Table 3 includes an overview of themes and subthemes as endorsed by specific participants.

\section{Theme One: Applications of the DSM}

Participants in this study contributed various perspectives on the ways in which the DSM applied (or failed to apply) to their professional practice as MHSWs. I have identified five subthemes that describe these various applications: diagnosis, 
Table 3

Overview of Subthemes (by Theme) in Relation to Participants

\begin{tabular}{lccccc}
\hline & \multicolumn{5}{c}{ Participants } \\
\cline { 2 - 5 } Subtheme & Paula & Molly & Seth & Leon & Robin \\
\hline & \multicolumn{1}{c}{ Theme One: Applications of the DSM } \\
Diagnosis & $\checkmark$ & $\checkmark$ & $\checkmark$ & $\checkmark$ & $\checkmark$ \\
Understanding clients & $\checkmark$ & $\checkmark$ & $\checkmark$ & $\checkmark$ & $\checkmark$ \\
Working with clients & $\checkmark$ & $\checkmark$ & $\checkmark$ & $\checkmark$ & \\
Helping clients make \\
meaning of diagnoses
\end{tabular}

Theme Two: Outcomes of Diagnosis

Service user selfunderstanding

Pathologizing

Misdiagnosis

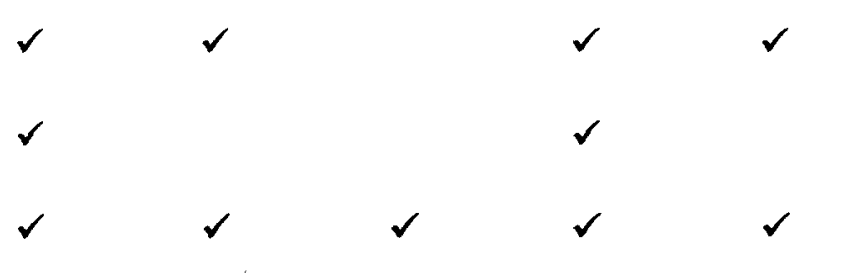

Theme Three: Subjectivity of the DSM

The DSM as a social construct

"Major mental illness" versus "everything else" Concerns regarding specific diagnoses

Theme Four: Context of the DSM's Use

The medical model

Programs/supports

Ubiquity of the DSM

Note. A checkmark $(\checkmark)$ means that a participant in the current study made comments that are related to the subtheme. 
Table 3 (Continued)

Overview of Subthemes (by Theme) in Relation to Participants

\begin{tabular}{|c|c|c|c|c|c|}
\hline \multirow[b]{2}{*}{ Subtheme } & \multicolumn{5}{|c|}{ Participants } \\
\hline & Kim & Geri & Sidney & Ashleigh & Sean \\
\hline \multicolumn{6}{|c|}{ Theme One: Applications of the DSM } \\
\hline Diagnosis & $\checkmark$ & $\checkmark$ & $\checkmark$ & & $\checkmark$ \\
\hline Understanding clients & $\checkmark$ & & $\checkmark$ & $\checkmark$ & $\checkmark$ \\
\hline Working with clients & & $\checkmark$ & $\checkmark$ & $\checkmark$ & \\
\hline $\begin{array}{l}\text { Helping clients make } \\
\text { meaning of diagnoses }\end{array}$ & $\checkmark$ & & & $\checkmark$ & $\checkmark$ \\
\hline Professional dialogue & $\checkmark$ & & $\checkmark$ & $\checkmark$ & \\
\hline Formal referencing & $\checkmark$ & $\checkmark$ & & $\checkmark$ & \\
\hline
\end{tabular}

Theme Two: Outcomes of Diagnosis

Service user selfunderstanding

Pathologizing

Misdiagnosis

\section{Theme Three: Subjectivity of the DSM}

The DSM as a social construct

"Major mental illness" versus "everything else" Concerns regarding specific diagnoses

Theme Four: Context of the DSM's Use

The medical model

Programs/supports

Ubiquity of the DSM 
understanding clients, working with clients, making meaning of diagnoses for clients and professional dialogue. In addition, a sixth subtheme, formal referencing, describes the extent to which participants directly referenced the DSM in their professional practice.

Diagnosis. Social workers in Canada (outside of BC) are not licensed to use the DSM or any other tools to diagnose individuals with a mental disorder. Thus, I did not ask participants during their interviews whether they used the manual to diagnose clients. Nevertheless, the majority of the study's participants brought up this issue, and explicitly mentioned that they do not diagnose clients. This subtheme briefly touches on the issue of diagnosis and contrasting perspectives on whether this inability to diagnose clients means that the DSM does or does not play a role in social work practice.

In every interview but one, the participants made a short and direct statement that indicated that they are not able to use the DSM to diagnose clients with mental disorders - for example, "Our college is very clear. We can't diagnose." (Seth), or "Thank god we can't diagnose, right!" (Robin). Although Sean argued that this inability to diagnose meant that the DSM "technically has no role" in his professional practice, further comments by Sean and other participants, explored in subsequent subthemes, indicate that the manual does play a role in various aspects of practice. Molly provides an indication of how the DSM could still be regarded as having an impact on mental health social work practice even though social workers are not licensed to diagnose: 
Only psychiatrists and psychologists are allowed to, legally...they're the only ones who are, not licensed but well, let's say licensed to diagnose somebody based on that [the DSM]. But it doesn't mean that other people in the world don't read it and don't have some understanding of it and maybe use it in some way in their mind.

To summarize, participants in the study uniformly expressed that they cannot diagnose clients. However, as argued by Molly, even though only specific professionals are allowed to use the DSM or other diagnostic tools, the manual can still be used in regard to the thinking of social workers.

Understanding clients. An important aspect of mental health social work practice is how members of the profession think about the clients that they work with. This subtheme encompasses the different perspectives participants held in regard to the appropriateness of using the DSM to help them understand their clients and, more specifically, whether it is beneficial or harmful to conceptualize a client's behaviours, emotions, thoughts and struggles as related to a diagnosed or suspected mental disorder. As described by several participants, it can be useful to understand a client via their diagnosis in order enhance one's appreciation of their experiences. In contrast, several participants raised concerns about how understanding clients in this fashion can undermine the values of social work and lead to a de-contextualized perspective on one's clients and problematic choices in how to support them. Nevertheless, some participants felt that it is possible to take a balanced understanding of one's clients, using the $D S M$ to give them a "general snapshot," while placing a greater emphasis on contextual factors. Going beyond 
this discussion of the merits of the DSM for understanding one's clients, Leon questions whether social workers apply the DSM in this fashion in order to support clients or reduce their own anxiety.

Those participants who highlighted the positives of the DSM in regard to understanding one's clients felt that knowing whether a client has a particular disorder, and knowing how that disorder is characterized within the DSM, gave them a better idea of what their clients were experiencing and how they could best support them. As Ashleigh stated:

I think we, as humans we just sort of like neat categories, we like simplified ways of understanding people. And people are complicated enough. And mental illness is so complicated. And so if there's a way for us to sort of categorize it in our minds to be able to think about different symptoms and different presentations, and prognoses, then, it helps us to wrap our heads around the population we're dealing with. And I don't think you can discount the variability in individuals, these clients are going to be more dissimilar than they are similar to each other, but I do find it helpful to know that, ok, everyone I'm working with in this program has, one or two or three of these problems or these symptoms, and it, it sort of, in a way, narrows your focus, so you know what you're going to be confronting and what you're going to need to be helping with here.

The idea that the DSM can help you "know what you're going to be confronting" is supported with a specific example from Paula. In this example, Paula discussed 
separate occasions when she referenced the DSM to aid with her understanding of clients whom she suspected might have a mental disorder:

On both occasions I had seen someone who was presenting kind of, odd, I guess you could say, but I couldn't really place why or what was happening. So, I was thinking in both cases that perhaps this is some sort of Autism spectrum disorder, or Aspergers, because it was, I guess the person was sort of socially awkward in some sort of way. So I'm like, "Does this fit? Is this, you know, what I might be working with here?" So, I do sort of crack it open to see what the criteria is, and in both cases it didn't fit at all, so I was like, “Ok, so there's something more going on, I don't know what it is, I'll just sort of go with it and see what happens."

Despite the advantages highlighted above, many participants also indicated that a diagnosis could offer an outdated snapshot of a client's experiences. As Paula described, emphasizing the meaning of a client's diagnosis in regard to their behaviour, emotions, thoughts and struggles, particularly when the diagnosis is not recent, may be contradictory to the core values of social work: I remember always kind of hearing, you know, "meet the person where they're at." So ok, why are they here, what is it they're looking for, you know. They're not asking for you to dig back through the medical file and look at this diagnosis from five years ago that may not be relevant right now. I mean, it might be helpful to know, but not necessarily so. I don't know, for me it kind of comes back to that. Again, what I think is kind of a basic 
principle of social work, of meeting the person where they're at. And I think that the use of the DSM can cloud that sometimes.

As described by Seth, when a client is diagnosed with a mental disorder it is important to understand that a diagnosis may have been temporal and situational, and thus the relevancy to where the person is at now might be limited. In fact, many participants regarded the situational factors that can inform the manifestation of symptoms of a mental disorder as more meaningful than a client's diagnosis for understanding them, and that the DSM itself promotes context-free understandings of clients. Sidney argued that it is often the role of social workers to resist an individualized understanding of clients by looking beyond a disorder in order to obtain other information regarding a client's identity and community:

Collateral information is important, and social workers bring the collateral information. The psychiatrists, they don't have time. Ok? So, digging into the information, from the patient, which maybe is, it [the symptoms of a mental disorder] might not be because of their emotional distress, but from their family or background, you know, race, class, where they come from, their education, culture, religion, and how mental illness is seen from that cultural perspective.

Several participants argued that to ignore these factors can lead to problematic outcomes, because ignoring the context of a client's life is to overlook issues that may need to be addressed to help aid them in their recovery. Seth stated:

Sometimes when you look at a kid, you know, looking at it just as the kid in isolation saying "the child is, you know, pretty anxious," and then you think 
about the context, in which the child is being brought up in, and you go, "oh yeah, it makes sense that they're anxious, I mean, look what's going on here, right?" So from a systemic perspective, there may be other issues that we need to address, you diagnose the child anxious - sure, I guess so, but is that really gonna be of any help when there's a whole bunch of issues that you need to address going on? Well no.

Despite such concerns regarding the DSM and psychiatric diagnosis, many participants still reflected that it is important to be aware of a client's diagnosis, provided that other aspects of the client's identity and environment are taken into account:

If social workers are using it [the DSM], I would hope that it's basically to just get them in and get a general snapshot of what they're looking at, or what to expect, not necessarily what they're looking at, but kind of what to expect, rather than using it as something that sort of defines the person in front of them. I think that that's not fair, and I think it's a bit dangerous. (Robin) Most of the arguments that were shared by participants during interviews around the merits of the DSM for understanding clients were framed around the impact that such an understanding would have on clients themselves. In contrast, Leon reflected on how embracing the DSM as a tool for understanding clients may be linked with broader needs on the part of social workers to feel that they know exactly what their client is experiencing in order to help "fix" it:

For those of us who can't regulate our own discomfort around ambiguous, confusing situations with clients, having clear diagnostic tools, it's about 
making us comfortable. It's not about being helpful to the client. And so, I think that that's a piece that gets missed, is how much do we use theoretical knowledge to deal with our own anxiety. Of not knowing. Of not being able to fix things, and say, "I need to know what this is, to be able to fix it." That's our discomfort, that's not the client's discomfort, so I think it's not about the content, it's about how do we learn, and how do we teach people to sit with ambiguous, complex, and sometimes undefinable realities. And still work on them.

Although no other participant expressed similar concerns about the way that theoretical knowledge can help to reduce service providers' anxiety, previously discussed comments by Ashleigh on how people like "neat categories" and "simplified ways of understanding people" offer a similar indication of how the DSM can appeal to a service provider's "need to know." These comments thus present an interesting perspective on the potentially self-serving nature of tools such as the DSM.

Working with clients. The work that MHSWs do with their clients is often multifaceted. While most participants were employed in a capacity in which their primary responsibility was providing clients with counselling support, several participants had other primary responsibilities, such as discharge planning and coordinating resources for clients. This subtheme encompasses the various opinions that participants shared in regard to the applications that the DSM has in informing the way that they work with clients. Some participants argued that one's interventions should be informed by a client's diagnosis, because it helped them 
identify a corresponding best-practices approach or factored into the choices they made in discharge planning. Other participants criticized this approach due to concerns about how it could overlook, and thus fail to address, contextual factors. Overall, this subtheme demonstrates the complex ways in which the DSM applies to how participants work with their clients.

The primary way that the DSM was described as being relevant for working with clients was in regard to whether one's interventions should be informed by a client's diagnosis/diagnoses. One participant (Seth) felt that the DSM had no impact on how he worked with clients, since the manual itself is just a way of labeling what clients are experiencing and doesn't provide treatment guidelines. However, other participants shared that their work with clients was often informed by the diagnoses their clients receive. For Paula, using the DSM in this fashion was akin to a workplace requirement (albeit one that she is critical of):

The psychiatrist and the psychologist, when they're doing their assessments they have to put, you know, the axis one, two, three, four diagnoses, that's what they're expected to do, and the rest of us are kind of expected to follow suit, and agree with it, and treat it.

Paula later described this as a more "traditional" way of using the DSM - that once a person receives a diagnosis then the goal of the service provider should be to identify a treatment approach that best fits with that diagnosis. Such an approach was sometimes used by Geri when working with a client who is diagnosed with a mental disorder that they are unacquainted with: 
Particularly with a diagnosis l'd never been exposed to before, I would go to best practice and figure out, "ok, based on this diagnosis, what's best practice in terms of the therapy?" And because I practice CBT [cognitive behavioural therapy], the first thing I go looking for is "ok, what style of CBT method would best [help] an individual with that particular diagnosis?"

While these comments highlight the ways that a client's diagnoses can inform one's approach to counseling, Ashleigh shared that when she is tasked with discharge planning and having to coordinate living arrangements for a client, then a diagnosis of schizophrenia can make a big difference in whether she judges if the client could live on their own and what kind of living arrangements would best support their recovery. However, as indicated by several participants, a client does not need a formal diagnosis to be dealing with mental health concerns, and thus supporting a client in dealing with their specific concerns does not always mean that the process of targeting these concerns began with a DSM diagnosis.

Several participants shared reservations about having a client's diagnosis inform the way they work with them. These concerns are similar to those that were described in the previous subtheme in regard to how understanding clients on the basis of their diagnosis can lead to the neglec of contextual factors. As Leon states, the $D S M$ can be an anchoring point, but it is important to take contextual factors into consideration:

I have one client in particular who really struggled when they started coming here, because he was having ECT [electroconvulsive therapy], was diagnosed with depression, the doctor had never done a history. And didn't know that 
he was molested by a priest, for six years. And I'm going - and he says to me, "no one's ever asked." So as a reference point, and as a treatment tool, I think yes, someone has depression, you look at how you alleviate the distress that they're experiencing. But if we do not, go further, and continue to look, then we're doing people a disservice. And so as long as it is part of a larger contextual analysis, I'm ok with that. But it's all about, does it include a larger context? And I don't think it does quite often.

Molly made a similar statement on the importance of looking beyond a client's diagnosis, and thus asking questions about contextual factors:

I think it's always wise to be aware of the potential for things like trauma, eating disorders, addictions, because people don't always disclose that right away, people sometimes, like, it becomes more evident, like I mentioned, as time goes on, that maybe what they said wasn't the problem is actually a HUGE problem ... Just because something's not written down as their diagnosis, I don't think you can totally throw it out and say "oh, so this person is only depressed, so I'm only going to ask questions about their depression."

As these comments illustrate, the DSM and a client's diagnosis can give a MHSW some information to guide their work with clients, but when this information is prioritized over contextual factors, it can lead to ineffective and/or inappropriate treatment.

Helping clients make meaning of diagnoses. While social workers may not diagnose using the $D S M$, several participants indicated that professionals who 
diagnose might not provide service users substantial information on the meaning of their diagnosis/diagnoses. As a result, participants indicated that they often help their clients make meaning of their diagnoses, which can involve referencing the $D S M$. This subtheme describes participants' justification for helping clients make meaning of their diagnoses, and the ways in which this meaning making process can involve referencing the DSM or actively avoiding diagnostic terminology when working with clients.

Several participants indicated that they have worked with clients (and family members of clients] who are not clear about what their diagnoses represent. As Kim describes, helping clients and family members understand their diagnoses is a basic requirement of working with individuals who have been diagnosed:

Every patient that I work with has some sort of diagnosis using the DSM. So, I have to know and understand it well enough that I can help a patient understand their diagnosis. And I have to understand and know it well enough that I can help a family know and understand the diagnosis.

Robin provides details on how they help clients make meaning of the diagnoses, which in her case involves critical reflection on the DSM:

You know, people say, "oh well, you know, I've got this diagnosis" and I'll say, "well, what's your understanding of that?" And they'll say, "well, you know it means that I'm crazy." And I'll say, "well, it doesn't really mean that," and then I'll pull out the DSM and I'll say "this is what it means, you know, it's right here." And then we'll talk about what the DSM is - you know, it's not, it's a living thing. It changes all the time. We talk about how, you know, I 
think it was in the DSM-III, homosexuality was still in it, and prior to that there's something else equally, there's a whole bunch of other equally ridiculous things. It grows, and it changes with information and knowledge ... and it's like a shorthand, it's a summation of things that are typically seen in somebody who's gone through this experience, but it's not you specifically. This quote illustrates how a critical understanding of the DSM can be used to shift clients away from internalized stigma, a potential outcome of diagnosis that will be further explored in Theme Two.

For some participants, ensuring that the meaning a client attaches to their diagnosis/diagnoses does not have negative consequences on their sense of self can require conscious attempts to avoid diagnostic language:

Nineteen year old girl, sitting right there. She's on six different psychiatric medications. She has eating disorder. She has personality disorder. She has anxiety. She has bipolar disorder. Nineteen year old girl. She has six psychiatric diagnoses and six psychiatric medications. I consider it a fucking crime - and she responded very well. I asked her to please write out her goal statements. And then we rewrote it taking out the words like anxiety, and panic attacks. And restricting. She responded incredibly well. (Sean) This example by Sean doesn't as much relate to an application of the DSM for professional practice as it does a concern that a client's diagnosis/diagnoses can have a negative meaning and harmful impacts on their sense of self, which runs counter to a strengths based approach. Thus, a relevant way to support clients is to look beyond these labels. Paula characterizes this approach - looking for exceptions 
to the negative symptoms that an individual can regard as permanent characteristics of their identity once they have received a diagnosis - as "basic social work".

Professional dialogue. Whether working in community settings where one's colleagues are often other social workers, or in more interdisciplinary hospital settings where social workers may just be one member of a team alongside members of other disciplines, it is important for MHSWs to be able to understand and communicate with the people they work with. This subtheme encompasses participants' perspectives on the important role that the DSM plays in supporting the understanding and communication that is required for professional dialogue. In addition, the specific benefits participants felt that a working knowledge of the DSM can have on professional dialogue, including enhanced professional standing and the ability to have input during meetings, will be discussed.

Many participants felt that the DSM serves as a common language for mental health professionals, with Sidney defining it as a language "that is dominating when you relate with others". As Ashleigh states, the DSM's status as a common language means it is important for social workers to be familiar with the manual and the diagnostic terminology it contains:

Obviously working in several different units within a mental health centre, it becomes really important to have those diagnoses as part of your vocabulary, and I don't see how I could work here without having a good understanding of the DSM. And I guess you pick it up along the way. But it's important, it's a 
really big part of working in mental health as a social worker. You just need to speak the language, because - yeah, we're working with psychiatrists. Having established the importance for social workers to "speak the language", the question of "why speak the language?" remains. Molly offers one possibility, indicating that familiarity with diagnostic terminology is an important way for social workers to establish their legitimacy as mental health service providers:

If you have no knowledge of it [the DSM], people are going to view you as being ignorant, and they're going to view you as not being qualified to work in the profession, in mental health practice, because they're going to think, "well, if you don't have any familiarity with any of this, how are you going to help us?"

Ashleigh extends this argument, stating that once a social worker is perceived as knowledgeable and qualified, they can have valued input in team meetings, and even, in this example, the diagnostic decision making of other professionals:

It's actually been discussed in the team, sometimes we get some really complex individuals, who probably have different, possibly different diagnoses that sort of overlap, it's hard to identify what exactly is going on. So at that those times, the psychiatrist will consult with the team, and I was just in a family meeting with a neuropsychologist, a psychiatrist and myself, a social worker, and we're all trying to figure out what's going on here. We all have enough knowledge and expertise to be able to discuss it intelligently, right? 
Although this statement indicates that Ashleigh is employed in a workplace in which her opinion is respected alongside that of other professionals, several participants provided contrasting descriptions of workplace settings with rigid professional hierarchies. Thus, while knowledge of the DSM may not always allow MHSWs to have input on par with doctors and psychiatrists, this subtheme demonstrates that it serves as a common language and that knowing the language is a basic requirement for having a voice in the mental health field.

Formal referencing. Having highlighted applications of the DSM on professional practice, participants in the study provided clarifying descriptions of the extent to which they formally reference the manual. This subtheme briefly describes these variations in formal referencing, which range from extensive to minimal. Several participants describe themselves as referencing the DSM on a regular basis, with two participants having a copy in their office and one having a copy at home. However, other participants felt that the manual did not factor in heavily into their professional practice, and thus they very infrequently referenced it. In fact, two participants estimate that they only referenced the manual two to three times a year. Geri, who describes her own referencing of the manual as minimal, discussed the way in which a MHSWs specific professional responsibilities could inform the degree to which the DSM factors into their practice:

My role is very much a therapist, but I think a lot of other social workers do the more housing, finances, discharge planning kind of social work. So it may not come up as often for them. But even then, it doesn't come up often for me. 
The question of whether the DSM can be said to have a significant relationship to the practice of MHSWs in Ontario when it may not be directly referenced on a regular basis by many members of the profession will be further explored in my Discussion. Theme Two: Outcomes of Diagnosis

For participants, a major source of concern relating to the DSM was the outcomes that diagnoses can have on the clients that receive them. Although some of these outcomes were regarded as being strongly connected to flaws with the DSM, many participants argued that the manual and the disorders it has reified can be misunderstood and misapplied to detrimental consequences in ways that are more closely related to the person who is using the DSM than the manual itself. As Robin states, "the problem, I think, is with the reader, right? Not necessarily with the tool. Because it's just a tool, I can misuse a hammer, right?" Thus, within this theme, both the DSM and mental health professionals (along with other members of society) are implicated as having a major role in informing the following three subthemes: service user self-understanding, pathologizing of service users and misdiagnosis.

Service user self-understanding. A significant issue for participants involved the ways a DSM diagnosis can affect the self-understanding of service users. This subtheme includes arguments that diagnoses can have either benefits or drawbacks for how service users understand themselves. The primary benefit highlighted by participants is the comfort that a diagnosis can offer an individual by giving them a label for their undesired behaviours, emotions and thoughts, and the belief that recovery is a possibility. The main drawback described by participants is that service users can identify with the negative connotations of their diagnoses, 
leading to internalized stigma. The final argument addressed within this subtheme involved the impact of the perceived "fit" of a diagnosis on whether the abovementioned benefits or drawbacks occur.

Several participants highlighted the beneficial aspects of a DSM diagnosis, such as the way that in that it can lead to clients having a sense of meaning, relief and hope that their symptoms can be alleviated. As Ashleigh stated:

There are people who will say that labels are all bad, but I see the opposite quite often. I see people finding some clarity and some reassurance and just knowing "ok, this is the diagnosis. This I can understand, this l can cope with."

As comments such as these indicate, in cases where service users are dealing with significant mental distress and feel isolated because they feel that this distress is inexplicable, a diagnosis may offer them comfort by giving them a label that helps them make sense of their distress.

The power of diagnoses to inform self-understanding was also regarded as a source of concern for several participants. In particular, participants argued that service users could identify with the negative connotations of their diagnoses, which can lead to internalized stigma and an assumption that their mental disorder is a permanent state from which they will never recover. Several participants indicated that this internalized stigma could become a significant barrier to recovery. As Sean stated:

We struggle a lot with people that are over-pathologizing themselves when they walk in the door, and then we want to send them out without pathology. 
They come in, and they feel that, they got dumped. People come in every day because they feel bad, because they're fighting with their boyfriend or their girlfriend. And they think there's a pill for it.

Although some participants did express fairly divided perspectives regarding the role of the DSM in informing service users' self-understandings, many participants did share more nuanced perspectives on this topic. In this statement, Molly reflected on her own experience with receiving a diagnosis, highlighting the important role that the client's identification with that diagnosis can play in whether it becomes a source of comfort or leads to negative impacts:

I always just kind of thought I was crazy, right? And then when I finally got talking about things and I got the diagnosis of PTSD, for me it was like, “Oh! Well ok! That explains a lot!" Like, ok, I have this symptom this symptom this symptom, like you can look down the list and it's like, ok, well I'm not crazy, because this is in this book, and all of the apparently other people are going through this same thing ... So in that respect I think it can be very helpful to people, if they thought they were the only one, if they thought they were literally losing their mind and they had no idea what was wrong, and they had all these confusing things going on in their head and then somebody can sit down and say, "It's ok, there's a name for this, and, it can help us guide the way of helping you." In that way I think it can be a great thing, to have a diagnosis. But, on the opposite side of it, if you get diagnosed with something and you don't agree with it or it doesn't fit for you or it doesn't feel right, then that can be an awful terrible thing, it can impact your life terribly in a 
negative way and once something is written on a piece of paper on your file somewhere it can travel along with you and can change the way people see you.

The ways in which a diagnosis can change the "way that people see you" will be explored in the following subtheme.

Pathologizing. In addition to impacting on the way that service users understand themselves, the majority of participants expressed concerns that the $D S M$ plays a role in the pathologizing of normal human functioning. Thus, rather than understanding service users with diagnoses as complex, multifaceted individuals, their behaviour and identity become defined as reflections of their mental disorder, which can then lead to labeling, stigma and discrimination. Concerns pertaining to the pathologizing of behaviours and emotions, the pathologizing of individuals with specific diagnoses, the impact of pathologizing in regard to the availability of services and the status of pathologizing as a specific concern from a social work perspective are explored within this subtheme.

Pathologizing can occur within the mental health system and also in other social contexts. A few participants linked this pathologizing to the DSM itself, with Sidney stating, "It [the DSM] is trying to pathologize our daily life". In contrast, several other participants argued that poor professional practices might inform the way that a client's diagnosis can become the end point for how they are understood by service providers. Kim made this argument:

Sometimes people focus too much on the label. And they don't see the person behind that label. So that's a huge issue. I don't know if I would 
blame that on the DSM. 1 think it has to do with how it's applied. And that we need to take some responsibility for that too. And so I think any classification system we had would have that danger.

Sidney provides an example of the ease by which behaviour that is culturally appropriate given a service user's background can be misinterpreted as an aspect of their perceived disorder:

Twenty years back, we had a woman from overseas [as a client] ... so, she was in the kitchen. She gets this batter. And she used to put it on her hair. And then the nurse's chart, and I read the chart, "she's putting batter on her hair, this is a symptom of her psychosis." I told her, in this woman's country, when people have headaches, or they're feeling no good, they apply ghee. So for her, this is like medicine.

Since many service providers are likely to have a far greater understanding of the symptoms of mental disorders than culturally diverse coping strategies, it is unsurprising that a client's diagnosis can become a potentially misleading way to explain their behaviour.

In addition to misinterpreting behaviour, several participants shared concerns about the misinterpretation of certain emotions as pathological. Sean feels that this type of pathologizing among other professionals can be due to a lack of experience:

Do I see it [pathologizing of emotions] with my colleagues? Absolutely. Sometimes. It depends on their particular school of thought, or often times how much experience they have. So if they've been a psychiatrist for ten 
minutes - they know everything, and everything is DSM. If they've been a psychiatrist for twenty years, they've grown to understand the difference between coping skills, emotions and pathology. But if they've been a psychiatrist for ten minutes they haven't quite figured out the distinction. This form of pathologizing is not unique to the mental health field. Seth indicates how young children can be stigmatized on the basis of a diagnosis, specifically ADHD:

You know, the greatest disadvantage to diagnosis - all right, once the kid has a label, you know, it can certainly affect many elements in their life. You diagnose ADHD, well, there are not going to be many teachers that want you in your class, right, you're going to have special needs, you're going to be disruptive, so that's immediately what people will start to think, and, that's certainly not helpful, so that's a definite disadvantage to our clients.

Several participants expressed further concerns about the consequences that pathologizing can have on service users. These included worries that other professionals could regard service users that are diagnosed with a mental disorder as not having personal responsibility or any hope of recovery. Leon describes one further concern, which is how diagnoses, particularly those that are highly stigmatized, such as personality disorders, can limit people from receiving certain services:

You know, if you have a diagnosis and it becomes public information, then it very much skews the way in which someone gets seen. We have laws that prevent discrimination based on mental illness, the term that they use, but 
clearly I know that everyday there are people that don't get housing, as a result of it, they don't get access to very basic things. And there are even people who, because of a diagnosis, are blacklisted from the hospital. So axis, I don't know if it's one or two, personality disorders, that's blacklisted. It's like "oh, this person is borderline, this person is narcissistic", they never get services in the hospital. And so it can become a very, very powerful way of excluding.

Although she herself argues that it is not the labels that cause harm to clients but rather how those labels are interpreted, Ashleigh describes how, for some social workers, concerns about specific diagnoses in the DSM and labeling can be linked to core professional values:

I mean, we're concerned with fighting stigma, and promoting social justice, and some people, I guess a lot of social workers would feel that diagnoses that, lead to a certain stigma, are contrary to the goal of promoting social justice. And that's a valid argument. And, there's definitely some tension sometimes between psychiatry and social work. And when your whole understanding of mental illness comes from this diagnostic manual, for psychiatry, that definitely, it's, I guess it's hard to work within that framework if you're, if you're anywhere on the spectrum.

Within the context of the afore-mentioned concerns regarding the pathologization of service users in response to their diagnoses, the comments of Ashleigh on the importance of challenging stigma as a social worker indicate that the issues 
addressed within this subtheme may be particularly relevant from a social work perspective.

Misdiagnosis. The majority of participants in the study described the misdiagnosis of mental disorders as a serious concern. Although no participant identified misdiagnosis as a sole consequence of the way the DSM is written, these comments do seem relevant for understanding the relationship between the DSM and MHSWs in Ontario, as they highlight the skepticism with which participants can occasionally regard the diagnoses given to service users. This subtheme explores the comments of participants regarding situations in which they felt that other professionals inaccurately diagnosed service users, and arguments about why misdiagnosis happens. Those explanations suggested by participants include structural pressures that impact on professionals, poor practices by professionals who use the DSM and concerns that the DSM possesses flaws that can lead to misdiagnosis. Lastly, this subtheme will explore the connection between misdiagnosis and treatment, which several participants regard as a concern since a misdiagnosis can result in a service user receiving inappropriate pharmacological interventions.

Several participants shared examples in which they felt other professionals who were licensed to make diagnoses applied them inappropriately. For example: There was a psychiatrist at [name of institution]. Every kid she saw had bipolar, every kid. It's like, wow, that's amazing, like it's in the water, what's going on? It was crazy. She moved out of town, but it's the lens, I mean she saw everyone a certain way, used that criteria. There's a pediatrician in 
town, every child he sees has got ADHD and Aspergers - every last one of them. (Seth)

Kim contributes another example of a colleague who made what she regarded to be a misdiagnosis, which prompted her to speak out:

There is one doctor who, not even in this program, but he diagnoses everyone with schizophrenia. So there were a couple of patients where he was taking over their care from another doctor who had given them another diagnosis. And he changed the diagnosis to schizophrenia. And to me, it didn't fit. For him, he was not receptive whatsoever to hearing that, very, you know, "my way or the highway". You know, I think, what did I do? For one of them, I just said, "I didn't even think that when I met with them, what was it that made you think that?" So I just kind of asked. And it didn't even make any difference and I don't even think they really answered me. So it really depends, some doctors, I have more faith in, in that sense, and I do agree. And otherwise I'm thinking what, I don't see it, where is that coming from? Although some participants felt confident that the psychiatrists they worked with were cautious in making diagnoses, comments such as those above indicate that some psychiatrists and other diagnosing professionals are perceived as not exercising such caution. Several participants argued that incomplete assessments, including a failure to review all five axes of the DSM, played a significant role in misdiagnosis. As Leon stated, "The DSM is supposed to be five different assessments, to create a context. People end up using one of the five. That is just misinformation and misuse." In regard to structural factors, the intense workloads 
of many diagnosing professionals were described as restricting their time, which creates a pressure to diagnose as quickly as possible. In Sidney's words, "How long to psychiatrists have to do an assessment? That's a major factor. Some psychiatrists only have five minutes." Ashleigh did argue that some instances of misdiagnosis may be associated with issues with how the disorders are described in the DSM: Personality disorders, for example, if I gave you a vignette with a description of someone with a personality disorder, and I tell you that that individual is a male, you might diagnose him with antisocial personality disorder. If I give you the exact same one and tell you it's a woman, the chances that you'll diagnose her with borderline or, histrionic or anything else is much higher. So I think there are still problems with the diagnostic categories, and I think we'll continue to, revise and revise and revise.

This comment is not speculative; as described in my Literature review, various studies have shown that diagnoses can be significantly influenced by a service user's gender. Thus, whether due to professional misunderstanding or misapplication of the DSM or issues with the manual itself, participants were aware of the potential that clients may be misdiagnosed.

Similar to comments in previous subthemes about the downside of failing to develop a contextual understanding of a client when working with them, participants identified that this issue can play a role in misdiagnosis. As Geri indicates, even when an individual is exhibiting symptoms that are characteristic of a specific disorder, diagnosing them with that disorder may still be inappropriate 
because it fails to acknowledge that their symptoms may actually be a normal response to a difficult situation:

I had a patient once, many years ago, who was sexually abused by her brother from her first day going to kindergarten ... and then for, every day, she was going to school, this happened, again and again and again. And she got diagnosed with attention deficit disorder, and my reaction was, well, how would one be expected to maintain any level of attention in school, knowing that this is what I've got to look forward to tonight when I go home from school, and tomorrow morning heading into school. So I sort of didn't feel like that, that while her symptoms were consistent with attention deficit, it didn't really understand her in her bigger context.

In addition to concerns about how misdiagnosis can involve the misunderstanding of service users' "symptoms" as evidence of a mental disorder (as opposed to a normal reaction to their situation and experiences), participants also commented on how a misdiagnosis can lead to inappropriate treatment. In particular, several participants discussed the potential downside of the reliance on psychiatric medication to treat mental disorders, particularly when a disorder is misdiagnosed. Sean indicated that he tried to regularly advocate on this very topic in his workplace during team meetings:

It's an open dialogue. So yeah, you're comfortable to say, "I completely disagree with you, this is ridiculous. She's sixteen years old, she's seventeen years old, her feelings are hurt. Let's not go down the road of giving her a message that there's a pill for this. Let's not go down the road that she 
should, you know, not go to school for a few months cause she feels bad. Let's please talk about how she can cope." But I'm not the doctor. They may or may not disagree with me.

As this comment illustrates, the "message" of a diagnosis can have direct consequences on the self-understanding of service users. Since a misdiagnosis, by definition, involves giving someone a label that does not reflect what they are experiencing, it is understandable that this issue is a serious concern for participants.

\section{Theme Three: Subjectivity of the DSM}

While participants in this study shared a range of perspectives in regard to the merits of the DSM, a common theme that emerged out of the interviews was that the DSM, as a produced document that is vulnerable to the subjective views of its creators, does not offer a completely objective taxonomy of mental disorders and criteria for determining the presence of such disorders. Participants held differing perspectives on the subjectivity of the $D S M$, including some appraisals of it as a completely socially constructed document, whereas others felt that it succeeded in categorizing and describing serious mental disorders but also included disorders that were less serious. Other participants took issue with specific disorders in the manual without commenting on the manual's overall subjectivity. I have identified three subthemes that relate to these different appraisals: the DSM as socially constructed, "major mental illness" versus "everything else" and concerns with specific disorders. 
The DSM as socially constructed. A small number of participants characterized the DSM, and the very concept of mental illness, as a social construction. That is, rather than being based on objective truth, these were both informed by subjective and inaccurate assumptions about normality. This subtheme will explore arguments that the DSM labels individuals with diagnoses that "didn't exist" before they were included in the manual, and that the manual's development has been influenced by politics rather than science. In addition, this subtheme includes perspectives that mental illness itself may be a label that is misapplied to normal coping strategies.

Many of the most critical arguments regarding the socially constructed nature of the DSM were made by Leon. Rather than simply criticizing the DSM as not adequately representing the phenomena of mental illness, Leon describes how mental illness is a construct and thus the diagnoses included in the DSM may not even correspond with actual illnesses:

It's really fascinating to have discussions with people, who say 'well, you know, mental illness is real.' And I'm like, ok, we seem to have some strong feelings about this, and I can go back through and I can trace the history, and I say, "It's not. It's a construct." How come they don't have a language for this in Japan? How come they treat it this way in Southern Africa? You know, it is something that we've constructed, and I can prove it, because somebody wrote this book, and there's no test, there is no definitive test that you can give any one individual, and come up with the same results. I know that historically diagnoses have been, we sort of joke around and say there's a 
diagnosis of the decade. Because schizoaffective was very popular in the $70 \mathrm{~s}$, and then bipolar was very popular in the 80s, and then PTSD became, you know, the diagnosis of choice in the 90 s, and in 2000 we have, all kinds of nice new, shiny diagnoses that are becoming popular, as well as for children. And people will say, "Maybe we're just getting better at diagnosing". Or I say, "Maybe we're just getting better at labeling". You know, cause I don't think people are suddenly developing illnesses that didn't exist before.

Similar to Leon's comment, both Robin and Kim discussed how the DSM, through its development process, is a constructed document. Kim commented on how those disorders that are included in the manual are not added because of "hard science": In the end, it's just a label. And it's, I don't think it's based on hard science. I think it's based on people noticing that certain behaviours happen to occur in the same people and the new slap a label on it. And so much of it is arbitrary as well. And sometimes people just don't fit. And there's a lot of people who just don't fit.

While not commenting on the DSM specifically, Robin shared her opinions on how what we label as mental illness may be an adaptive means of responding to trauma or other stressful circumstances:

You know, the brain is a remarkably resilient organ that develops ways to navigate the world, and so sometimes what we see as a sort of mental illness may actually be a fairly reasonable response to a situation that is otherwise not reasonable. Depression, for example, you know, there's all these really interesting articles about evolutionary biology, and how depression is a 
fairly, you know, if you've gone through something that is really horrific, for example - you know, what better way then having somebody sort of have the pause button pressed on them, where they can't function the way that they did before, to heal from that horrific experience?

Although several participants shared concerns regarding the constructed nature of the DSM, only Sidney and Leon argued that there is a more sinister motive to the choices made by the manual's developers. Sidney argued that the DSM is "trying to pathologize our daily life, and it is influenced by corporations and big money." Leon similarly argued that revisions to the manual have been influenced by the pharmaceutical industry:

For me, it's about how it's used, and how it's being revised, for political reasons. You know, people will say, "You're just being paranoid, you think it's the drug companies again", and it's like "Uh, they're a major lobby [group]. Let's be serious." You know, the pharmaceutical industry has a huge investment in how many diagnoses end up in the DSM. Cause every new diagnosis means another slew of medications. Because we need treatment. For these illnesses. And don't we treat illnesses with medication? The connection between diagnosing mental disorders and treating them with medication was raised by several participants in this study, and will be touched on in the final theme in this section. Although the above comment and other arguments within this subtheme were not shared across all participants in this study, they do indicate that some MHSWs hold critical perspectives toward the DSM and the 
concept of mental illness that contrast with other MHSWs more accepting viewpoints.

"Major mental illness" versus "everything else." The title for this subtheme is based on a comment by Sean that the DSM "has its place, with major mental illness. And then there's everything else." The idea that the DSM properly categorizes and defines more "serious" forms of mental illness while inappropriately categorizing and defining less serious and non-pathological behavioural and emotional states as mental disorders is explored within this subtheme. In addition, this subtheme encompasses the perspectives of several participants that serious mental disorders may be the result of internal biological processes.

For several participants in this study, concerns regarding the potential pathologizing of normal human behaviour as disordered were counter-balanced by the belief that serious mental disorders are real, non-constructed phenomena. Sean described major depression, schizophrenia and anxiety disorders as examples of "major mental illness", and went into further detail on why major depression should be understood in this way:

Major depression is what it is. You can look at somebody and say, "Oh my god, you need more serotonin". This person is crippled. And absolutely that's a DSM diagnosis of depression. It's not my place to do it. But you can look at somebody and say, “Oh my god". You can actually see it on their face. They're very sick and they're utterly crippled. They're not candidates for psychotherapy. They need medication first. And then they're candidates. 
And so that's pragmatic. Feeling bad and major depression are two very different things. Some think feeling bad requires a pill and a DSM diagnosis, and that's what you're going to get if you're a family doctor, typically. But then there's major depression, where I've seen people in here - yeah, you know what, we'll spend a few minutes with you talking about what's going on. And then I'm going to have you go see your family doctor, and I entertain you to talk about pills, and then l'll see you in a week to see how you're doing. Similarly to Sean, Paula identified depression and anxiety disorders more broadly as potentially reflective of serious mental illness, while Molly ascribed the same status to PTSD, which is categorized in the DSM as a specific anxiety disorder. Illustrating the tension relating to whether an individual's diagnosis should be regarded as a stigmatizing label or an accurate reflection of their internal state, Molly described herself as wrestling with how to balance these two perspectives: Even the work that I do with my clients, I would describe mental illness like that [as a failure to utilize external or internal resources to deal with a difficulty they're experiencing]. But having said that, I mean, I do believe too that there are other kinds of, you know, more - I don't know how to put it, I do think there are the more serious or severe mental illnesses as well, that get into kind of medical causes, and whether it's having to do with brain chemicals and imbalances and that sort of thing, I mean, you can't just totally refute that that exists. 
Having discussed the existence of more "legitimate" disorders, Molly emphasized the importance of having tools like the DSM that can help with identifying when individuals are experiencing such disorders.

Concerns regarding specific disorders. In contrast with concerns regarding the $D S M$ as an overall taxonomic and diagnostic document, a far larger number of participants expressed concerns regarding specific disorders that are included in the manual. These concerns, which will be explored within this subtheme, were premised on different worries, such as certain disorders being vulnerable to misdiagnosis, potentially leading to high levels of stigma for those labeled with them or more reflective of social standards than "real" internal dysfunction.

Describing her concerns with different disorders grouped within the category of personality disorders and connecting the issue of misdiagnosis to flaws within the DSM, Robin stated:

You know, personality disorders still send shivers down my spine. Why is it that when you're under 5 years old, you have an attachment disorder, and then when you're over 5 you have a personality disorder, like how does that go away? And why are women by and large diagnosed with borderline personality disorder, and dudes get PTSD? Like, come on, they both relate to the same experience, it's the same collection of symptoms, but one gets one and one gets the other, it doesn't make any sense. So it's a flawed, flawed document, and when you start looking at people as their diagnosis and sort 
of, you know, because PTSD is treatable, whereas borderlines, well, you can't do anything with them.

Borderline personality disorder and personality disorders as a whole also received critical comments from several other participants in this study. These participants raised concerns about how women who are diagnosed with borderline personality disorder are often regarded as untreatable and have their concerns written off, and that the symptoms that lead women to receive the diagnosis are typically produced by experiences of trauma. Paula described the frequency with which clients in her agency are defined by their having received an Axis II diagnosis. ${ }^{14}$ As she described, "one of the things that you hear a lot at my work, especially if it's a difficult client, is 'oh, they must be Axis II. Oh, it's an Axis Il issue."' As she further described, this label is problematic for many of the same reasons as that of borderline, with assumptions that individuals will be impossible to work with.

Other specific disorders that were criticized by participants include oppositional defiant disorder, gender identity disorder in children and ADHD. In his comments regarding ADHD, Seth described how the increasing number of children who receive the diagnosis might be the result of unfair social expectations of how children should behave:

There's always kids with ADHD, but if I had a kid with ADHD on the farm, he's running around milking the cows and bringing in the hay, I'm happy as hell, I've got a kid with ADHD! Stick him in a classroom with 30 kids and I'm

${ }^{14}$ Axis Il is the section of the DSM in which personality disorders such as borderline personality disorder are grouped. 
asking him to pay attention for, five, six hours at a time, listening to these teachers drone on and on - well, that's the problem. So, you know, the context has changed, and all of a sudden we have more kids with ADHD, so no we don't! They're just now being diagnosed and they're being medicated. Because you want them to be quiet and sit there still with the rest of them. As this comment illustrates, simply changing a person's context can turn a perceived strength (a high levels of energy to assist with chores) into a sign of pathology (an inability to pay attention for long periods of time in a classroom) that is deserving of a diagnosis. Since the DSM includes several disorders that participants similarly felt could pathologize individuals for non-pathological behaviours, emotions and thoughts, this is one further reason that they regard the manual as problematic.

\section{Theme Four: Context of the DSM's Use}

As this final theme will highlight, the way that MHSWs use and view the DSM is associated with different contextual factors that characterize the mental health system. These are encompassed within three subthemes: the Medical Model, Programs/Services and the Ubiquity of the DSM.

The medical model. Although my initial interview guide did not include any questions pertaining to a medical model, the majority of participants in the study raised concerns regarding the impact of psychopharmacological thinking on Ottawa's mental health system. This subtheme encompasses participants' characterizations of a medical model perspective as problem-focused and biomedically oriented, and that such thinking is associated with the DSM. Additionally, other comments within this subtheme demonstrated that participants held 
contrasting perspectives on the compatibility of a medical model with social work practice, seeing it as either an impediment to the recovery of service users or a useful approach that can be combined with the strengths-based focus of social work. The majority of participants characterized a medical model perspective as dominating the mental health field (both within the narrow context of Ottawa and the broader North American context], and emphasizing a problem-focused approach to understanding and treating mental health issues. This makes diagnosing someone with a specific disorder an important part of any successful intervention. Additionally, a medical model perspective was described by several participants as emphasizing a bio-medical conceptualization of mental illness, in which medication is regarded as the best means of treatment. While describing this approach as more influential with older psychiatrists in Ottawa, Seth provided a description of a medical model perspective that captured many of the above-described elements:

The medical model is you've got to diagnose something before you can treat it, you know, you give it a handle, and you bring out the meds, and you start attending to it. Certainly, I mean again, there's some psychiatrists that would operate in that way, and I mean, they're retiring! So that's a good thing, but yeah, that's all a foundation for the medical model. Diagnosis, as I said, that's the first step, you assess and then you diagnose.

When asked to define what a medical model perspective represented to her, Kim described its connections to the $D S M$, in that a medical model perspective emphasizes searching for specific, diagnosable "pathology" and the DSM is the 
primary source for defining and establishing standards for specific mental disorders:

To me, that [a medical model perspective] means - I mean and the DSM comes in huge there, because we're looking for pathology, within a person. To explain what went wrong in their life ... and if you look at that, that everything exists within that person, it's all just neurochemistry that's gone wrong, and we just need to give them the right meds and they'll shape right up - that is so limiting, so, we don't do that, I have to help make sure that that doesn't happen.

Sidney also discussed the connection between a medical model perspective and the $D S M$, stating that social workers employed in settings in which a medical model perspective dominates "have to educate ourselves on DSM terms," but also need to work hard to "see the individual, not the disease" in order to challenge the medical model's problem-focus.

Several participants expressed concerns about how a medical model perspective impacts on the recovery of service users. In particular, participants described it as setting people up for failure if they expect that receiving a diagnosis means that they can expect to receive some type of "cure". Molly criticized the idea of "pure diagnosis and treatment", stating that "there are very few people out there that can just go see a doctor, get a prescription and feel better". While Paula indicated that many social workers were skeptical about medical model thiunking, she believed it can still inform the practice of some social workers, and especially the practice of professionals from other disciplines: 
I think most social workers, and even the mental health nurses I work with, take a similar view to me. But some of the social workers, and I'd say many of the psychologists and psychiatrists, kind of look more at the problem and the triggering cause and that sort of thing. I think again, that's something that's maybe a little bit more medical model. I mean sometimes, it is helpful, if there is an event or a trigger or whatever, however you want to put it, that kind of lead to something, it can be - I mean, it's helpful to know that. But in a lot of cases, you don't know what that cause is, or the client doesn't know what the cause is. And sometimes you don't need to know, you don't need to know what that is to always help the person, but I find that, a lot of the other people in the clinic get kind of frustrated when they don't know what that is. So it's almost like well "if we can figure out what that is, we can prevent it, and then they'll be better". It's like, well, maybe not!

As Molly described, the possibility of incorporating this medical-model related focus on "what's wrong" with the more strengths-based emphasis of social work can be beneficial for service users:

I think medicine tends to find out what's going wrong and tries to stop it, whereas I think maybe social work can take the idea of what's going right, and try to multiply it, because both approaches are needed, I think, not just one or the other.

Although no participant presented an argument that the important status of the DSM in the mental health system is a consequence of a medical model perspective, or that the dominance of a medical model perspective is a consequence 
of the DSM's status, several comments within this subtheme do suggest a relationship between the two. Thus, to understand how MHSWs in Ontario use and understand the $D S M$, it may be important to reflect on the widespread impacts of a medical model perspective.

Programs/supports. This subtheme encompasses the perspectives of several participants on how the programs and supports that are available to service users are reflective of the DSM's diagnostic categorization system. Comments indicated that programs and supports for clients are grouped in this fashion, which may enhance or limit service users' ability to access these programs and supports given their particular diagnosis/diagnoses. Thus, it is important for social workers to use the DSM to help their clients access resources.

Although participants did not argue that the DSM had a direct role in defining the structure of programs and supports in the mental health system, several participants expressed concerns with the way that programs and supports mirror the DSM's diagnostic categorization system. Seth described how a client's diagnosis/diagnoses inform what programs they can access within a mental health setting, and the issues that are related to this:

Here, you come in because of your diagnosis. So you have a mood and anxiety issue, that means you've been diagnosed with depression or anxiety, you come to one team. If you have ADHD, it's been a diagnosis, you go to the ADHD team. Right? You've been abused? Ok abuse and trauma team. I mean it's ridiculous that we set up a program based on diagnosis. You know, it's absolutely ridiculous, cause people aren't diagnoses, they're very complex 
situations, the co-morbidity rates are very high, a lot of them are misdiagnosed, a lot of them, so cases go to the ADHD team, they're anxious, you know, then what? We've got to transfer them to another team, "oh, you've got to wait another six months". You know, it's silly, silly, silly, silly, but that's how they get here. Based solely on diagnosis.

As this quote illustrates, having programs structured in this fashion can both open and close doors for clients. Kim provided an example in which a client's new diagnosis changed their ability to access different supports:

We had a guy, a young man, who'd been only diagnosed with personality disorders in the past, and he'd been struggling with mental health problems since the age of six, his family had really been through the wringer. And even when he came to us he still had just, I forget what it was, but he was diagnosed with a specific personality disorder. And so accessing services like an ACT [Assertive Community Treatment] team, ${ }^{15}$ which he needed, or different hospital services, was really difficult. Because their mandate is to treat people who have an Axis I disorder. So when he was with us he was actually diagnosed with schizophrenia, and all of a sudden doors opened, where we were able to get him onto an ACT team, we were able to - the difference was amazing. A lot of it is I think stigma, of personality disorders, but it's also just the way the services are designed, and because they're so scarce, they've set up these things to kind of weed people out.

${ }^{15}$ In Ontario, ACT teams provide intensive, community-based treatment and support for individuals with "serious and persistent mental illness" (Ontario Assertive Community Treatment Team Association, 2012). 
Given that programs and supports were regarded as being structured along diagnostic lines, some participants felt that this created a greater need for them to work with the DSM in order help support their clients:

I think that having a tool like the DSM, it's just another thing in your in your Batman belt, right? Like, in your utility belt you just have this extra bit of knowledge, like being able to fill out the Ontario tools assessment, right? Just, "Oh, I can do that", so you do that so they don't have to wait, like, three months for the mental health nurse to come around so that they can get the tools assessment done for, a treatment centre, so having these little bits of arcane knowledge, in order to navigate those bureaucracies, and those systems, anything that you can do to kind of helping somebody feel better, or, work through something is like an added bonus. (Robin) Reflecting on potential new diagnoses that may be included in DSM-5, Sean stated that, while this could lead to increased pathologizing of normal emotions and behaviours, there is also the possibility that new diagnoses can make counseling services more financially accessible for individuals:

Marital dysfunction or couple's dysfunction, it's an absolute crime to put it in the DSM. But, is it also fair that some couples simply can't afford me? If we put it in the DSM, then it's covered. Then it can be under OHIP ${ }^{16}$ at the hospital. People can come to see me for relational dysfunction at the hospital. And then OHIP is paying for it. So there it has it's place.

${ }_{16}$ The Ontario Health Insurance Plan (OHIP) provides Ontario residents with provincially funded health coverage for specific medical services. 
However, as Leon describes, the fact that a diagnosis can allow a service user to receive more financial support can also create difficulties when they are considering taking steps toward recovery:

The labeling process works in many ways to have people get access to resources, it's a screening tool. And that creates a certain tension. So on the one hand you need it to get through the door, but you don't want it to stick so well that it becomes an identity that you can never move away from. And I have clients who say, "I can't get better, because I'll lose my funding." Like, "I can't afford to function any better, but I'm unhappy. Because I'll lose my disability. I'll lose my ODSP. ${ }^{17}$ They're doing a review. I have to make sure that I have symptoms". So, it's a very interesting paradox that gets created for people.

Since the DSM has a crucial role in how individuals are diagnosed with mental disorders, Seth described the "cut and dry" nature of diagnosis, combined with a system in which diagnoses can open and close doors, as a serious source of tension for social workers.

Ubiquity of the DSM. Beyond any specific merit that the DSM has as a tool for mental health social work practice, several participants described it as something that social workers simply need to know if they were going to work in the mental health field due to the ubiquity of the manual and psychiatric diagnoses. This subtheme briefly touches on perspectives regarding the manual's ubiquity,

17 The Ontario Disability Support Program (ODSP) allows Ontario residents who are living with disabilities (including mental disorders) to receive financial support to cover living expenses. 
including criticism of the fact that this does not translate to any training on the manual for social work students. In describing the manual's ubiquity, Seth stated "you've got to know it.....it's just the way it is, it's just part of the landscape of working in mental health". For Geri and Sean, the manual's ubiquity is a consequence of the fact that to work with clients accessing support services out of formal mental health settings is to work with individuals who have received a diagnosis.

While they describe the ubiquity of psychiatric diagnoses as an important reason to be familiar with the manual, Ashleigh indicated that this is not supported by the education that social work students receive:

Considering that, as a social worker, it doesn't matter where you work, you're bound to work with clients who have mental illness in one form or the other, the fact that it's not really part of the curriculum to talk about mental health diagnoses, and diagnostic criteria of the DSM, it's surprising, it's really surprising.

Although this subtheme may describe a certain circular logic, in that the need to know the $D S M$ is described as a consequence of the need to know the DSM, it's possible that the DSM's ubiquitous status is related to other subthemes that have been discussed. Taken together, the various ways that the DSM impacts on social work practice, informs diagnoses that have problematic impacts on clients, promotes a flawed representation of mental disorders and exists within a mental health system in which a medical model perspective and programs and supports are 
structured along diagnostic categories, it is unsurprising that the manual has achieved a ubiquitous status for MHSWs.

\section{Discussion}

My aim with this exploratory study was to investigate how MHSWs in Ontario use the DSM, and what views they have toward the manual. My findings indicate that the DSM has an inconsistent impact on mental health social work practice in Ontario, and that MHSWs in the province have various critical perspectives toward the manual. These findings overlap with previous research and literature in numerous ways, highlighting that the contentious relationship that the DSM has with social work practice in the U.S. is mirrored in Ontario. After summarizing the findings of the current study and their connections with previous research and literature, practical implications, theoretical issues, limitations and future research suggestions will be discussed.

\section{Connections with Previous Research}

In this section I will discuss the connections between the individual subthemes I have described in my Findings section and previous U.S. research and literature. I will discuss these subthemes in the same order that they were introduced in my Findings section. When relevant, I have combined different subthemes that have overlapping elements.

Diagnosis. The primary (and predictable) contrast between the findings of the current study and previous U.S. research was in regard to the DSM's relevance as a diagnostic tool for MHSWs. In the current study, the majority of participants indicated that they do not use the DSM for diagnostic purposes. This was an 
anticipated finding, since the participants in the current study were MHSWs in Ottawa, Ontario, and social workers in all Canadian provinces - excluding BC - are not allowed to diagnose. This contrasts with several U.S. studies which have indicated that an important reason that MHSWs use the manual is to diagnose clients, and that many MHSWs are comfortable with this aspect of their professional role (Dziegielewski et al., 2003; Holmes and Raffoul, 1984; Rubinson, 1999). However, as I will discuss in the theoretical applications section, these findings only indicate that MHSWs in Ontario are prohibited from formally diagnosing clients, and do not mean that MHSWS do not attempt to search for what they perceive as problematic cognitive, emotional and behavioural patterns exhibited by their clients.

\section{Understanding clients and working with clients. These two separate} subthemes will be discussed together, since participants in the current study shared overlapping arguments in regard to whether the DSM aided or hindered understanding and working with clients. In terms of understanding clients, some participants in the current study felt that having knowledge of their clients' diagnosis/diagnoses enhanced their appreciation of their clients' experiences. Several other participants raised contrasting concerns that diagnoses could offer an outdated snapshot of a client's experiences, and that emphasizing the meaning of diagnoses could lead to a reduced appreciation of the contextual factors that might be informing a client's mental distress. In terms of working with clients, several participants in the current study indicated that a client's diagnosis/diagnoses informed their interventions, while other participants described how such an 
approach could lead to interventions that do not address important contextual factors.

Previous U.S. research has discussed the merits of the DSM for MHSWs in regard to understanding and working with clients. Kutchins and Kirk (1988) and Hitchens (2009) identified that many MHSWs used the DSM to help with understanding clients and treatment planning. However, an equal or higher number of participants in both studies also described the manual as being of minor importance (or unimportant) in both regards. Other research has also described the $D S M$ as having a mixed impact on understanding and working with clients (Frazer, et al., 2009; Probst, 2011), and highly divisive arguments are found within the literature. Some authors have argued that the DSM supports an improved understanding of clients (Turner, 2002) and better treatment (Taylor, 2006). Other authors have argued that the DSM inspires decontextualized understandings of clients, contradicting the person-in-environment perspective (Austrian, 2005) and strengths-based approach (Grae and Zide, 2008; McQuaide, 1999) that often inform social work practice (Spearman, 2005). Social work scholars have also argued that prioritizing the importance of a client's diagnosis/diagnoses can lead to interventions that de-emphasize the social justice aims of the profession (Corcoran and Walsh, 2006). In terms of diagnoses offering an outdated snapshot of a client, and how emphasizing diagnoses can contradict client-centered practices, many service user narratives include examples of receiving diagnoses that disregarded the contextual factors, particularly traumatic experiences, which had informed their mental distress (Everett, 2000). The rejoinder to such arguments, as stated in the 
DSM-IV-TR Guidebook (First et al., 2004), is that the manual still provides "enormous benefits" for the understanding and treatment of mental disorders (p. 21). However, from a social constructionist perspective, regarding the DSM as having "enormous benefits" is likely rooted in the taken-for-granted assumption that medical model informed discourses and practices of mental health professionals are inherently legitimate and beneficial. Nevertheless, much like other research and scholarship, participants in the current study had conflicted perspectives on whether the DSM has a positive or negative role to play in regard to key components and core approaches (e.g., person-in-environment and strength based) of their professional practice, indicating that it may be a contentious tool for MHSWs in Ontario.

Helping clients make meaning of diagnoses. Another contrast between the current study and previous research was in regard to the role of the DSM in helping clients make meaning of their diagnoses. Several participants in the current study indicated that many of their clients have been diagnosed by other professionals without being given any explanation of what their diagnoses mean, and that many clients understand their diagnoses in ways that lead to internalized stigma. Participants felt that due to these factors, it was important to either discuss the DSM with clients or largely avoid diagnostic terminology in order to better emphasize a client's strengths and help them understand that they are not just their diagnosis/diagnoses. Only one previous U.S. study that I am aware of has asked MHSWs whether they used the DSM to educate clients on disorders (Frazer et al, 2009). In that study, participants indicated that this was not a typical reason that 
they used the manual in their professional practice. Nevertheless, McQuaide (1999) argues that for social workers to use the DSM in a way that aligns with the values of the profession, they must ensure that their clients see themselves as distinct from their diagnoses, which can involve explaining diagnoses to clients and avoiding pathologizing language. Walker (2006) argues that such practices are important from a social constructionist perspective, because describing mental disorders to clients as if they are "essential realities" validates other discourses that undermine recovery, such as clients being "fragile" and service providers being "experts". Thus, participants in the current study who engaged in such practices are aligned with social work values, and this may reflect how other MHSWs in Ontario practice in order to counteract the negative outcomes of diagnosis on their clients.

Professional dialogue. In terms of professional dialogue, participants in the current study described the DSM as a common language in the mental health field, and pointed out different ways that understanding this language supported interprofessional work and improved their status in interprofessional settings. The DSM's status as a common language, and the accompanying need for MHSWs to use this language when communicating with other professionals, has been discussed in previous U.S. research (Hitchens, 2011; Kutchins and Kirk, 1988; Rubinson, 1999). In fact, participants in Rubinson's (1999) study identified this as the DSM's main strength. Various scholars have described the DSM as playing an important role in enhancing communication and understanding between MHSWs and other professionals, and indicated that professional knowledge of the manual can enhance the status of individual social workers and the overall profession (Brubeck, 1999; 
McQuaide, 1999; Regehr and Glancy, 2010; Turner, 1999). Therefore, the current study's findings indicate that from the perspective of MHSWs, the DSM can inform communication within interprofessional mental health settings in Ontario to a similar degree that it has been described as having in the U.S.

Formal referencing. In the current study, formal referencing of the DSM ranged from extensive to minimal. This contrasts with previous U.S. research, in which many MHSWs describe themselves as regularly referencing the DSM in their professional practice (Frazer et al., 2009; Hitchens, 2011; Kutchins and Kirk, 1988). However, as discussed in my Literature review and supported by my research findings, many of the reasons that MHSWs in the U.S. would need to regularly reference the DSM (i.e., diagnosing clients and meeting agency and insurance requirements) do not influence the practice of MHSWs in Ontario to the same degree. Even if these findings indicate that the majority of MHSWs in Ontario are not regularly referencing the DSM, the Ontario Association of Social Workers (OASW) (2006) still includes knowledge of the manual among the basic expectations for MHSWs in the province, which means that MHSWs in Ontario would still have some understanding and awareness of the DSM. Moreover, as I will discuss in the theoretical applications section of this Discussion, MHSWs do not need to regularly reference the DSM for the manual to have an impact on their professional practice.

Service user self-understanding. Many participants in the current study felt that diagnostic labels can impact on service user self-understanding in ways can be beneficial (e.g., a diagnosis can give someone a way to label and make meaning of their experiences) or harmful (e.g., someone can over-identify with their diagnosis 
and lose hope of recovery.) Only one study that I am aware of has explored whether MHSWs regard the DSM and diagnostic labels as impacting on how service users see themselves (Probst, 2011). Similar to the current study, Probst (2011) indicated that some MHSWs feel that diagnoses gave clients validation and meaning for their experiences, while some MHSWs were also concerned about how diagnoses limited how clients saw themselves.

In terms of the impacts of diagnostic labels on service user selfunderstanding that are found in the literature, Shimrat (1997) has described how service users who are diagnosed can receive messages from service providers that lead them to regard themselves as "sick" and incapable of recovery. As a result, service users may "perpetuate the culture of the mental health system and start to present themselves in terms of the diagnosis" (Ishabashi, 2005, p. 72). This is such a common occurrence that it is mentioned as a "reasonable concern" within the DSMIV-TR Guidebook (First et al., 2004). Due to the ways that internalized stigma can limit the possibility of recovery, McQuaide (1999) argues that social workers should ensure that their clients understand that their identity is distinct from their diagnosis/diagnoses, which I have already described as a relevant goal from a social constructionist orientation. The current study's findings illustrate that this is an equally relevant responsibility for MHSWs in Ontario.

Pathologizing. Many participants in the current study were concerned that the DSM (and how it is interpreted) plays a role in the pathologizing of normal human functioning. This pathologizing involves a service user's thoughts, emotions and behaviours being regarded as simple reflections of their diagnosis/diagnoses, 
which can lead to labeling, stigma and discrimination. Research by Probst (2011) and Rubinson (1999) has identified that many MHSWs in the U.S. are similarly concerned that diagnoses can lead to the pathologizing of service users.

Concerns about the potential stigma connected to diagnostic labels are acknowledged as a "reasonable concern" in the DSM-IV-TR Guidebook (First et al., 2004), and are also discussed by Scheyett (2005) as having significant impacts on service users. In Ontario, service users have described numerous ways in which, partly due to their diagnoses, they commonly encounter stigmatizing attitudes and receive discriminatory treatment from mental health service providers (Everett, 2000). Gormley and Quinn (2009) argue that the DSM has had a substantial role in increasing the amount of stigma faced by service users, since the manual has inspired an overuse of diagnostic labels. However, the pathologizing of service users with psychiatric diagnoses has also been described as the result of discourses and practice that go beyond the DSM, with Turner (2002) stating that the negative outcomes of diagnostic labels are due to the misuse and misunderstanding of these labels. Nevertheless, the DSM is the main taxonomic system for mental disorders in Canada (Goldner et al., 2011), and thus it is reasonable that MHSWs in Ontario who feel that psychiatric diagnoses can lead to pathologizing would question that manual that is the source for these diagnoses.

Misdiagnosis. A majority of participants in the current study described the misdiagnosis of mental disorders by other service providers as being a common occurrence, which was mostly attributed to poor professional practices by these service providers (as opposed to strictly being due to flaws with the DSM.) 
Misdiagnosis is a well-recognized and commonly cited concern in the literature (Linder, 2004; Kress et al., 2005; Pottick et al., 2003). McLaughlin (2002) argues that misdiagnosis can be attributed to both issues with the DSM and the flawed diagnostic practices of many mental health service providers. Based on the current study's findings, it appears that MHSWs in Ontario are similarly aware of and concerned about the prevalence of misdiagnosis.

The DSM as socially constructed and "major mental illness" versus "everything else." These two separate subthemes will be discussed together, since they represent closely linked concerns pertaining to the subjectivity of the DSM. The first subtheme (the DSM as socially constructed) involved the belief that the DSM and the mental disorders included therein should be understood as totally subjective, while the second subtheme ("major mental illnesss" versus "everything else") involved the view that only certain disorders in the DSM are subjective, while other disorders represent "serious" forms of mental illness. Previous U.S. research indicates that there is similar diversity in regard to whether MHSWs regard the DSM as totally or partially subjective. The majority of participants in studies by Kutchins and Kirk (1988) and Hitchens (2011) felt that the DSM inappropriately applied medical labels to non-medical problems, while the majority of participants in a study by Rubinson (1999) felt that the manual contains mostly valid diagnostic criteria. Similar to arguments made by participants in the current study who felt that the DSM allowed for the appropriate identification and treatment of "major mental illness," many participants in Probst's (2011) study described DSM 
diagnoses as being valid and useful in regard to conditions that are perceived as more "severe" (e.g., schizophrenia and major depression.)

Within the literature there are many critiques of the manual's subjectivity that overlap with the divided perspectives of the participants in the current study. Numerous authors have identified the DSM as a subjective document. Caplan (1995) argues that "scientific evidence" has played a much smaller degree in the manual's historical development than it's authors and supporters would contend. Numerous authors have criticized the DSM as being a social construction and problematized the subjective means by which the manual imposes a boundary between normal and abnormal thoughts, feelings and behaviours (Cooper, 2005; Cotton and Ridings, 2011; Kutchins and Kirk, 1997). However, other critics of the manual make similar arguments while also contending that the manual does include some diagnoses that possess greater validity (British Psychological Society, 2011; Frances, 2012). Either type of argument raises serious concerns about the DSM's status as a valid taxonomic and diagnostic system. It is noteworthy that a document that is as influential in Ontario's mental health field as the DSM would be so skeptically regarded by the professionals who play such a substantial role in the field.

Concerns regarding specific diagnoses. Many participants in the current study shared specific concerns regarding particular diagnoses in the manual. The literature includes many discussions of reliability and validity issues pertaining to specific diagnoses in the $D S M$, including those diagnoses that were mentioned by participants in the current study. Those diagnoses that have been criticized in the 
literature and which were mentioned in the current study include: ADHD (Moncrieff and Timimi, 2010), Borderline Personality Disorder (Shaw and Proctor, 2005), Gender Identity Disorder in Childhood (Bartlett et al., 2000), Oppositional Defiant Disorder (Wakefield and First, 2003) and Personality Disorders (Caplan, 1995). Those MHSWs in Ontario who are concerned about the legitimacy of these diagnoses thus have legitimate reasons for having such concerns.

The medical model. The majority of participants in the current study took issue with what they regarded as the problem-focused and bio-medical orientation of a medical model perspective, and felt that it was connected with the DSM. In addition, participants expressed mixed opinions on whether a medical model perspective was compatible or incompatible with the values of social work. In a study by Hitchens (2011), MHSWs in the U.S. expressed similar concerns about the relationship between the DSM and a medical model perspective. In the literature, a medical model perspective is widely acknowledged as having a significant influence over mental health discourses and practices in North America (Beresford, 2005), and is often characterized in similar terms to how it was defined by participants in the current study (Eriksen and Kress, 2005). Furthermore, the DSM has been described as promoting a medical model perspective (Saleebey, 2001), and ArndCaddigan and Pozzuto (2010) contend that a focus on treating the symptoms of a DSM diagnosis is a key element of a medical model perspective. However, Nesse and Stein (2012) argue that it is important to distinguish a "narrow" medical model (the version criticized by participants in the current study) from a "broader" medical model, which can inspire understandings of mental disorders that challenge the 
narrow model and the DSM. Thus, MHSWs in Ontario have relevant reasons for questioning how a narrow medical model perspective reinforces the problematic aspects of the DSM.

Programs/supports. Many participants in the current study were aware that certain diagnoses allow service users to receive insurance coverage and gain access to different programs and supports. As some participants indicated, this aspect of the DSM's influence has positive and negative outcomes for service users, in that it can either enhance or limit their ability to access services. Either way, this was described as an incentive to have professional knowledge of the $D S M$, in order to help clients with gaining this access. The several participants who discussed the positive and negative aspects of having diagnoses inform whether service users can access programs and supports were quite passionate about this issue; nevertheless, many participants did not bring this up during their interview. This could mean that the connection between diagnoses and insurance reimbursement and/or accessing services was not a major concern for participants, or it could just as likely be a reflection of the more open-ended nature of the interviews I conducted, which did not include a specific question on this topic. Several U.S. studies have indicated that a major reason that MHSWs use the DSM is to obtain insurance reimbursement for their services (Kutchins and Kirk, 1988; Frazer et al., 2009; Hitchens, 2011). Given these U.S. findings, and the fact that many DSM diagnoses allow Canadian service users to receive insurance funding for mental health supports (Parker, 2006) and can enhance (or limit) their access to different programs and supports (Davis, 2006), further Ontario-focused research is warranted on this issue. 
Ubiquity of the DSM. The final subtheme explored in the current study relates to participant's perspectives that the DSM is ubiquitous in the mental health field, and thus something they simply need to know. In the literature and popular press, the DSM is regularly referred to as the "bible" of psychiatry, and it is the most regularly utilized taxonomic and diagnostic system in Canada's mental health field. As further indication of the manual's ubiquity, the OASW (2006), as already mentioned, lists "specialized knowledge" of the DSM as a knowledge standard for MHSWs in the province. Since some participants in the current study were surprised that, given the DSM's ubiquity, there is not a greater amount of training on the manual at the university level, future research should explore this issue.

\section{Practical Implications}

The findings of this exploratory study have numerous implications for government policy, social work practice and social work education in Ontario. Beginning with policy applications, since 2005, qualified MHSWs in BC have been allowed to use the DSM for diagnostic purposes. ${ }^{18}$ This could prove to be an isolated exception to the limitations imposed on MHSWs elsewhere in Canada, or it could signify that there is the potential for future policy shifts that would allow MHSWs in Ontario (or other provinces/territories in Canada) to use the DSM for diagnostic purposes. If such a shift were ever considered in Ontario, then it is important to have research that indicates whether members of the profession regard the DSM as a relevant tool for social work practice. The current study's findings indicate that some MHSWs in the province may have critical perspectives toward the DSM and

${ }^{18}$ For a brief discussion of how MHSWs in BC are deemed to be "qualified" to diagnose, please refer back to page 12 of my Literature Review. 
the role that it already plays in the mental health system. These critical perspectives may potentially overlap with those of participants in the current study who felt that there was a poor fit between the DSM and the strengths-based, person-centered and person-in-environment orientations that are recognized as key values of the social work profession. Numerous authors have also discussed this poor fit within the context of social work practice in the U.S. (Austrian, 2005; Corcoran and Walsh, 2006; Ishabashi, 2005; Lyter and Lyter, 2010; McQuaide, 1999). Thus, any policy shifts similar to those in $\mathrm{BC}$ could be unwanted and poorly received by some MHSWs in Ontario.

In terms of applications for social work practice, the current study's findings indicate that the impact of the DSM on service users can be regarded as a social justice issue. This has significant implications for social work practice, since the pursuit of social justice is defined as a core social work value in the Canadian Association of Social Workers' (CASW) Code of Ethics (2005). This requires social workers to "oppose prejudice and discrimination against any person or group of persons, on any groups, and specifically challenge views and actions that stereotype particular persons or groups" (CASW, 2005, p. 5). The incompatibility between the $D S M$ and social work's emphasis on social justice has been cited as a relevant concern in the literature (Corcoran and Walsh, 2006; Lyter and Lyter, 2010; Saleebey, 2001). Although no participant in the current explicitly described the DSM as being specifically incompatible with the social justice goals of the social work profession, many of the critical comments that participants made in regard to the $D S M$, and particularly the negative outcomes that psychiatric diagnoses can have on 
service users, imply that diagnoses (and how they are misunderstood and misapplied) can increase the prejudice, discrimination and stereotyping that is directed toward service users. The narratives of service users in Ontario also include many examples of how psychiatric diagnoses can lead to pathologizing (Everett, 2000). Since diagnoses can lead to pathologizing, and this pathologizing is driven by various discourses (e.g. a more narrow medical model) that inform the views and actions by service providers and the general public, the ethical guidelines for the social work profession emphasize that it is important for MHSWs to oppose and challenge these discourses, views and actions.

Although there are many practical reasons why opposing and challenging these discourses, views and actions may be difficult within certain professional settings (particularly in interprofessional settings that subscribe to a more narrow medical model), these are also the settings where such advocacy may be most important. Following the example of several participants in the current study, it is important for social workers to take whatever steps they can in order to advocate for service users who are being pathologized and mistreated on the basis of their diagnoses. This can involve speaking up, whether in team meetings or in conversation with colleagues (as illustrated in the current study in quotes from Sidney on page 87, Kim on page 91 , Sean on page 93 and Leon on page 95). On a smaller, but no less important scale, challenging the pathologizing and mistreatment of service users can be achieved in direct work with clients. This study's findings indicate that it is important to be aware of the potential for internalized stigma associated with a psychiatric diagnosis, and to practice from a strengths-based 
orientation that helps to reduce internalized stigma and promote recovery. However, there is also a limit on how much can be accomplished through isolated individual actions. Professional organizations such as the Ontario Association of Social Workers should also take steps to advocate around these issues and challenge pathologizing and the professional practices that increase internalized stigma among service users. Unfortunately, many of the practical concerns shared by participants in the current study, such as the impact of the medical model and the way that programs/services are structured along diagnostic lines, are deeply ingrained characteristics of the mental health system. Thus, advocacy efforts may have to go beyond a specific focus on the DSM and include a broader focus on underlying issues within the mental health system.

The current study's findings also raise potential implications for social work education in the province. Unfortunately, no research currently exists on how social work undergraduate or graduate students in Ontario or elsewhere in Canada are taught about the DSM. Nevertheless, the current study does indicate what specific DSM-focused content would be important to include in any courses at the undergraduate or graduate level that are designed to prepare students for mental health practice. Given the ubiquity of the DSM in the mental health system, it is certainly relevant for social work students to be familiar with the manual's content and development. It would also be useful for students to learn about the different applications that the manual has for social work practice, and the advantages and disadvantages associated with each application. Courses should also emphasize the impacts that diagnoses can have on service users, and ensure that social work 
students can understand and communicate about the manual and diagnoses with clients and colleagues in a non-pathologizing fashion.

Mental health services in Canada are a provincial (and not federal) responsibility, guaranteeing some differences between provinces/territories in regard to funding and service provision. Since the current study involved MHSWs in Ontario, the current study's findings and implications may not be generalizable to MHSWs in other parts of Canada. However, the DSM has been described as playing a significant role in the mental health system across Canada, and thus it is possible that it may have a similarly contentious relationship with mental health social work practice outside of Ontario. If future research were to demonstrate that the DSM indeed has such a relationship, then the above-described practical implications could be extended to a national scale.

\section{Theoretical Issues}

The findings of the current study, when explored from a social constructionist perspective, raise some important theoretical considerations. The first issue relates to a question that l posed in my Findings section: whether the DSM can be said to have a significant relationship to mental health social work practice in Ontario when MHSWs do not directly reference the manual on a regular basis. Even though the majority of participants did not directly reference the DSM on a regular basis, statements by many of the participants in the current study highlight that the DSM still influences various aspects of professional practice. From a social constructionist perspective, this apparent contradiction - that a document that is rarely consulted can exert a multifaceted influence on mental health social work 
practice - is quite explicable. The DSM is an extremely influential document that, along with the medical model, has helped to shape contemporary discourses that inform how mental disorders are understood in North America (Cooper, 2005). The two are connected in numerous ways, since, in North America, the medical model places an importance on defining, identifying and treating individual pathology (Eriksen and Kress, 2005), and the DSM has helped to reify many mental disorders, such that they are understood as "real" forms of individual pathology that can be reliably defined, identified and treated (Kutchins and Kirk, 1997). Although the main conclusion that I have drawn from my findings is that the DSM has an inconsistent impact on mental health social work practice in Ontario and that MHSWs have various critical perspectives toward the manual, some participants also described that their understanding of and work with a client can be informed by that client's diagnosis/diagnoses, and that they consider certain diagnoses in the $D S M$ to represent serious forms of mental illness. Such approaches and perspectives are at least partially influenced by $D S M$ - and medical model-informed discourses. These discourses shape how mental disorders are conceptualized in North America to such a profound extent that MHSWs in the current study did not actually need to reference the DSM in order to be informed by it.

In regard to other ways that the $D S M$ - and medical model-informed discourses inform the professional practice of MHSWs in Ontario, it is relevant to offer a critical interpretation of the assumption that MHSWs in Ontario do not use the DSM to diagnose. Although there are unambiguous legal restrictions in Ontario that ensure that MHSWs are not allowed to diagnose, it would be inappropriate to 
therefore conclude that they do not search for signs of pathology behind a client's struggles within their assessments. Ishabashi (2005) describes how the context of professional practice in the mental health field can motivate social workers to search for pathology, and how the DSM can inform what are defined as specific forms of pathology:

A social worker rarely meets a client without any background information. At the very least, the social worker will be predisposed to think there is something that merits intervention. Based on that predisposition, social workers are inclined to look for pathology, a task the DSM-IV facilitates because of its over-inclusiveness. (p. 73)

The fact that the legal limits on MHSWs in Ontario do not preclude them from searching for $D S M$-defined pathology in their clients was recently illustrated for me at a workshop that I attended in Toronto. During that workshop, which was mostly comprised of MHSWs, the facilitator (a psychologist) suggested that even if social workers couldn't use the DSM or other tools to diagnose, that it was still useful for them to have a thorough knowledge of the DSM's diagnostic criteria for different disorders (N. Lazar, personal communication, August 15, 2012). The rationale that the facilitator provided for why we should have this knowledge was that it would allow us to informally diagnose our clients during an assessment process - that is, to decide on a diagnosis without communicating it to the client or documenting it in their file - and thereby have information on what type of cognitive-behavioural therapy protocol we should utilize. This experience made me think back to a comment by Molly, one of the participants in the current study, in which she stated 
that even mental health professionals other than psychiatrists and psychologists are not allowed to diagnose, they can still "use it in some way in their mind". I believe that Molly's comment was quite insightful. Several participants in the current study stated that they find it helpful to understand clients via their diagnoses or made other comments that indicate that they viewed their clients' difficulties as reflections of inner pathology. This indicates that many MHSWs can and do use the $D S M$ "in their mind" in various ways, and one important (and easily overlooked) way is in regard to whether they believe that certain cognitive, emotional and behavioural patterns that they perceive their client as exhibiting are an expression of inner pathology. Even if MHSWs are prohibited from diagnosis, their professional practice can still be characterized by diagnostic thinking. There are some MHSWs in Ontario who may potentially exhibit such diagnostic thinking, and the role of the $D S M$ in informing and validating such thinking cannot be overlooked.

\section{Limitations}

There are several limitations pertaining to the current study that warrant reflective appraisal. The first limitations that I will discuss relate to Shenton's (2004) recommendations for ensuring the trustworthiness of one's qualitative research. Although I have already described the steps I took to ensure the triangulation (and thus credibility) of my study, Shenton (2004) also recommends using multiple methods of data collection so that a researcher can compensate for the flaws that are inherent in any individual data collection method. However, the only data I collected for the current study was through individual interviews. Nevertheless, this is only one recommended way to ensure triangulation, and I feel 
that I was able to ensure triangulation in other regards, specifically by drawing on participants from different professional settings. In terms of other limitations pertaining to the study's credibility, while I did employ member checks in my study, of those eight participants who I emailed for feedback, only two responded with feedback on my thematic model. While that feedback was positive, it would have been helpful to received responses from other participants in the study. The fact that I did not get a greater number of responses could simply be an indication of the busy work schedules of the participants in the study.

Another limitation of the current study concerns a lack of diversity among participants in regard to educational background and geographical location. The majority of participants in the current study $(n=9)$ obtained their Master of Social Work degree from Carleton University. Carleton's social work program has a structural social work emphasis, which involves a focus throughout the program on the impact of structural factors (e.g., political, economic and cultural contexts) on lived experience and the importance of challenging structural factors that promote hardship (Carleton University School of Social Work, 2012). This emphasis is much more consistent with social constructionist understandings of mental disorders then those promoted by a narrow medical model. It is possible that in past years individuals with strong structural orientations, and thus strong aversions to a narrow medical model, have enrolled in Carleton's social work program due to this emphasis, or that the program has shaped students into social workers with unique structural emphases and other practice approaches and values that are distinct from the graduates of other social work programs. However, from my own experience at 
Carleton, the student body (and faculty) includes individuals with diverse experiences, practice approaches and values. Moreover, since participants in the current study had an average of 11.9 years of varied experience working in mental health settings, it is likely that these practical experiences have had a more substantial role in shaping how they use the DSM and the perspectives they have toward the manual then the one or two years they would have spent as graduate students at Carleton.

An additional limitation pertaining to the diversity of participants is the geographical location of my sample. I only recruited participants who worked in mental health settings in the Ottawa area. In part, this was due to my preference for conducting in-person interviews, which, given my other school, work and volunteer commitments at the time, largely precluded travel outside of Ottawa. Nevertheless, since my study's findings and applications are being discussed in regard to mental health social work in Ontario, it is important to reflect on whether MHSWs in Ottawa are similar to MHSWs in other parts of the province. O'Brien and Calderwood (2010) recently conducted a province-wide survey exploring the roles of MHSWs in Ontario. Participants in the current study had engaged in all of the fourteen types of work identified by 0'Brien and Calderwood (2010) (see Table 4), indicating that the current sample had at least some experience with the types of work that are practiced by other MHSWs in the province. Nevertheless, among my recommendations for future research (discussed below) is a future study with a more geographically diverse sample of participants. 
Table 4

Services provided by MHSWs in Ontario

\begin{tabular}{lc}
\hline Type of work & $\%$ \\
\hline Assessment and referrals & $88 \%$ \\
Supportive counselling & $84 \%$ \\
Crisis intervention & $71 \%$ \\
Psychotherapy & $56 \%$ \\
Advocacy & $55 \%$ \\
Case management & $52 \%$ \\
Education & $46 \%$ \\
Discharge planning & $38 \%$ \\
Addictions counselling & $34 \%$ \\
Outreach & $27 \%$ \\
Administration & $20 \%$ \\
Research & $19 \%$ \\
Teaching activities of daily living & $18 \%$ \\
Other & $9 \%$ \\
\hline
\end{tabular}

Note: Adapted from "Living in the Shadows: A Canadian Experience of Mental Health Social Work," by. A.-M. O'Brien and K. A. Calderwood, 2010, Social Work in Mental Health, 8, p. 328.

One unfortunate limitation of the current study is that I was not able to satisfy my initial recruitment goal, which was to recruit and interview several participants who, in addition to being MHSWs, also identified as service users. The reason behind this goal was that I hoped to explore whether service user experience informed unique perspectives on the DSM. Since I was only able to recruit one MHSW who self-identified in this regard, I felt that it would be inappropriate to explore this question in my thesis. Although the current study's findings and 
implications are by no means limited by this recruitment challenge, 1 do feel that having a larger number of service users involved in the current study may well have allowed for a richer discussion of issues pertaining to the outcomes of diagnosis. As such, I have recommended that future research should explore this very issue.

A final limitation of the current study is that I have been solely responsible for the interviewing, transcribing, coding and analysis. My own perspectives and related biases have clearly had many opportunities to inform this study in substantial ways. I have been extremely conscious that this could limit the depth of my research, and thus been transparent about my own background and biases in this thesis and have engaged in frequent debriefing with my thesis supervisor and encouraged feedback on my thematic model from peers. Through these latter steps I have received critical feedback at every stage of my research, which has played a helpful role in allowing me to obtain outside perspectives on my work and to challenge aspects of my thinking. In addition, I have taken several lengthy breaks between and during the different stages of my research, and I feel that this has allowed me to gain fresh perspectives on my work and notice many assumptions and biases that I had previously overlooked.

\section{Recommendations for Future Research}

The findings and limitations of the current study offer several possibilities for future qualitative and quantitative research. It would be useful for a future study to explore these same questions as the current study, but with a larger and more diverse (in regard to geographic location in the province and academic background) sample of participants. Such a study could also provide a richer pool of 
data for exploring how MHSWs in hospital-based, community-based and/or privatepractice-based settings differ in regard to their use of and perspectives on the DSM, a relevant question that I did not explore in the current study. Furthermore, such a study could also more directly explore some of the issues that I have identified through my analysis but that I did not explore to a significant extent in interviews with participants, such as the relationship between the DSM and accessing insurance coverage along with programs/supports.

An additional possibility for future research would be a nation-wide study involving participants from all the provinces/territories in Canada. It would be particularly interesting to explore whether the use of and views on the DSM among MHSWs differ between BC (where MHSWs are allowed to diagnose) and other provinces/territories (where MHSWS are not allowed to diagnose.) Since DSM-5 will include many changes from previous editions, and will likely have as significant an influence on Canada's mental health system as previous editions, it would also be useful for future research to explore whether DSM-5 has any distinct impacts on the professional practice of MHSWs or whether MHSWs have perspectives on the manual that differ from previous editions.

Although it was among my initial goals for this study, I was only able to recruit one participant who identified as a service user, and thus was not able to explore whether service user experiences can inform unique perspectives on the $D S M$. Nevertheless, the one participant in this study who did identify as a service user had very passionate views on the topic of the DSM, and they discussed many of these views within the context of their personal history in the mental health system. 
It would be interesting if future research was better able to include perspectives from individuals with dual experiences as service providers and service users, and to explore whether such experiences inform how those individuals use the DSM and what views they have toward the manual.

Lastly, in addition to research that explores the perspectives and practices of MHSWs in Ontario and other provinces, it would be useful for future research to look at the way that students in undergraduate and graduate social work programs in Canada are taught about the DSM. Such studies could be modeled on previous U.S. research (Lacasse and Gomory, 2003; Newman et al., 2007). Given the manual's ubiquity in and impact on the mental health system, it would be useful to find out what kind of education Canadian social work students are receiving on the DSM, because how students are taught about the manual could play a significant role in whether they have the knowledge and comfort to challenge it among colleagues and clients.

\section{Conclusion}

This study is a useful first step to addressing gaps in Canadian-focused research on the relationship between the DSM and social work. In regard to the impacts of the DSM on the professional practice of MHSWs, the current study indicates that the manual's applications are inconsistent. While the majority of participants endorsed certain ways that the manual is applicable to mental health social work practice (e.g. helping clients make meaning of diagnoses, professional communication) other applications (e.g. understanding clients, working with clients) were more contentious. In regard to their perspectives on the manual, 
participants were largely critical of the ways that the DSM impacts on service users and defines and categorizes mental disorders. Based on these findings, the current study highlights that the DSM has a contentious relationship with social work, making the two an "odd couple". However, just because MHSWs in Ontario cannot diagnose does not mean that they are removed from the DSM, and recognizing the influence that the manual and the medical model has on professional practice can help professionals be aware of the ways in which they may unintentionally perpetuate the many negative outcomes on the mental health system and service users that they associate with the manual.

\section{Personal Reflection}

This study stemmed out of a long-term interest that I have had in how mental health and mental disorders are conceptualized in mainstream, governmental and academic discourses. When I first encountered critical literature on the DSM and the medical model as an undergraduate student, it helped me to re-evaluate the recent experiences I had gone through as a service user, and convinced me that there were many problematic aspects of psychiatric diagnosis. My sense that the $D S M$ and medical model promoted stigmatizing discourses and practices became part of my motivation to pursue a social work degree, so that I could provide services and supports that would better support the recovery of service users. Although the process of conducting this research has certainly affirmed many of my concerns around psychiatric diagnosis, it has also exposed me to more ambiguous perspectives on the DSM and the medical model, and highlighted the significant challenge of promoting a social change agenda within mental health social work 
practice. As a result, although I set out to answer a very specific question with this thesis - how do MHSWs in Ontario use the DSM, and what perspectives do they have towards it? - I am finishing this study with many unanswered questions on my mind. Is the concept of "mental disorder" inherently pathologizing? To what degree are the pathologizing discourses and practices that impact on service users attributable to the DSM, or is the manual just a convenient target for critics, while the real issue is with historically rooted assumptions and linguistic practices that have helped shape a narrow medical model in North America? Is the social change aspect of social work inherently undermined by the highly individualized emphasis within the mental health field? In contrast to the suggestions for future research that I already proposed, these are not questions that can be easily explored with any specific study, but questions that I believe will motivate a career's worth of critical inquiry. Moreover, since these are questions that have developed out of this study, I must once again thank the many people who have influenced this research, especially my participants, for helping me to explore old questions and discover new ones. 


\section{References}

American Psychiatric Association (APA). (1952). Diagnostic and statistical manual of mental disorders ( $1^{\text {st }}$ ed. [DSM-I]). Washington, DC: Author.

American Psychiatric Association (APA). (1980). Diagnostic and statistical manual of mental disorders ( $3^{\text {rd }}$ ed. [DSM-III]). Washington, DC: Author.

American Psychiatric Association (APA). (2000). Diagnostic and statistical manual of mental disorders (4th ed., Text Revision [DSM-IV-TR]). Washington, DC: Author.

American Psychiatric Association (APA). (2010). DSM-5 field trials in academic or large clinical settings: Frequently asked questions. Retrieved from http://www.dsm5.org/Research/Documents/FAQs\%20field\%trials_final_05 0311.pdf

American Psychiatric Association (APA). (2012a). The people behind DSM-5. Retrieved from http://dsmfacts.org/wp-content/uploads/2012/05/ThePeople-Behind-DSM-51.pdf

American Psychiatric Association (APA). (2012b). Recent updates to proposed revisions for DSM-5. Retrieved from http://www.dsm5.org/Pages/ RecentUpdates.aspx

Arnd-Caddigan, M., \& Pozzuto, R. (2010). Evidence-based practice and the purpose of clinical social work. Smith College Studies in Social Work, 80(1), 35-52. doi:10.1080/00377310903504965

Austrian, S. G. (2005). Mental disorders, medications, and clinical social work. New York, NY: Columbia University Press. 
Barker, R. L. (2003) The social work dictionary (4th ed.). Washington, DC: National Association of Social Work Press.

Bartlett, N. H., Vasey, P. L., \& Bukowski, W. M. (2000). Is gender identity disorder in children a mental disorder? Sex Roles, 43(11), 753-785.

doi:10.1023/ A:1011004431889

Beresford, P. (2005). Social approaches to madness and distress: User perspectives and user knowledge. In J. Tew (Ed.), Social perspectives in mental health: Developing social models to understand and work with mental distress (pp. 3252). Philadelphia, PA: Jessica Kingsley Publishers.

Blashfield, R. K., Flanagan, E., \& Raley, K. (2010). Themes in the evolution of the $20^{\text {th }}$ century DSMs. In T. Millon, R. F. Krueger \& E. Simonsen (Eds.), Contemporary directions in psychopathology: Scientific foundations of the DSM-V and ICD-11 (pp. 53-72). New York, NY: The Guildford Press.

Board of Registration for Social Workers in British Columbia. (2005). Rules of the Board of Registration for Social Workers in British Columbia. Copy in possession of author.

Boyatzis, R. E. (1998). Transforming qualitative information: Thematic analysis and code development. New York, NY: Sage Publications.

Braun, V., \& Clarke, V. (2006). Using thematic analysis in psychology. Qualitative Research in Psychology, 3, 77-101. doi:10.1191/1478088706qp063oa

British Columbia College of Social Workers. (2009). Code of ethics and standards of practice. Retrieved from www.bccollegeofsocialworkers.ca/documents/ Bylawamendmentswebnotice.pdf 
British Psychological Society. (2011, June). Response to the American Psychiatric Association: DSM-5 Development. Retrieved from http://apps.bps.org/uk/ _publicationfiles/consultation-responses/DSM-5\%202011\%20\%20BPS\%20response.pdf

Brubeck, M. (1999). Social work and the DSM. In F. J. Turner (Ed.), Adult psychopathology (pp. 121-135). New York, NY: Free Press.

Burr, V. (2005). Social constructionism. New York, NY: Routledge. Canadian Association of Social Workers [CASW]. (2001). The role of social work in mental health. Retrieved from http://www.casw-acts.ca/en/role-socialwork-mental-health.

Canadian Association of Social Workers [CASW]. (2005). Code of ethics. Retrieved from http://www.casw-acts.ca/en/what-social-work/casw-codeethics/code-ethics

Caplan, P. J. (1995). They say you're crazy: How the world's most powerful psychiatrists decide who's normal. Don Mills, ON: Addison-Wesley Publishing Company.

Carlat, D. J. (2010). Unhinged: The trouble with psychiatry - A doctor's revelations about a profession in crisis. New York, NY: Free Press.

Carleton University School of Social Work. (2012). Master of Social Work Handbook. Retrieved from http://www.carleton.ca/socialwork/ccms/wpcontent/Ccmsfiles-MSW-Handbook-2012-2013.pdf

Castillo, R. J. (1997). Culture and mental disorder: A client-centered approach. Toronto, ON: Brooks/Cole Publishing Company. 
Charmaz, K. (2002). Qualitative interviewing and grounded theory analysis. In J. F. Gubrium and J.A. Holstein (Eds.), Handbook of interview research: context and methods (pp. 675-694). New York, NY: Sage Publications.

Chesler, P. (2005). Women and madness. (1st ed., revised and updated.). New York, NY: Palgrave Macmillan.

Cooper, R. (2005). Classifying madness: A philosophical examination of the diagnostic and statistical manual of mental disorders. Dordrecht, The Netherlands: Springer.

Corcoran, J., \& Walsh, J. (2006). Clinical assessment and diagnosis in social work practice. New York, NY: Oxford University Press.

Corrigan, P. (2007). How clinical diagnosis might exacerbate the stigma of mental illness. Social Work, 52(1), 31-40. doi:10.1093/sw/52.1.31

Corrigan, P. W., Watson, A. C., Byrne, P., \& Davis, K. E. (2005). Mental disorder stigma: Problem of public health or social justice? Social Work, 50(4), 363369.

Cosgrove, L., \& Krimsky, S. (2012). A comparison of DSM-IV and DSM-5 panel members' financial associations with industry: A pernicious problem persists. PLOS Medicine, 9(3), 1-4.

Cosgrove, L., Krimsky, S., Vijayaraghavan, M., \& Schneider, L. (2006). Financial ties between DSM-IV panel members and the pharmaceutical industry. Psychotherapy and Psychosomatics, 75, 154-160. doi:10.1159/000091772

Cotton, C., \& Ridings, J. W. (2011). Getting out/getting in: The DSM, political activism, and the social construction of mental disorders. Social Work in Mental Health, 
9, 181-205. doi: $10.1080 / 15332985.2010 .534359$

Crowe, M. (2000). Constructing normality: A discourse analysis of the DSM-IV. Journal of Psychiatric and Mental Health Nursing, 7(1), 69-77. doi:10.1046/j.1365-2850.2000.00261.x

Davis, S. (2006). Community mental health in Canada: Policy, theory, and practice. Vancouver, BC: UBC Press.

Dougherty, J. L. (2005). Ethics in case conceptualization and diagnosis: Incorporating a medical model into the developmental counseling tradition. Counseling and Values, 49(2), 132-140. doi:10.1002/j.2161-007X.2005.tb00259.x

Dziegielewski, S. F. (2010). DSM-IV-TR in action. Hoboken, NJ: John Wiley and Sons. Dziegielewski, S. F., Johnson, A. J., \& Webb, E. (2003). DSM-IV and social work professionals. Social Work in Mental Health, 1(1), 27-41. doi: 10.1300/J200v01n01_03

Eriksen, K., \& Kress, V. E. (2005). Beyond the DSM story: Ethical quandaries, challenges, and best practices. Thousand Oaks, CA: Sage Publications.

Eriksen, K., \& Kress, V. E. (2006). The DSM and the professional counseling identity: Bridging the gap. Journal of Mental Health Counseling, 28(3), 202-217.

Esterberg, K. G. (2002). Qualitative methods in social research. Boston, MA: McGrawHill.

Everett, B. (2000). A fragile revolution: Consumers and psychiatric survivors confront the power of the mental health system. Waterloo, ON: Wilfrid Laurier University Press. 
Fine, M. (2002). Disruptive voices: The possibilities for feminist research. Ann Arbor, MI: University of Michigan Press.

First, M. B., Frances, A., \& Pincus, H. A. (2004). DSM-IV-TR guidebook. Washington, DC: American Psychiatric Publishing, Inc.

Foucault, M. (1965). Madness and civilization: A history of insanity in the age of reason. (R. Howard, Trans.). New York, NY: Random House.

Foucault, M. (1972). The archeology of knowledge. (A. M. Sheridan Smith, Trans.). London, United Kingdom: Tavistock Publications.

Foucault, M. (1973). The birth of the clinic: An archeology of medical perception (A. M. Sheridan Smith, Trans.). New York, NY: Pantheon Books.

Foucault, M. (2003). Psychiatric power: Lectures at the College De France, 1973-74. (G. Burchell, Trans.). J. Lagrange, F. Ewald \& A. Fontana (Eds.). New York, NY: Palgrave Macmillan.

Frances, A. (2010, February 11). Opening Pandora's Box: The 19 worst suggestions for DSM5. Psychiatric Times. Retrieved from http:// www.psychiatrictimes.com/display/Article/10168/1522341.

Frances, A. (2012, April 5). Why social workers should oppose DSM-5. Psychology Today. Retrieved from http://www.psychologytoday.com/blog/dsm5-indistress/201204/ why-social-workers-should-oppose-dsm-5

Frazer, P., Westhuis, D., Daley, J. G., \& Phillips, I. (2009). How clinical social workers are using the DSM-IV: A national study. Social Work in Mental Health, 7(4), 325-339. doi:10.1080/15332980802052100

Gasson, S. (2003). Rigor in grounded theory research - an interpretive perspective 
on generating theory in qualitative field studies. In M. Whitman \& A. Woszczynski (Eds.), Handbook for Information Systems Research (pp. 79102). Hershey, PA: Idea Group Publishing.

Gergen, K. J. (1985). The social constructionist movement in modern psychology. American Psychologist, 4O(3), 266-275.

Gergen, K. J. (2003). Knowledge as socially constructed. In M. Gergen \& K. J. Gergen (Eds.), Social constructionism: A reader (pp. 15-17). Thousand Oaks, CA: Sage Publications.

Goldner, E. M., Jenkins, E., Palma, J., \& Bilsker, D. (2011). A concise introduction to mental health in Canada. Toronto, ON: Canadian Scholars' Press Inc.

Gormley, D., \& Quinn, N. (2009). Mental health stigma and discrimination: The experience within social work. Practice, 21(4), 259-272. doi:10.1080/09503150902993621

Grae, S. W., \& Zide, M. R. (2008). Psychopathology: A competency-based assessment model for social workers. Belmont, CA: Thomson Brooks/Cole.

Health Canada. (2002). A report on mental illnesses in Canada. Retrieved from www.phac-aspc.gc.ca/publicat/miic-mmac/pdf/men_ill_e.pdf

Hibbard, F. J. (2005). Unfolding social constructionism. New York, NY: Springer.

Hitchens, K. (2011). The DSM and social work: Twenty years after Kutchins and Kirk. (Doctoral dissertation). Retrieved from Proquest Dissertations and Thesis database. (UMI No. 3450836)

Holmes, K. A., \& Raffoul, P. R. (1984). The diagnostic manual (DSM-III) and social work practice. Free Inquiry in Creative Sociology, 12, 69-72. 
Hook, D. (2010). Foucault, psychology and the analytics of power. New York, NY: Palgrave Macmillan.

Horwitz, A. (1999). The sociological study of mental illness. In C. S. Aneshensel \& J. C. Phelan (Eds.), Handbook of the sociology of mental health (pp. 57-78). New York, NY: Springer Science and Business Media.

Hyman, S. E. (2010). The diagnosis of mental disorders: The problem of reification. Annual Review of Clinical Psychology, 6, 155-179. doi:10.1146/annurev.clinpsy.3.022806.091532

Ishabashi, N. (2005). Barrier or bridge: The language of diagnosis in clinical social work. Smith College Studies in Social Work, 75(1), 65-80. doi:10.1300/J497v75n01_05

Jordan, C., \& Franklin, C. (1995). Clinical assessment for social workers: Quantitative and qualitative methods. Chicago, IL: Lyceum Books, Inc.

Kerson, T. S., McCoyd, J. L. M., \& Chimchirian, J. M. (2005). Spanning boundaries: An enriched ecological perspective for social workers practicing in health and mental health care. In T. Heinonen \& A. Metteri (Eds.), Social work in health and mental health: Issues, developments, and actions (pp. 8-25). Toronto, ON: Canadian Scholars' Press Inc.

Kielbasa, A. M., Pomerantz, A. M., Krohn, E. J., \& Sullivan, B. F. (2004). How does clients' method of payment influence psychologists' diagnostic decisions? Ethics and Behavior, 14, 187-195. doi:10.1207/s1532709eb1402_6

Kirk, S. A., \& Kutchins, H. (1992). The selling of DSM: The rhetoric of science in psychiatry. New York, NY: Aldine De Gruyter. 
Kleinman, A. (1996). How is culture important for DSM-IV? In J. E. Mezzich, A. Kleinman, H. Fabrega \& D. Parron (Eds.), Culture and diagnosis: A DSM-IV perspective (pp. 15-26). Washington, DC: American Psychiatric Press.

Kress, V. E. W., Eriksen, K. P., Rayle, A. D., \& Ford, S. J. (2005). The DSM-IV-TR and culture: Considerations for counselors. Assessment and Diagnosis, 83, 97-104. doi:10.1002/j.1556-6678.2005.tb00584.x

Kutchins, H., \& Kirk, S. A. (1988). The business of diagnosis: DSM-III and clinical social work. Social Work, 33(3), 215-220.

Kutchins, H., \& Kirk, S. A. (1995). Should DSM be the basis for teaching social work practice in mental health? No! Journal of Social Work Education, 31, 159-165.

Kutchins, H., \& Kirk, S. A. (1997). Making us crazy: DSM: The psychiatric bible and the creation of mental disorders. New York, NY: Free Press.

Lacasse, J. R., \& Gomory, T. (2003). Is graduate social work education promoting a critical approach to mental health practice? Journal of Social Work Education $39(3), 383-408$.

Lane, C. (2007). Shyness: How a normal behavior became a sickness. New Haven, CT: Yale University Press.

Leiba, T. (1994). Inter-professional approaches to mental health care. In A. Leathard (Ed.), Going inter-professional: Working together for health and welfare (pp. 136-142). New York, NY: Routledge.

Linder, M. (2004). The construction of illness. In P. J. Caplan \& L. Cosgrove (Eds.), Bias in psychiatric diagnosis (pp. 3-7). Toronto, ON: Jason Aronson. Lowe, I., Pomerantz, A. M., \& Pettibone, J. C. (2007). The influence of payment 
method on psychologists' diagnostic decisions: Expanding the range of presenting problems. Ethics and Behavior, 17(1), 83-93.

doi: $10.1080 / 10508420701310141$

Lundy, C. (2011). Social work, social justice and human rights: A structural approach to practice (2nd ed.). Toronto, ON: University of Toronto Press.

Lyter, S. C., \& Lyter, L. L. (2010). Diagnosis and mental illness: Maximizing fit with social work mission and values [Powerpoint slides]. Retrieved from http:// www.changinghealthdublin2010.com/slides/Lyter-3.pdf

Marecek, J. (2003). Dancing through minefields: Toward a qualitative stance in psychology. In P. M. Canic, J. E. Rhodes \& L. Yardley (Eds.), Qualitative research in psychology: Expanding perspectives in methodology and design (pp. 49-69). Washington, DC: American Psychological Association.

McLaughlin, J. E. (2002). Reducing diagnostic bias. Journal of Mental Health Counseling, 24(3), 256-269.

McLeod, J. (2001). Qualitative research in counseling and psychotherapy. New York, NY: Sage Publications.

McPartland, J. C., Reichow, B., \& Volkmar, F. R. (2012). Sensitivity and specificity of proposed DSM-5 diagnostic criteria for autism spectrum disorder. Journal of the American Academy of Child \& Adolescent Psychiatry, 51(4), 368-383. doi:10.1016/j.jaac.2012.01.007

McQuaide, S. (1999). A social worker's use of the Diagnostic and Statistical Manual. Families in Society: The Journal of Contemporary Human Services, 80(4), 410416. 
Mehta, S., \& Farina, A. (1997). Is being "sick" really better? Effect of the disease view of mental disorder on stigma. Journal of Social and Clinical Psychology, 16(4), 405-419. doi:10.1521/jscp.1997.16.4.405

Mezzich, J. E. (1999). Ethics and comprehensive diagnosis. Psychopathology, 32, 135140. doi: $10.1159 / 000029080$

Moncrieff, J., Hopker, S., \& Thomas, P. (2005). Psychiatry and the pharmaceutical industry: Who pays the piper? The Psychiatrist, 29, 84-85. doi:10.1192/pb.29.3.84

Moncrieff, J., \& Timimi, S. (2010). Is ADHD a valid diagnosis in adults? No. British Medical Journal, 340, c. 547. doi:10.1136/bmj.c547

Morrow, S. L. (2005). Quality and trustworthiness in qualitative research in counselling psychology. Journal of Counselling Psychology, 52, 250-260. doi: $10.1037 / 0022-0167.52 .2 .250$

National Association of Social Workers (NASW). (2005). NASW standards for clinical social work in social work practice. Retrieved from http:// www.socialworkers.org/Practice/standards/naswclinicalstandards.pdf

Nesse, R. M., \& Stein, D. J. (2012). Towards a genuinely medical model for psychiatric nosology. BMC Medicine, 10(5). doi:10.1186/1741-7015-10-5

Neuman. (2006). Social research methods: Qualitative and quantitative research. Boston, MA: Allyn and Bacon.

Newman, B. S., Clemmons, V., \& Dannenfelser, P. L. (2007). The Diagnostic and 
Statistical Manual of Mental Disorders in graduate social work education:

Then and now. Journal of Social Work Education, 43(2), 297-308.

doi:10.5175/JSWE.2007.200600106

O'Brien, A., Calderwood, K. A. (2010). Living in the shadows: A Canadian experience of mental health social work. Social Work in Mental Health, 8, 319-335. doi:10.1080/15332980903484988

0'Hagan, M., McKee, H., \& Priest, R. (2009). Consumer survivor initiatives in Ontario: Building for an equitable future. Retrieved from http://www.awaycourier.ca/ uploads/file/CSI\%20Builder\%20Report.pdf

Oldham, J. (November 21, 2011). Letter to Don. W. Locke, President of the American Counselling Association. Retrieved from http://www.psychiatrictimes.com/ all/editorial/psychiatrictimes/pdfs/apa-response-aca.pdf

Ontario Assertive Community Treatment Team Association. (2012). ACT model. Retrieved from http://www.ontarioacttassociation.com/act_model Ontario Association of Social Workers [OASW]. (2006). Role of social work in mental health. Retrieved from http://www.oasw.org/media/82286/ MentalHealthRoleStatement2006.logo.pdf

Parker, G. (2006). The DSM classification of depressive disorders: Debating its utility. The Canadian Journal of Psychiatry, 51(14), 871-880.

Phillips, J., Frances, A., Cerullo, M. A., Chardavoyne, J., Decker, H. S., First, M. B.,...Zachar, P. (2012). The six most essential questions in psychiatric diagnosis: A pluralogue part 2: Issues of conservatism and pragmatism in 
psychiatric diagnosis. Philosophy, Ethics, and Humanities in Medicine, 7(9). doi: $10.1186 / 1747-534-1-7-8$

Pilecki, BC, Clegg, J. W., \& McKay, D. (2011). The influence of corporate and political interests on models of illness in the evolution of the DSM. European Psychiatry, 26, 194-200. doi:10.1016/j.eurpsy.2011.01.005

Pomerantz, A. M., \& Segrist, D. J. (2006). The influence of payment method on psychologists' diagnostic decisions regarding minimally impaired clients. Ethics and Behavior, 16, 253-263. doi:10.1207/s15327019eb1603_5

Pottick, K. J., Wakefield, J. C., Kirk, S. A., \& Tian, X. (2003). Influence of social workers' characteristics on the perception of mental disorder in youths. Social Service Review, 77(3), 431-454. doi:10.1086/375790

Probst, B. (2011). Walking the tightrope: Using diagnostic and environmental perspectives in clinical practice. (Master's thesis). Retrieved from Proquest Dissertations and Thesis database. (Accession No. 201203537)

Rawson, D. (1994). Models of inter-professional work. In A. Leathard (Ed.), Going inter-professional: Working together for health and welfare (pp. 38-63). New York: Routledge.

Reaume, G. (2002). Lunatic to patient to person: Nomenclature in psychiatric history and the influence of patients' activism in North America. International Journal of Law and Psychiatry, 25, 405-426.

doi:10.1016/S0160-2527(02)00130-9

Regehr, C., \& Glancy, G. (2010). Mental health social work practice in Canada. Don Mills, ON.: Oxford University Press. 
Rooke-Matthews, S., \& Lindow, V (1998) The experiences of mental health service users as mental health professionals. Findings 488. York, United Kingdom: Joseph Rowntree Foundation.

Rosenberg, C. E. (2006). Contested boundaries: Psychiatry, disease, and diagnosis. Perspectives in Biology and Medicine, 49(3), 407-424. doi:10.1353/pbm.2006.0046

Rubinson, E. (1999). DSM-IV: A comparison of social workers and psychiatrists on knowledge, attitudes and behaviors. (Doctoral dissertation). Retrieved from Proquest Dissertations and Theses database. (UMI No. 9916546)

Saleebey, D. (2001). The diagnostic strengths manual? Social Work 46(2), 183-187. doi: $10.1093 / \mathrm{sw} / 46.2 .183$

Schatzberg, A. F., \& Nemeroff, C. B. (Eds.). The American Psychiatric Publishing textbook of psychopharmacology. Washington, DC: American Psychiatric Publishing.

Scheyett, A. (2005). The mark of madness: Stigma, serious mental illness, and social work. Social Work in Mental Health, 3(4), 79-97. doi:10.1300/J200v03n04_05

Schulte-Markwort, M., Marutt, K., \& Riedesser, P. (2008). Cross-Walks ICD-10/DSMIV: A synopsis of classifications of mental disorders. Cambridge, MA: Hogrefe \& Huber Publishers.

Shaw, C., \& Proctor, G. (2005). Women at the margins: A critique of the diagnosis of borderline personality disorder. Feminism \& Psychology, 15(4), 483-490. doi:10.1177/0959-35305057620

Shenton, A. K. (2004). Strategies for ensuring trustworthiness in qualitative 
research projects. Education for Information, 22(2), 63-75.

Shimrat, I. (1997). Introduction. In I. Shimrat (Ed.), Call me crazy: Stories from the mad movement (pp. 1-10). Vancouver: Press Gang Publishers.

Skene, A. (1999). Psychiatric classification, medicine and madness: An examination of ontology and epistemology in DSM-IV. (Doctoral dissertation). Retrieved from Proquest Dissertations and Theses database. (UMI No. NQ43452)

Society for Humanistic Psychology, Division 32 of the American Psychological Association. (2011). Open letter to the DSM-5. Retrieved from http:// www.ipetitions.com/petition/dsm5/

Spearman, L. (2005). A developmental approach to social work practice in mental health: Building on strengths. In T. Heinonen \& A. Metteri (Eds.) Social work in health and mental health: issues, developments, and actions (pp. 45-64). Toronto, ON: Canadian Scholars' Press Inc.

Stanley, N., Ridley, J., Harris, J., \& Manthorpe, J. (2011). Disclosing disability in the context of professional regulation: A qualitative UK study. Disability and Society, 26(1), 19-32. doi:10.1080/09687599.2011.529663

Stein, D. J., Phillips, K. A., Bolton, D., Fulford, K. W. M., Sadler, J. Z., \& Kendler, K. S. (2010). What is a mental/psychiatric disorder? From DSM-IV to DSM-V. Psychological Medicine, 40, 1759-1765. doi:10.1017/S0033291709992261

Taylor, E. H. (2006). The weaknesses of the strengths model: Mental disorder as a case in point. Best Practices in Mental Health, 2(1), 1-15.

Turner, F. J. (1999). Introduction. In F. J. Turner (Ed.) Adult psychopathology: A social work perspective (pp. 1-9). New York, NY: The Free Press. 
Turner, F. J. (2002). Diagnosis in social work: New imperatives. Binghampton, NY: The Haworth Press.

Van de Sande, A., \& Schwartz, K. (2011). Research for social justice: A communitybased approach. Black Pint, NS: Fernwood Publication.

Wakefield, J. C. (2005). Disorders versus problems of living in DSM: Rethinking social work's relationship to psychiatry In S. A. Kirk (Ed.), Mental disorders in the social environment: Critical perspectives (pp. 83-95). New York, NY: Columbia University Press.

Wakefield, J. C., \& First, M. B. (2003). Clarifying the distinction between disorder and nondisorder: Confronting the overdiagnosis (false-positives) problem in DSM-V. In K. A. Phillips, M. B. First, \& H. A. Pincus (Eds.), Advancing DSM: Dilemmas in psychiatric diagnosis (pp. 23-56). Washington, DC: American Psychiatric Publishing, Inc.

Walker, M. T. (2006). The construction of mental illness and its implications for the recovery model. International Journal of Psychosocial Rehabilitation, 10(1), 71-87.

Walton, P. (1999). Social work and mental health: refocusing the training agenda for ASWs. Social Work Education, 18(4), 375-388.

doi:10.1080/02615479911220381

Whitaker, R. (2011). Anatomy of an epidemic: Magic bullets, psychiatric drugs, and the astonishing rise of mental illness in America. New York, NY: Broadway Paperbacks.

Williams, J. B. W. (1981). DSM-III: A comprehensive approach to diagnosis. Social 
Work, 26, 101-106.

Williams, J. B. W., \& Spitzer, R. L. (1995) Should DSM be the basis for teaching social work practice in mental health? Yes! Journal of Social Work Education, 31, 148-153.

Wykes, T., \& Callard, F. (2010). Diagnosis, diagnosis, diagnosis: towards DSM-5. Journal of Mental Health, 19(4), 301-304. doi:10.3109/09638237.2010.494189 


\section{Appendix A}

\section{Ethics Clearance Form}

and Carleton

Comoda's Captel Univarxity

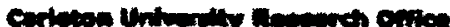

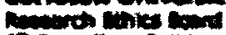

Pnoer Tory nim

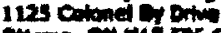

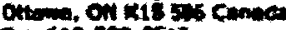

Tet: $633-500 \times 25$

Prow: 613-500-253

conto.

\section{Ethice Clemerance Form}

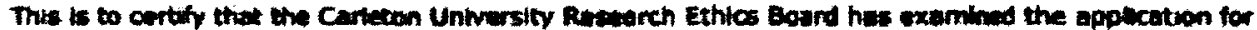

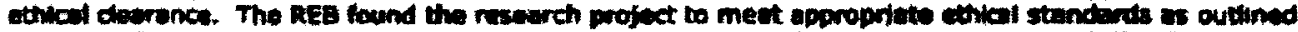

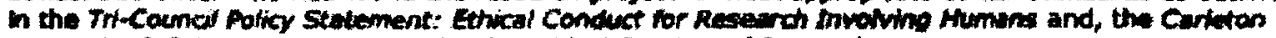

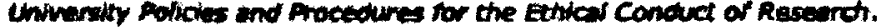

x naw clouranow

o Renewal of ortoind clearance

Othinal date of clearnew

Doto of cianrance

Rewerctiers

Stotus

Supanwor

Funding stabu:

Project number

Thib of project
20 3aning 2012

Johnus coeculum

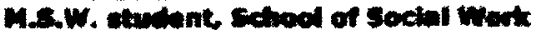

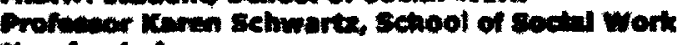

mon-twede

12-1074

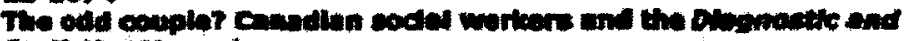

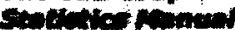

Coerence expires: $31 \mathrm{may} 2012$

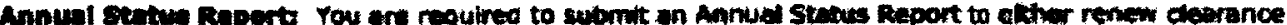

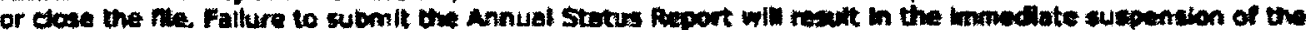

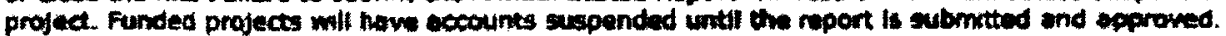

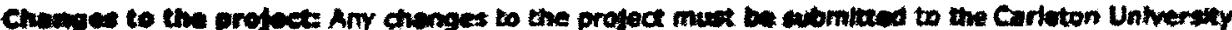

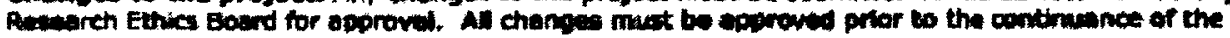
niving.

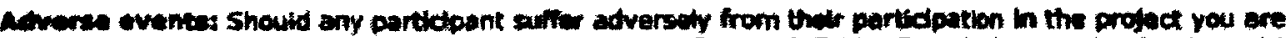
copukred to repart the mattar to the Cortaton Unversity Amseanch Ethies Board. Vou must submit a wrtten

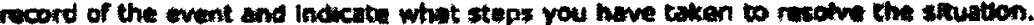

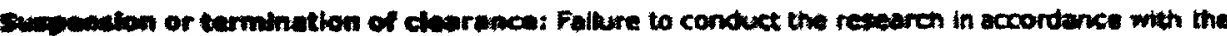

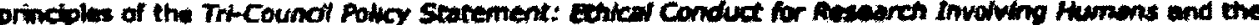
Conteton University Policies and Procmdures for the extical Conduct of Research moy result th the suspension or termination at the research project. 


\section{Appendix B}

\section{Recruitment Email}

\section{From Principal Investigator Josh Goodbaum}

Dear [Insert Name],

The purpose of the Letter of Information attached to this email is to provide you with information about an exploratory research project that I am undertaking as part of the requirements for the Master's degree in Social Work from Carleton University. The project will examine how Canadian social workers that are engaged in frontline mental health practice use and understand the Diagnostic and Statistical Manual (DSM), and what personal values and experiences inform their use and understanding. The Letter of Information attached to this email will enable you to make an informed decision as to whether or not you wish to participate in this project.

Additionally, if you are aware of any colleagues in the Ottawa area who may be interested in participating in the project, it would be greatly appreciated if you could forward the Letter of Information along to them.

Sincerely,

Josh Goodbaum (jgoodbau@connect.carleton.ca)

\section{From Research Supervisor Dr. Karen Schwartz}

Dear [Insert Name],

The purpose of the Letter of Information attached to this email is to provide you with information about an exploratory research project that I am supervising. The principal investigator for the project is a student in Carleton University's Master of Social Work program. The project will examine how Canadian social workers that are engaged in frontline mental health practice use and understand the Diagnostic and Statistical Manual (DSM), and what personal values and experiences inform their use and understanding. The Letter of Information attached to this email will enable you to make an informed decision as to whether or not you wish to participate in this project.

Additionally, if you are aware of any colleagues in the Ottawa area who may be interested in participating in the project, it would be greatly appreciated if you could forward the Letter of Information along to them.

Sincerely,

Dr. Karen Schwartz (karen_schwartz@carleton.ca) 


\section{Appendix C}

\section{Informed Consent}

Project Title: The Odd Couple: Canadian Social Workers and the Diagnostic and Statistical Manual

This project has received ethics review and clearance by the Carleton University Research Ethics Board

Date of Ethics Clearance: January $20^{\text {th }}, 2012$

Ethics Clearance for the Collection of Data Expires: May 31st, 2012

The purpose of this Informed Consent form is to provide you with information that will enable you to make an informed decision as to whether or not you wish to consent to participate in this exploratory research project.

Purpose: This exploratory research project is being done to fulfill part of the requirements for the Master's degree in Social Work from Carleton University. The objective of this research project is to examine how Canadian social workers who are engaged in frontline mental health practice use and understand the Diagnostic and Statistical Manual (DSM), and what personal values and experiences shape their use and understanding.

Participation Requirements: To be involved in this project, you must be a registered social worker who is either currently engaged in frontline mental health practice, or has engaged in frontline mental health practice in the past year. In addition, you must be a fluent English speaker. In this project, you will be asked to take part in a 60 to 90 minute audio recorded in-person interview in which you will be asked about: a) your professional practice; b) your perspectives on social work; c) your perspectives on mental health; d) your education, training, professional and personal experiences relevant to your use and understanding of the $D S M$; $f$ your work with clients who have received a diagnosis; g) your use of the DSM; and h) your perspectives on the advantages and disadvantages of the DSM. One question that will be explored during the interview is whether, in addition to experiences of being a mental health service provider, you have also been a service user at some point in your life. If you have had experiences as a service user, it is required for your participation in this study that you are not currently experiencing, nor have you experienced over the past six months, any mental health concerns that you feel are serious enough to be significantly impairing your daily functioning.

Benefits of the Project: To date, no research has explored the topic of the DSM and social work within a Canadian context. This research project will thus provide you with the opportunity to add your opinions on this topic to academic literature and professional discourse, thereby hopefully informing social work education and 
practice. This data will not only be utilized in the principal investigator's Master's thesis, but may also be disseminated via academic journals, conference presentations and other academic/professional reports, publications and presentations.

Potential Risk/Discomfort: Some participants may experience discomfort as the result of their participation in this study. If you identify as being a mental health service user, you will be asked to describe some personal experiences. This may potentially cause psychological/emotional and/or economic harm, as there is significant stigma in regard to utilizing mental health services. Although the steps taken to ensure anonymity and confidentiality (described below) will help mitigate this, it is still extremely important that you understand that your participation in this project is entirely voluntary. Moreover, you can choose to not answer any question that are asked of you or can stop your participation at any time during the interview without having to provide any explanation. You may also ask to withdraw from the project within a period of one week from the day the interview was conducted.

Anonymity and Confidentiality: The data collected during the interviews will remain anonymous. The information will be coded and stored in a secure location to ensure that confidentiality is maintained. As such, your identity will not be revealed, either directly or by inference, in any reports or presentations resulting from this project.

If you have any questions regarding the project, please contact: The principal investigator, Josh Goodbaum, at jgoodbau@connect.carleton.ca, or the research supervisor, Dr. Karen Schwartz, at karen_schwartz@carleton.ca.

If you have any ethical concerns about how this project was conducted, please contact: Professor Antonio Gualtieri (Chair of Carleton University's Research Ethics Board) at 613-520-2517 or ethics@carleton.ca.

\section{Signature}

My signature indicates that I understand the above description of the study and agree to participate in the study and to be contacted for follow-up to clarify information expressed during the interview.

Participant's Signature:

Date:

\section{Consent to Audiotape}

My signature indicates that I grant my permission for this interview to be audiorecorded for the purposes of accuracy.

Participant's Signature:

Date: 


\section{Appendix D}

\section{Interview Schedule}

Consent: Review and sign, answer any questions pertaining to study.

Background Info: Age, education, employment history

\section{Characteristics of Professional Practice}

- Can you tell me about the agency/hospital that you work for?

- What services does it provide?

- What are the values of the agency/hospital?

- What services do you provide for clients?

- What theories inform your approach to professional practice?

- What approach or approaches do you take to assessing and working with clients?

- Do you have to engage in interprofessional practice at your work setting? Explain.

\section{Perspectives on Social Work}

- What would you describe the values of social work to be?

- Do you see any conflict between what you define the values of social work to be and the demands of professional practice in the mental health sector? Explain.

\section{Perspectives on Mental Health}

- How do you define the term mental health?

- How do you define the term mental illness?

- In what ways do you think a mental disorder may impact on a person's life?

\section{Education, Training, Professional and Personal Experiences}

- The main question I am hoping to explore with this study is how social workers understand and use the Diagnostic and Statistical Manual (DSM). Can you tell me about any experiences in the following areas that have informed your use and understanding of the DSM? 
- Education (e.g. college, university, graduate school)?

- Training (e.g. professional development opportunities, conferences, etc.)?

- Professional Experiences (e.g. experiences with specific clients, working with colleagues, etc.)?

- Personal Experiences?

- In addition to your experiences as a service provider, have you ever had any experiences as a service user? If you feel comfortable with sharing this, can you tell me about this experience, and how it has informed your praxis?

\section{Work with Clients who have received a Diagnosis}

- When you are working with a client, how important is it for you to know whether they have been diagnosed with a mental disorder? Explain.

- How does knowing that a client has a diagnosis of a mental disorder impact on your work with them?

- Have you ever disagreed with a diagnosis that a client of your has received? If so, what did you do in that situation?

- Have you ever worked with a client who did not have a diagnosis, but you felt that one may have been appropriate? If so, what did you do in that situation?

\section{Use of the DSM}

- Have you ever referred to the DSM at any point in your professional practice?

- Can you tell me in what circumstances you have referred to it?

- Did you find it useful?

- Have you ever used the DSM to help with:

- Assessing a client?

- Treatment planning?

- Improving your understanding of a client?

- Meeting agency requirements? 
- Communication with colleagues?

- Are there any aspects of your professional practice that the DSM plays a role in that I haven't mentioned?

\section{Advantages and Disadvantages of the DSM}

- There have been extensive debates on the advantages and disadvantages of the DSM in both academia and the popular press. Do you think these debates inform your perspective on the DSM? Explain.

- In your opinion, what advantages do you see regarding the use of the DSM by:

- Social workers engaging in direct mental health practice?

- Other professionals?

- In your opinion, what disadvantages do you see regarding the use of the DSM by:

- Social workers engaging in direct mental health practice?

Other professionals?

- Can you discuss any advantages and/or disadvantages you think the DSM has for service users?

- Do you think the DSM is compatible with the values of social work that you previously discussed? Explain.

- Do you think that social work students who are hoping to work in the mental health sector should learn about the DSM in school? Explain.

- What things do you think would be important for them to learn about the manual?

- If you could suggest any changes to the DSM for future editions of the manual, what would those changes be?

\section{Wrapping Up:}

- Is there anything else about your perspective on the DSM or any other topics we have touched on that you think I should know or that you want to tell me? Is there anything that I missed?

\section{Additional Info}


- Is there a particular pseudonym you would like me to use in the final report?

- Would you like me to provide you with a copy of the transcript of this interview so you can check it for accuracy before I begin my data analysis? If yes, email:

- Would you like to receive a summary of my findings? If yes, email:

Debriefing: Verbal and Written 


\section{Appendix E}

Face Sheet

Participant pseudonym:

Date and location of interview:

Length of Interview:

Participant age and gender:

Participant pseudonym:

Donation to Charity/Social Service Agency: Yes / No

If yes, name of charity/agency:

If yes, anonymous: Yes / No

Receipt for Donation to Charity/Social Service Agency: Yes / No

If yes, Contact Info:

Follow up transcript approval permission: Yes / No

If yes, contact info:

Date email sent/call made:

Wants final results? Yes / No

If yes: Contact info:

Date email sent/call made: 


\section{Appendix F}

\section{Debriefing Form}

\section{The Odd Couple: Canadian Social Workers and the Diagnostic and Statistical Manual}

What am I trying to learn with this research? The goal of this exploratory research project is to examine how Canadian social workers who are engaged in frontline mental health practice use and understand the Diagnostic and Statistical Manual (DSM), and what personal values and experiences shape their use and understanding.

Where can I learn more? I would be happy to provide specific references pertaining to the DSM and social work practice. If you would like to learn more about this topic, please email the principal investigator, Josh Goodbaum, at igoodbau@connect.carleton.ca.

What if I have questions or concerns later? If you have any questions or concerns about this project, please feel free to contact the principal investigator, Josh Goodbaum, at igoodbau@connect.carleton.ca. Additionally, you can contact the research supervisor, Dr. Karen Schwartz, at karen schwartz@carleton.ca. Should you have any ethical concerns about this project please contact the Chair of Carleton University's Research Ethics Board, Professor Antonio Guialteri, at ethics@carleton.ca or 613-520-2517.

What do I do if I decide that I don't want the things I shared to be included in the project? If you decide, after your interview, that you would prefer the comments you shared to not be included in the thesis or any other publications or presentations resulting from this research, you must contact the principal investigator, Josh Goodbaum, at igoodbau@connect.carleton.ca. The date by which you must contact the principal investigator to withdraw from the study is

Is there anything that I can do if this study has caused me discomfort? Some people may feel some discomfort or distress as the result of answering some of the questions in this study. If you would like to discuss any distress or discomfort that may have resulted from participating in this project, you may wish to contact the Ottawa \& Region Distress Centre at 613-238-1089 (www.dcottawa.on.ca) or the Ottawa Mental Health Crisis Line at 613-722-6914 (http://www.crisisline.ca/home.htm).

Thank you for your participation. Your time and effort are greatly appreciated. 
Appendix G

\section{Post Interview Comment Sheet}

Mood of the Interview

Emotional reaction of participant throughout interview

My emotional reactions to the participant

My reactions to what the participant said

Strengths of the Interview

Weaknesses of the Interview

Additional comments 